\title{
QUEEN'S
UNIVERSITY
BELFAST
}

\section{Mercury content of sediments in East Fork Poplar Creek: Current assessment and past trends}

Brooks, S., Eller, V., Dickson, J., Earles, J., Lowe, K., Mehlhorn, T., Olsen, T., DeRolph, C., Watson, D., Phillips, D., \& Peterson, M. (2017). Mercury content of sediments in East Fork Poplar Creek: Current assessment and past trends. (ORNL/TM-2016/578 ed.) Oak Ridge National Laboratory, UT-Battelle, LLC, US Dept. of Energy.

\section{Queen's University Belfast - Research Portal:}

Link to publication record in Queen's University Belfast Research Portal

\author{
Publisher rights \\ Copyright 2017 Oak Ridge National Laboratory
}

\section{General rights}

Copyright for the publications made accessible via the Queen's University Belfast Research Portal is retained by the author(s) and / or other copyright owners and it is a condition of accessing these publications that users recognise and abide by the legal requirements associated with these rights.

\section{Take down policy}

The Research Portal is Queen's institutional repository that provides access to Queen's research output. Every effort has been made to ensure that content in the Research Portal does not infringe any person's rights, or applicable UK laws. If you discover content in the Research Portal that you believe breaches copyright or violates any law, please contact openaccess@qub.ac.uk. 


\section{Mercury Content of Sediments in East Fork Poplar Creek: Current Assessment and Past Trends}

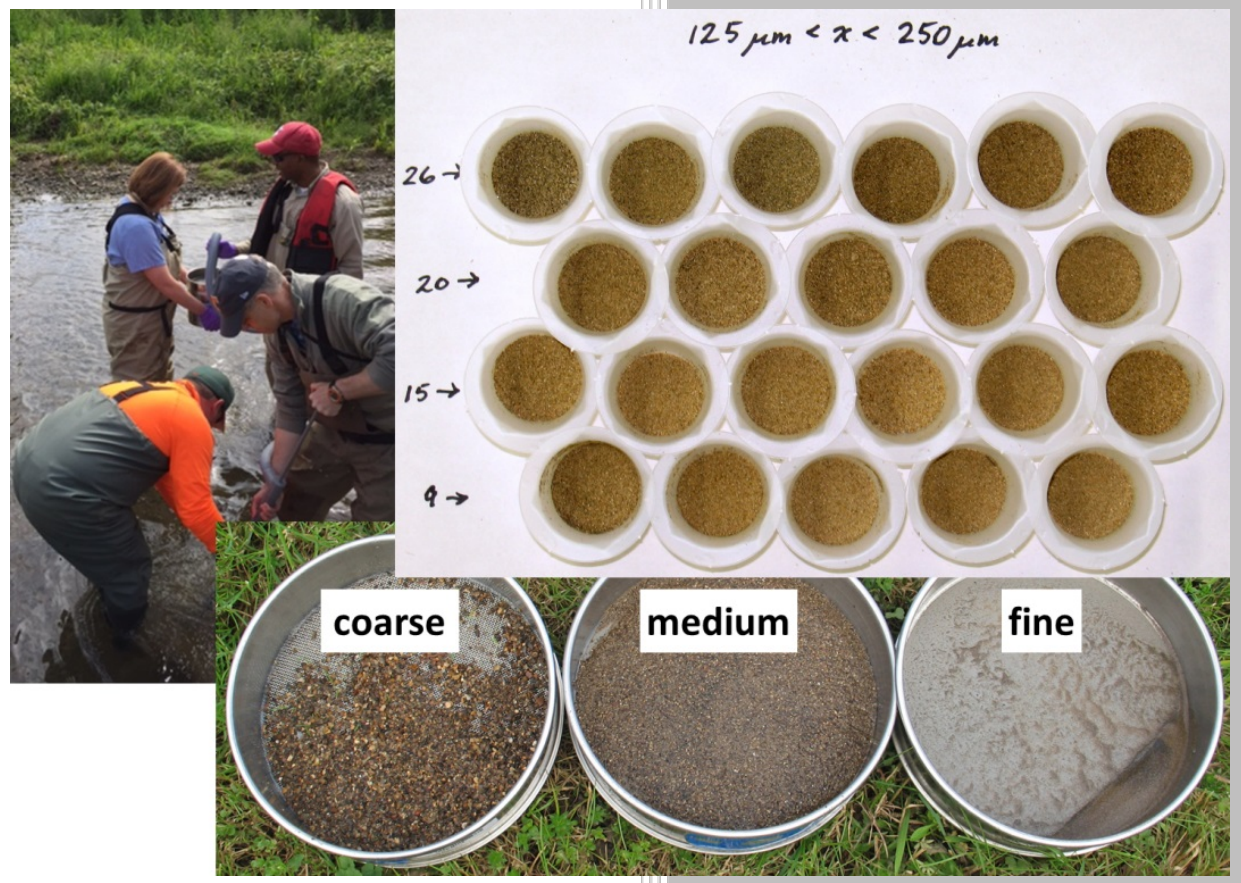

Approved for public release. Distribution is unlimited.
Scott Brooks Virginia Eller John Dickson Jennifer Earles Kenneth Lowe Tonia Mehlhorn Todd Olsen Chris DeRolph David Watson Debra Phillips Mark Peterson January 2017 


\title{
DOCUMENT AVAILABILITY
}

Reports produced after January 1, 1996, are generally available free via US Department of Energy (DOE) SciTech Connect.

Website http://www.osti.gov/scitech/

Reports produced before January 1, 1996, may be purchased by members of the public from the following source:

\author{
National Technical Information Service \\ 5285 Port Royal Road \\ Springfield, VA 22161 \\ Telephone 703-605-6000 (1-800-553-6847) \\ TDD 703-487-4639 \\ Fax 703-605-6900 \\ E-mail info@ntis.gov \\ Website http://www.ntis.gov/help/ordermethods.aspx
}

Reports are available to DOE employees, DOE contractors, Energy Technology Data Exchange representatives, and International Nuclear Information System representatives from the following source:

Office of Scientific and Technical Information

PO Box 62

Oak Ridge, TN 37831

Telephone 865-576-8401

Fax 865-576-5728

E-mail reports@osti.gov

Website http://www.osti.gov/contact.html

This report was prepared as an account of work sponsored by an agency of the United States Government. Neither the United States Government nor any agency thereof, nor any of their employees, makes any warranty, express or implied, or assumes any legal liability or responsibility for the accuracy, completeness, or usefulness of any information, apparatus, product, or process disclosed, or represents that its use would not infringe privately owned rights. Reference herein to any specific commercial product, process, or service by trade name, trademark, manufacturer, or otherwise, does not necessarily constitute or imply its endorsement, recommendation, or favoring by the United States Government or any agency thereof. The views and opinions of authors expressed herein do not necessarily state or reflect those of the United States Government or any agency thereof. 
Environmental Sciences Division

\title{
MERCURY CONTENT OF SEDIMENTS IN EAST FORK POPLAR CREEK: CURRENT ASSESSMENT AND PAST TRENDS
}

\author{
Scott Brooks, ORNL \\ Virginia Eller, ORNL \\ John Dickson, ORNL \\ Jennifer Earles, ORNL \\ Kenneth Lowe, ORNL \\ Tonia Mehlhorn, ORNL \\ Todd Olsen, ORISE \\ Chris DeRolph, ORNL \\ David Watson, ORNL \\ Debra Phillips, Queen's University of Belfast \\ Mark Peterson, ORNL
}

Date Published: January 2017

Prepared for

Charlie Mansfield, UCOR/RSI

Oak Ridge, TN 37831

Prepared by

OAK RIDGE NATIONAL LABORATORY

Oak Ridge, TN 37831-6283

managed by

UT-BATTELLE, LLC

for the

US DEPARTMENT OF ENERGY

under contract DE-AC05-00OR22725 



\section{CONTENTS}

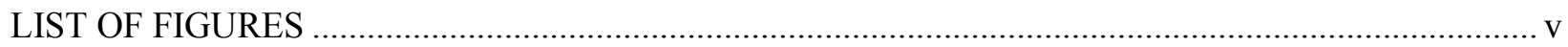

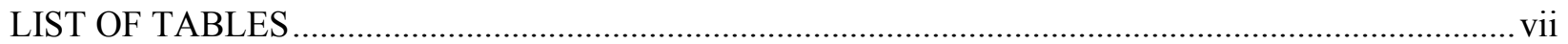

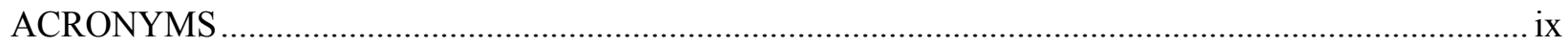

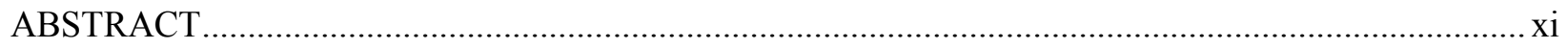

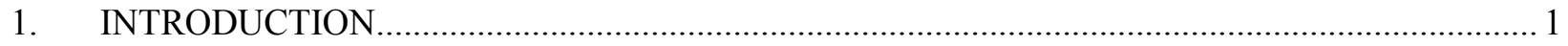

2. RELEVANT ASPECTS OF MERCURY CHEMISTRY …................................................. 1

3. IMPORTANCE OF CONTAMINATED SEDIMENTS IN FLUVIAL SYSTEMS …..................... 2

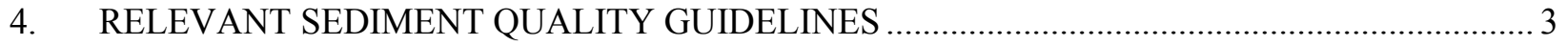

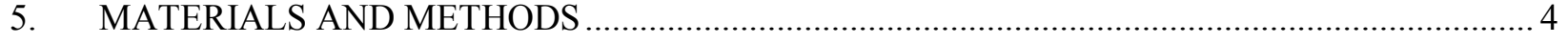

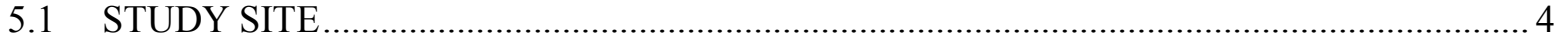

5.2 SITE DESIGNATION CONVENTION ……................................................................ 4

5.3 SEDIMENT SAMPLE COLLECTION, PRESERVATION AND SEQUENTIAL

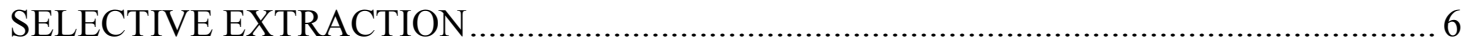

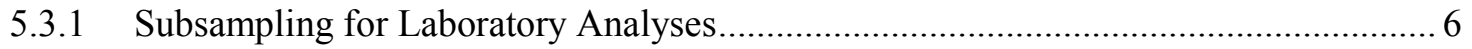

5.3.2 Reagent Preparation and Sequential Extraction Procedure......................................... 6

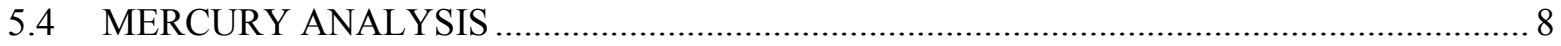

5.4.1 Total Mercury Determination and Investigation of Sample Variability ....................... 8

5.5 METHYLMERCURY EXTRACTION AND ANALYSIS ............................................. 9

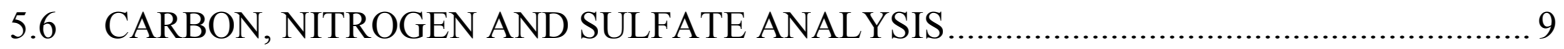

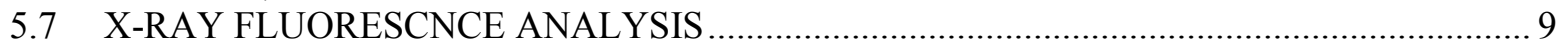

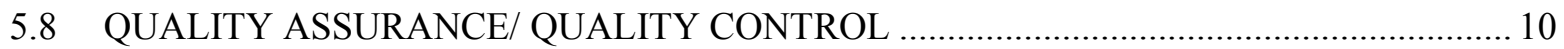

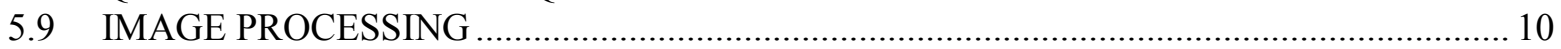

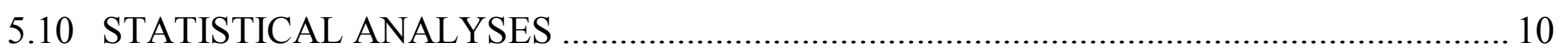

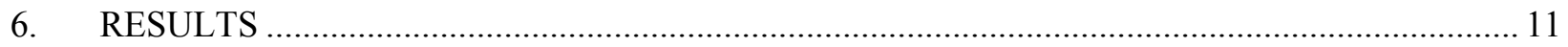

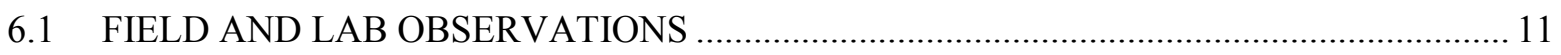

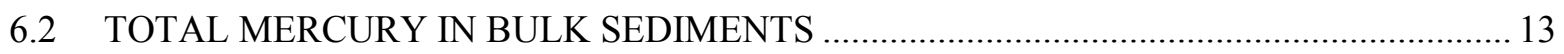

6.3 MERCURY CONCENTRATION BY GRAIN SIZE .................................................... 15

6.4 SEQUENTIAL EXTRACTION RESULTS FOR TOTAL MERCURY …........................... 17

6.5 TOTAL MONOMETHYLMERCURY IN BULK SEDIMENT …….................................... 19

6.6 MONOMETHYLMERCURY CONCENTRATION BY GRAIN SIZE................................. 20

6.6.1 Percent Monomethylmercury in Sediments as a Function of Grain Size ................... 21

6.7 STREAM SEDIMENT MERCURY AND MONOMETHYLMERCURY INVENTORY ..... 22

6.8 RELATIONSHIPS AMONG MERCURY, MONOMETHYLMERCURY AND

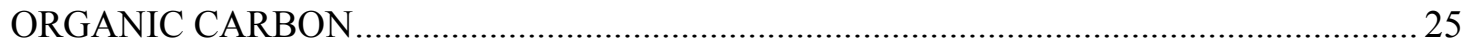

6.9 RELATIONSHIPS AMONG MERCURY AND OTHER ELEMENTS PRESENT IN

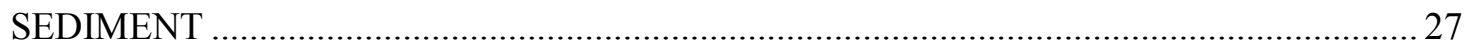

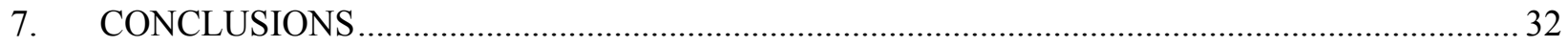

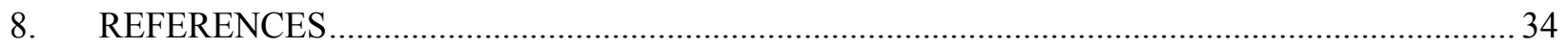

APPENDIX A. DATA TABLES AND SUPPLEMENTARY FIGURES ….....................................A-1 APPENDIX B. MERCURY DETERMINATION BY X-RAY FLUORESCENCE SPECTROSCOPY $(\mathrm{XRF})$ 


\section{LIST OF FIGURES}

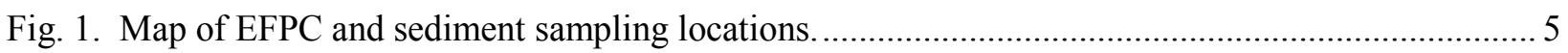

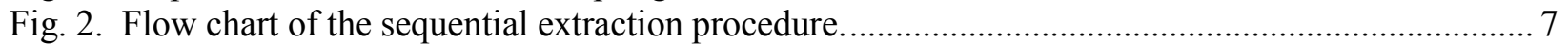

Fig. 3. Photographs of the sediment samples sorted by grain size................................................... 12

Fig. 4. Sediment brightness value along EFPC as a function of grain size............................................. 13

Fig. 5. Total Hg in bulk sediments along East Fork Poplar Creek...................................................... 14

Fig. 6. Total Hg in bulk sediments along East Fork Poplar Creek........................................................ 15

Fig. 7. Total Hg in separate sediment size classes along East Fork Poplar Creek............................... 16

Fig. 8. Fraction of total $\mathrm{Hg}$ leached from sediments in the F3, F4, and F5 fractions. ............................. 18

Fig. 9. Total MMHg in bulk sediments along East Fork Poplar Creek................................................. 20

Fig. 10. Total MMHg in separate sediment size classes along East Fork Poplar Creek......................... 21

Fig. 11. Percent MMHg in separate sediment size classes along East Fork Poplar Creek. ...................... 22

Fig. 12. Hg to organic C ratio in separate sediment size classes along East Fork Poplar Creek. .............26

Fig. 13. Carbon to nitrogen ratio in separate sediment size classes along East Fork Poplar Creek........... 27

Fig. 14. Relationship between sediment concentrations of $\mathrm{Hg}$ and Iron (Fe) as a function of

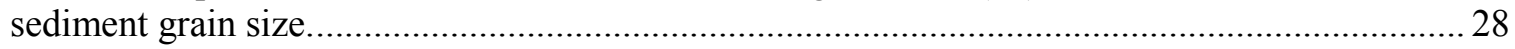

Fig. 15. Total strontium (Sr) concentration in EFPC sediments as a function of grain size.....................29

Fig. 16. Sediment rubidium $(\mathrm{Rb})$ concentration as a function of grain size along EFPC........................ 31 


\section{LIST OF TABLES}

Table 1. Some consensus-based sediment quality guidelines for $\mathrm{Hg}$................................................. 3

Table 2. Estimated inventory of mercury $(\mathrm{Hg})$ and methylmercury $(\mathrm{MMHg})$ in streambed sediments 


\section{ACRONYMS}

ACS

ANOVA

CBSQG

CVAAS

DMA

DOM

dw

EDX

EFK

EFPC

GC-CV-AFS

HDPE

HRD

$\mathrm{kg}$

$\mathrm{km}$

LDPE

LEFPC

MF

$\mathrm{mg}$

$\mathrm{MMHg}$

OC

PEC

PP

QA/ QC

SEM

TDEC

TEC

UEFPC

US DOE

US EPA

XRF

Y-12 NSC
American Chemical Society

analysis of variance

consensus-based sediment quality guideline

cold vapor atomic absorption spectroscopy

direct mercury analyzer

dissolved organic matter

dry weight

energy dispersive x-ray spectroscopy

East Fork kilometer

East Fork Poplar Creek

gas chromatography - cold vapor - atomic fluorescence spectroscopy

high density polyethylene

Historic Release Deposit

kilogram

kilometer

low density polyethylene

lower East Fork Poplar Creek

mass fraction

milligram

monomethylmercury

organic carbon

probable effect concentration

polypropylene

quality assurance/ quality control

scanning electron microscopy

Tennessee Department of Environment and Conservation

threshold effect concentration

upper East Fork Poplar Creek

United States Department of Energy

United States Environmental Protection Agency

$\mathrm{x}$-ray fluorescence spectroscopy

Y-12 National Security Complex 


\begin{abstract}
The last comprehensive assessment of mercury $(\mathrm{Hg})$ concentration in creek sediments of East Fork Poplar Creek (EFPC) was in 1984. Because of the potentially important role bed sediments can play in overall ecosystem health, $\mathrm{Hg}$ inventory, and as a source for the more toxic and bioaccumulative monomethylmercury (MMHg) coupled with the 30-year elapsed time, an updated assessment of EFPC creek sediments was warranted. This work was conducted under the Mercury Remediation Technology Development for Lower East Fork Poplar Creek project (TD project). Objectives of this study included:
\end{abstract}

- To provide a current assessment of total $\mathrm{Hg}$ and monomethylmercury (MMHg) concentration in EFPC bed sediment at approximately $1 \mathrm{~km}$ spatial resolution and to compare these values to previous data sets

- To relate EFPC sediment $\mathrm{Hg}$ concentrations to published sediment quality guidelines

- Quantify Hg and MMHg concentrations in bed sediments as a function of grain size

- Assess the strength of $\mathrm{Hg}$-sediment association through the use of a sequential extraction procedure

- Examine the relationship among $\mathrm{Hg}$ and other sediment chemical and physical characteristics (e.g., carbon content, grain size)

- Provide a contemporary baseline against which system response to future remedial actions can be compared

- Determine if some segments of the creek are more highly contaminated than others as a means to guide targeted actions addressing creek bed sediment

The current inventory of $\mathrm{Hg}$ in EFPC bed sediments was estimated to be $334 \mathrm{~kg}$ which represents a $\sim 67 \%$ decrease relative to the initial investigations in 1984. Improved sediment quality likely resulted from improvements in water quality being released from Y-12, transport of contaminated sediment out of EFPC, and inputs of cleaner sediment to the creek. Elevated $\mathrm{Hg}$ flux from Y-12 associated with storm drain cleanout actions in 2011-2012 was too small to detect reliably in EFPC sediments using the current methods. Monomethylmercury sediment inventory was estimated to be $44.1 \mathrm{~g}$, lower but roughly similar to past estimates. Comparing MMHg concentrations or inventories among different data sets is more challenging than for total $\mathrm{Hg}$ due to a dependence on sampling date, among other factors.

Total $\mathrm{Hg}$ in bulk sediments is relatively constant downstream of Y-12. A localized reach of higher concentration coincides with the one area of the Historical Release Deposit (HRD). A similar but less prominent feature farther downstream is suggestive of another localized area of creek bank or floodplain with elevated $\mathrm{Hg}$ levels. The relative improvement in $\mathrm{Hg}$ sediment concentration is greater upstream which is suggestive of downstream transport of contaminated sediments. Overall, sediment $\mathrm{Hg}$ concentration has decreased substantially over the last 30 years but still remains far above consensusbased sediment quality guidelines.

Sediment $\mathrm{Hg}$ concentration varied with particle size. In the upper reaches of the creek concentration as a function of grain size followed the expected pattern fine $(250 \mu \mathrm{m}>x>125 \mu \mathrm{m})>$ medium $>$ coarse $(2$ $\mathrm{mm}>x>1 \mathrm{~mm}$ ). In the lower reaches of the creek this pattern unexpectedly reversed (coarse $=$ medium $>$ fine) due to unknown causes.

Medium grain sized sediment $(1 \mathrm{~mm}>x>250 \mu \mathrm{m})$ dominated the collected materials by mass. Sediments were angular to subrounded with intermediate to high sphericity. Sediments became lighter in appearance with decreasing grain size and with increasing distance downstream from Y-12. 
More than $85 \%$ of sediment $\mathrm{Hg}$ was strongly bound regardless of grain size or location along the creek, being removed only with concentrated acid or a mixture of concentrated acids. In the fine sediments, the amount of $\mathrm{Hg}$ held less strongly (removed with $1 \mathrm{M} \mathrm{KOH}$ ) increases steadily downstream. The fraction of $\mathrm{Hg}$ removed with this reagent has been correlated with $\mathrm{Hg}$ methylation potential in aquatic sediments. This may indicate an increasing propensity for sediment-associated $\mathrm{Hg}$ to be methylated with increasing distance downstream from Y-12.

Monomethylmercury (MMHg) in bulk sediment generally decreased monotonically with distance downstream. A three kilometer reach from EFK 23 to EFK 20 had significantly higher MMHg concentrations reaching $10.4 \mu \mathrm{g} / \mathrm{kg}$. The region with elevated MMHg concentration occurred upstream of the region with elevated total $\mathrm{Hg}$ in sediments. The reasons for this localized enrichment are not understood. The trend of decreasing sediment $\mathrm{MMHg}$ concentration with downstream distance opposes the increase in water column dissolved MMHg over the same length of creek.

In general, $\mathrm{MMHg}$ concentration decreased monotonically downstream for all grain sizes similar to the bulk sediment. However, the localized enrichment in MMHg from EFK 23 to EFK 20 was due solely to higher concentration in the coarse-grained sediments in this reach. MMHg concentration in the mediumand fine-grained sediments did not change or decreased over the same reach. MMHg concentration in medium and fine sediments was significantly correlated with $\mathrm{Hg}$. The percent $\mathrm{MMHg}$ with distance varied by grain size: percent MMHg decreased downstream for the coarse sediments, did not change in the medium sediments, and increased in the fine sediments. The percent MMHg in fine sediments was significantly correlated with the fraction of $\mathrm{Hg}$ extracted by $1 \mathrm{M} \mathrm{KOH}$ (the $\mathrm{F} 3$ reagent).

Mercury and $\mathrm{MMHg}$ are correlated with sediment organic carbon $(\mathrm{OC})$ and nitrogen $(\mathrm{N})$. The $\mathrm{Hg}$ to $\mathrm{OC}$ ratio increased downstream for coarse and medium sediments but decreased for fine sediments. The divergent patterns in $\mathrm{Hg}$ :OC by grain size coupled with similarity of $\mathrm{Hg}$ : $\mathrm{OC}$ between bank soils and fine sediments suggests contribution of fine particles from creek bank soils to the bed sediments. Organic carbon to nitrogen ratio suggests out-of-stream sources are the dominant source of organic carbon to the creek. The narrow range of sediment OC:N values throughout EFPC coupled with their similarity to bank soils suggest bank soil erosion and entrainment into the creek sediments. Trace element analyses also suggested localized areas of stream bank erosion input and derivation of sediments from bedrock underlying the EFPC channel.

This study provided new information on sediment $\mathrm{Hg}$ and MMHg content and chemistry. The results support the relevance and potential impacts of other active and planned investigations within the TD project (e.g., assessment and control of bank soil inputs, sorbents for $\mathrm{Hg}$ and $\mathrm{MMHg}$ removal, reintroduction of freshwater clams to EFPC) and identify gaps in current understanding that represent opportunities to understand controlling variables that may inform future technology development studies. 


\section{INTRODUCTION}

During the 1950's and early 1960's processes and practices at the Y-12 National Security Complex (Y-12 NSC) led to the loss of large amounts of mercury (Hg) to the local environment (Brooks and Southworth, 2011). These losses included approximately $193,000 \mathrm{~kg} \mathrm{Hg}$ lost to soils within Y-12 and 128,000 kg Hg discharged to the headwaters of East Fork Poplar Creek (EFPC) primarily as a combination of dissolved $\mathrm{Hg}$ (II) species, small particles of mercuric oxide, and these forms associated with other particulates in the stream. Consequently, EFPC and its environs (water, bed sediment, bank soils, areas of the floodplain) are contaminated with $\mathrm{Hg}$. EFPC continues to receive smaller loads of $\mathrm{Hg}$ from legacy point and diffuse sources within Y-12 NSC and the stream corridor (e.g., eroding stream banks). Remediation of this contaminant is a high priority for the U.S. Department of Energy (US DOE).

Much of the EFPC watershed was heavily characterized during initial site investigations in the early to mid-1980's. Sampled matrices included water, sediments, floodplain soils, and biota. Specifically, creek sediment was sampled at thirty locations along EFPC (Tennessee Valley Authority, 1985). In the 30 years since the original site investigations several remedial actions have improved water quality decreasing the concentration and flux of $\mathrm{Hg}$ coming from $\mathrm{Y}-12 \mathrm{NSC}$. Concomitant decreases in $\mathrm{Hg}$ concentration in water have been documented for EFPC downstream of Y-12. Nevertheless, less effort has been devoted to monitoring the status of bed sediment $\mathrm{Hg}$ concentrations over that time. Southworth et al. (Southworth et al., 2010) sampled sediments at four roughly equally-spaced locations over a $16 \mathrm{~km}$ reach of lower EFPC and found Hg concentrations were substantially lower than the values measures in the 1980's. This report summarizes the results of sediment sampling and analysis conducted in April May 2015. Objectives of the study included:

- To provide a current assessment of total $\mathrm{Hg}$ and monomethylmercury (MMHg) concentration in EFPC bed sediment at approximately $1 \mathrm{~km}$ spatial resolution and to compare these values to previous data sets

- To relate EFPC sediment $\mathrm{Hg}$ concentrations to published sediment quality guidelines

- Quantify Hg and MMHg concentrations in bed sediments as a function of grain size

- Assess the strength of $\mathrm{Hg}$-sediment association through the use of a sequential extraction procedure

- Examine the relationship among $\mathrm{Hg}$ and other sediment chemical and physical characteristics (e.g., carbon content, grain size)

- Provide a contemporary baseline against which system response to future remedial actions can be compared

- Determine if some segments of the creek are more highly contaminated than others as a means to guide targeted actions addressing creek bed sediment

A summary of the results of the sampling and analysis are provided below. Complete data tables are provided in Appendix A.

\section{RELEVANT ASPECTS OF MERCURY CHEMISTRY}

Mercury properties relevant to $\mathrm{Hg}$-sediment interactions are summarized; a detailed review of $\mathrm{Hg}$ biogeochemical properties and cycling is beyond the scope of the present report. $\mathrm{The}_{\mathrm{Hg}^{2+}}$ ion is a soft, 
or B-type, metal with high propensity to form poorly soluble precipitates and strong aqueous complexes with reduced sulfur in both its inorganic (e.g., $\mathrm{S}^{2-}$ ) and organic (e.g., organic $\mathrm{S}^{-}$in dissolved organic matter, DOM) forms (Stumm and Morgan, 1981). In the well-aerated surface water of EFPC, reduced inorganic $\mathrm{S}$ is virtually nonexistent whereas there is abundant DOM that contains reduced S groups (Dong et al., 2009; Kocman et al., 2013; Riscassi et al., 2016). Additionally, Hg has a high affinity for associating with solid surfaces (adsorption) whether complexed with DOM or not. These sediment particles may be suspended in the water column or on the bed of the creek.

As a direct consequence of these two properties (affinity for particles, propensity to complex with reduced $\mathrm{S})$ most of the $\mathrm{Hg}$ in EFPC is associated with particles. Dissolved $\mathrm{Hg}$ is overwhelmingly in the form of $\mathrm{Hg}-\mathrm{DOM}$ complexes. These properties also suggest that decreasing $\mathrm{Hg}$ concentration in surficial creek sediments would occur via: 1) physical transport out of system, 2) burial or mixing of contaminated material under clean(er) deposits, 3) $\mathrm{Hg}$ partitioning to the aqueous phase and subsequent transport out of the system as a dissolved solute.

\section{IMPORTANCE OF CONTAMINATED SEDIMENTS IN FLUVIAL SYSTEMS}

The goal of most aquatic monitoring programs is to document water quality and its responses to directed actions, the assumption being that water quality will respond relatively quickly to such actions. In contrast, freshwater fluvial sediments are not frequently included in long-term monitoring programs as they are not considered to respond rapidly to changes in water quality. Indeed, the primary means by which surficial sediment quality (with respect to inorganic contaminants) would improve (e.g., contaminant desorption from sediments to water, mass transport of contaminated sediment downstream, burial by less contaminated materials) occur over time scales that are long relative to the water column residence time. A case in point is EFPC itself: although water and biota sampling have continued along the length of EFPC on a semi-annual basis over the past 30 years, there has been no similar sediment sampling program over the same time period.

Nevertheless, contaminated sediments are important to overall site monitoring. Contaminated sediments themselves can be directly toxic to aquatic organisms. They can form the initial link for bioaccumulation in the food chain. Aquatic organisms in proximity to contaminated sediments can show adverse effects even when water quality criteria are not exceeded (Chapman, 1989). Mercury has a high affinity for particles and associated organic material (see above). Consequently, $\mathrm{Hg}$ accumulates in sediments from which it can subsequently be released. Therefore, bed sediments can be a sink for $\mathrm{Hg}$ and can be a reservoir of $\mathrm{Hg}$ for future release back into the water column. Additionally, burial of $\mathrm{Hg}$ contaminated sediments, followed by the development of anoxic conditions can lead to the undesirable production of $\mathrm{MMHg}$. Previous and ongoing research has shown a correlation between mercury methylation potential and total Hg in EFPC sediments (Miller et al., 2013).

Southworth (Southworth et al., 2013) estimated that streambed gravels in EFPC hold the majority of $\mathrm{Hg}$ inventory among gravels, creek banks, and streambed biofilm $(88.3 \%, 11.6 \%$, and $0.16 \%$, respectively). Mercury inventory in creek banks was estimated for a 1-cm thickness of bank soil which was assumed to be the actively erodible layer. Extending the calculation to a greater soil thickness was limited by the sampling depth in that study. Subsequent work has shown that there can be substantial variability in bank soil $\mathrm{Hg}$ concentration with distance into the face of the bank (Peterson et al., 2014). The bank inventory estimate included some samples from the Historical Release Deposit (HRD; (Watson et al., 2016)) but was made prior to the discovery of the full extent of the HRD. Therefore, the bank soils likely account for a higher percentage of the Hg inventory. Nevertheless, creek sediments remain important to the EFPC 
$\mathrm{Hg}$ budget and given their potential role in aquatic health and MMHg generation, a more detailed study of the current status of $\mathrm{Hg}$ concentration in EFPC sediments was warranted.

\section{RELEVANT SEDIMENT QUALITY GUIDELINES}

Consensus-Based Sediment Quality Guidelines (CBSQGs) are a means of identifying concentrations of contaminants at which there will be no predicted toxicity to organisms or above which, toxicity is expected. The threshold effect concentration (TEC) is defined by MacDonald as the "concentration below which adverse effects are not expected to occur in sediment-dwelling organisms" and the probable effect concentration (PEC) as the "concentration above which adverse effects are expected to occur more often than not." (MacDonald et al., 2000). Published values for CBSQGs can vary over a broad range depending on many factors including the methodology by which they are derived, the biological receptors considered, the intended degree of protection, the intended use of the guideline (e.g., screening level, remedial goal), and geographical area to which it is to be applied (site-specific, regional, national).

Three examples of CBSQGs for Hg are provided in Table 1. Two are taken from US EPA national assessments of sediment quality (USEPA, 1997, 2004) and the third from an assessment conducted by MacDonald and co-authors (MacDonald et al., 2000). The EPA assessments included coastal sediments and sediments from the Gulf of Mexico while that of MacDonald was limited to lotic and lentic

freshwater sediments. The Tennessee Department of Environment and Conservation (TDEC) references the TEC and PEC recommended by MacDonald when discussing EFPC (e.g., (TDEC, 2015).

Table 1. Some consensus-based sediment quality guidelines for $\mathbf{H g}$

\begin{tabular}{ccc}
\hline Source & TEC (mg/kg) & PEC (mg/kg) \\
\hline USEPA (1997) & 0.13 & 0.696 \\
USEPA (2004) & $0.23^{a}$ & $0.87^{b}$ \\
MacDonald (2000) & 0.18 & 1.06 \\
\hline
\end{tabular}

${ }^{a}$ In the 2004 assessment EPA changed from TEC to $\mathrm{T}_{25}$ defined as the concentration at which the probability of observing sediment toxicity is greater than $25 \%$. The value listed was derived from saltwater acute toxicity data. ${ }^{b}$ In the 2004 assessment EPA changed from PEC to $\mathrm{T}_{50}$ defined as the concentration at which the probability of observing sediment toxicity is greater than $50 \%$. The value listed was derived from saltwater acute toxicity data. 


\section{MATERIALS AND METHODS}

\subsection{STUDY SITE}

The detailed history and characterization of EFPC have been previously published (Brooks and Southworth, 2011; Loar et al., 2011; Riscassi et al., 2016; Stewart et al., 2011). Briefly, the Y-12 NSC is located at the headwaters of EFPC. Flow in the upper reaches originates from springs, groundwater, storm water runoff, and process and cooling water from Y-12 operations. The upper three kilometers of the creek lie within Y-12 and the channel consists of unlined, armored and channelized sections lined with concrete. From the Y-12 boundary the creek flows another 23 kilometers through commercial, residential, open-land, and forested areas until its confluence with Poplar Creek. The three-kilometer reach within Y-12 is administratively referred to as upper East Fork Poplar Creek (UEFPC) and the lower 23 kilometer reach is referred to as lower East Fork Poplar Creek (LEFPC). Mercury concentrations in water are highest near Y-12 NSC and decrease downstream. Conversely, MMHg concentrations in water are lowest near Y-12 and increase downstream.

\subsection{SITE DESIGNATION CONVENTION}

Sites along EFPC are designated using an alphanumeric identifier: EFK\#\#. EFK stands for East Fork kilometer and the number indicates the creek kilometer, measured upstream from the mouth of the creek which has the designation EFK0. Sediment sampling sites followed a similar naming convention using Sed-\#\# to identify samples and sampling sites (Fig. 1; Table A-2).

Additionally, the sample locations were binned into five creek reach segments following the segments assigned in a modeling study of EFPC (Watson et al., 2016); see Section 5.10). Similar to the EFPC kilometer designation, reach segments were numbered in ascending order beginning from the mouth of the creek. Creek kilometers encompassed by each reach are provided in Appendix Table A-1. 


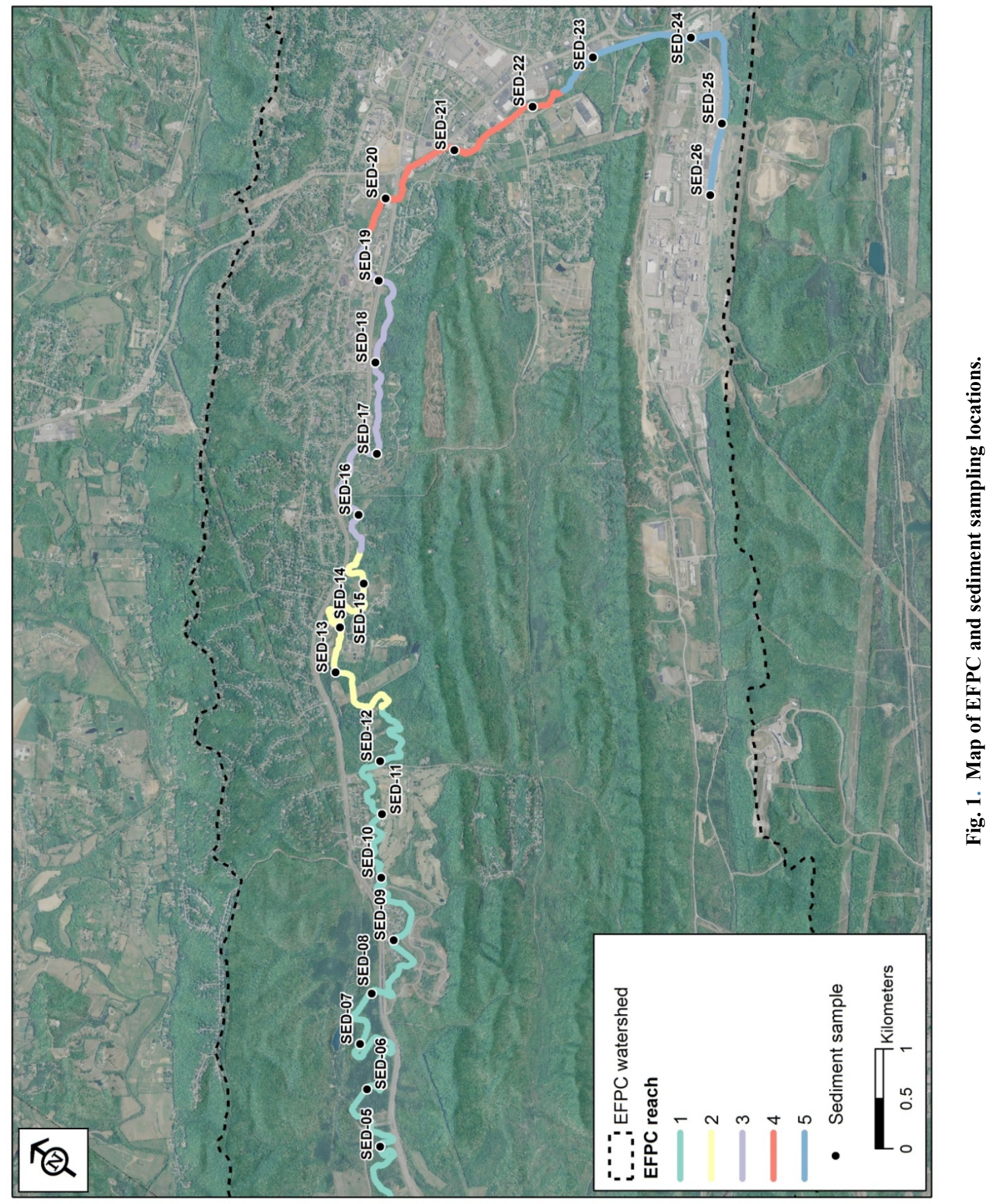




\subsection{SEDIMENT SAMPLE COLLECTION, PRESERVATION AND SEQUENTIAL SELECTIVE EXTRACTION}

Sediment samples were collected from 22 sites along the creek, in approximate $1 \mathrm{~km}$ increments beginning downstream at EFK 4.7 and ending at EFK 26, inside Y-12 NSC (Table A-2, Fig. 1). Sediments from each site were collected in bulk using either a hand-operated bilge pump or by scooping bulk sediments with a 5 gallon plastic bucket. Sediments were wet-sieved in the field using ambient creek water to minimize loss of $\mathrm{Hg}$ from the solid phases during sample processing. Three particle size fractions were separated from the bulk sample: $2 \mathrm{~mm}>x>1 \mathrm{~mm}$ (coarse); $1 \mathrm{~mm}>x>250 \mu \mathrm{m}$ (medium); $250>x>125 \mu \mathrm{m}$ (fine). Sediments larger than $2 \mathrm{~mm}$ and smaller than $125 \mu \mathrm{m}$ together constituted a minor proportion $(<3 \%)$ of the sediment collected. Each size fraction was placed in a zipclosure bag after sieving in the field and held on dry ice until returned to the laboratory. Once back in the laboratory, sieved sediments were stored at $-80^{\circ} \mathrm{C}$ until subsampling and further processing.

At each site outside of Y-12 NSC an additional bulk sample was collected. Upon return to the lab the sample was air dried, weighed, and sieved to the same size fractions as described previously. The mass of material recovered in each size fraction was recorded and used to calculate the fractional contribution of each size fraction to the overall sample mass. These estimates were used with the total $\mathrm{Hg}$ in each size class to reconstruct the total $\mathrm{Hg}$ in a representative bulk $1 \mathrm{~kg}$ sample.

$$
H g_{T, \text { bulk }}=M F_{\text {coarse }} H g_{T, \text { coarse }}+M F_{\text {medium }} H g_{T, \text { medium }}+M F_{\text {fine }} H g_{T, \text { fine }}
$$

Where $\mathrm{Hg}_{T}=$ total $\mathrm{Hg}, \mathrm{MF}=$ mass fraction, bulk= bulk sample, coarse = coarse grain size fraction, medium $=$ medium grain size fraction, fine $=$ fine grain size fraction.

Bulk sediment samples for the three sample locations within the Y-12 NSC were not available for grainsize mass fraction determination. For these three sites bulk sediment reconstructions were estimated by using the average grain size distribution from the remaining 19 sites.

\subsubsection{Subsampling for laboratory analyses}

Zip-closure bags containing sieved sediment were removed from the $-80{ }^{\circ} \mathrm{C}$ freezer and thawed at room temperature. Sample bags containing kg-weight masses of material were thawed overnight at $40{ }^{\circ} \mathrm{C}$. When sediments had thawed appreciably, fresh gloves were donned and subsamples were taken in a 50 $\mathrm{mL}$ skirted LDPE centrifuge tube. Forty to $85 \mathrm{~g}$ of wet subsample were removed, external surfaces of the tube were immediately wiped, and the tube was stored temporarily with the remaining sieved sediments in a $-20{ }^{\circ} \mathrm{C}$ freezer. Sieved sediments and subsample tubes were returned to the $-80{ }^{\circ} \mathrm{C}$ freezer at the end of the day for long term storage. The subsamples were preserved by freeze-drying at $-45^{\circ} \mathrm{C}$ then held at -80 ${ }^{\circ} \mathrm{C}$ until further processing.

\subsubsection{Reagent Preparation and Sequential Extraction Procedure}

A five-step sequential extraction method (Bloom et al., 2003) was used to characterize different operationally-defined fractions of total mercury in a sample. In this method, a sediment sample is equilibrated, in sequence, with five extractants of increasing chemical aggressiveness to characterize the strength of the $\mathrm{Hg}$-solid phase association in the sample (Fig. 2). 


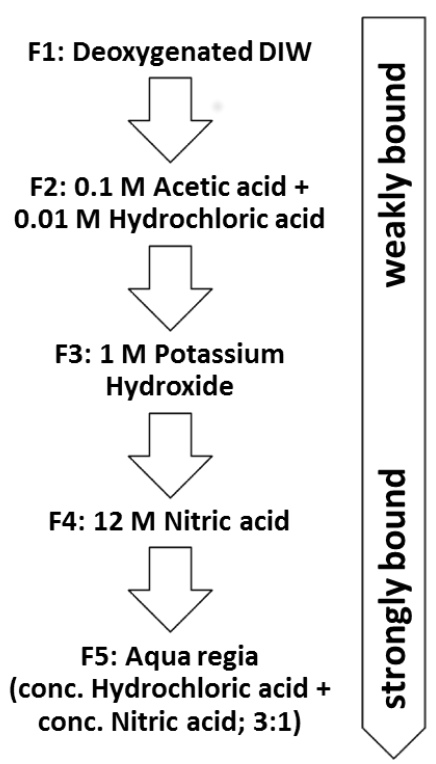

Fig. 2. Flow chart of the sequential extraction procedure.

\subsubsection{Reagent Preparation}

To prepare reagents, trace-metal grade acids and $18 \mathrm{M} \Omega$ reagent water (MilliQ) were used; all other reagents were ACS grade or better. The five extractants are denoted by their fraction number, F1 - F5. Extractants F1 - F3 were made in 2L HDPE bottles. Extractant F4 was prepared in a 2L PTFE bottle and extractant F5 was prepared individually in each extraction vial.

F1, Deoxygenated MilliQ water: $18 \mathrm{M} \Omega$-cm reagent water was purged with ultra-high purity argon overnight.

F2, $0.01 \mathrm{M} \mathrm{HCl}$ plus $0.1 \mathrm{M}$ acetic acid: $12 \mathrm{~mL}$ glacial acetic acid $(17.45 \mathrm{M})$ and $1.6 \mathrm{~mL} \mathrm{HCl}$ were added to $1986.4 \mathrm{~mL}$ MilliQ water.

F3, 1 M KOH: $132 \mathrm{~g} \mathrm{85 \%} \mathrm{mass} \mathrm{potassium} \mathrm{hydroxide} \mathrm{pellets} \mathrm{were} \mathrm{slowly} \mathrm{added} \mathrm{to} \mathrm{a} \mathrm{2L} \mathrm{HDPE} \mathrm{bottle}$ half filled with reagent water. The bottle was capped and swirled to dissolve remaining solids then filled to the neck of the vessel.

F4, $12 \mathrm{~N} \mathrm{HNO}_{3}: 500 \mathrm{~mL}$ reagent water was added to a 2L PTFE bottle, followed by slow addition of $1500 \mathrm{~mL}$ concentrated nitric acid.

F5, Aqua regia (AR): 3:1 conc. $\mathrm{HCl}$ : conc. $\mathrm{HNO}_{3}$. It was the most aggressive reagent in the sequence and was prepared individually in each extraction vial.

SAFETY NOTE: Because aqua regia produces noxious nitrosyl chloride gas, all work with this reagent was conducted in a fume hood with adequate ventilation.

Bromine monochloride $(\mathrm{BrCl})$ : $\mathrm{BrCl}(0.2 \mathrm{~N})$ was made by adding $27 \mathrm{~g}$ potassium bromide crystals to a $2.5 \mathrm{~L}$ bottle of $12.1 \mathrm{M} \mathrm{HCl}$. The solution was stirred for 1 hour, after which $38 \mathrm{~g}$ potassium bromate was added with stirring. Preparation and use of the $\mathrm{BrCl}$ solution was also conducted in a fume hood because it can evolve halide radicals or halogen gases. 


\subsubsection{Extraction Procedure}

The sediment to be extracted was added to a skirted $50 \mathrm{~mL}$ LDPE centrifuge tube with plug-type cap. The sample mass used for extraction was determined based on total $\mathrm{Hg}$ analysis and with consideration that the sample be large enough to be representative (see Section 5.4.1).

For the first four steps in the procedure $40 \mathrm{~mL}$ extractant was added to the sample which was then equilibrated on an end-over-end tumbler. Following an $18-22$ hour equilibration period, samples were centrifuged at $3000 \mathrm{rpm}(174 \times \mathrm{g})$ for 20 minutes and the supernatant was filtered into $125 \mathrm{~mL}$ amber glass bottle using $0.2 \mu \mathrm{m}$ Supor ${ }^{\mathrm{TM}}$ syringe filter. To preserve sample mass and solid to solution ratio across all fractions, care was taken to decant extractant volumes into $20 \mathrm{~mL}$ syringes for filtration. Some samples had entrained very fine sediments; those samples with fine sediments and larger masses required higher centrifuge speeds ( $3200 \mathrm{rpm}$ or $198 \times \mathrm{g}$ ) and multiple filters. Samples were rinsed by adding 40 $\mathrm{mL}$ of the respective extractant, capping and shaking vigorously, and re-centrifuging for 20 minutes. The supernatant was filtered as above and this filtrate was composited with the previous filtrate. The filtrate from the F1, F2, and F4 extractants were preserved with $1.25 \mathrm{~mL} 0.2 \mathrm{~N} \mathrm{BrCl}$. The filtrate from the F3 fraction was preserved with $10 \mathrm{~mL} 0.2 \mathrm{~N} \mathrm{BrCl}$ to neutralize the $1 \mathrm{M} \mathrm{KOH}$.

For the aqua regia (F5) extraction, sample pellets were quantitatively transferred into glass vials by rinsing the initial centrifuge tube with $1-2 \mathrm{~mL} \mathrm{HCl}$ aliquots to a total of $10 \mathrm{~mL}$ and swirling, then repeating with $3 \times 1 \mathrm{~mL}$ aliquots of $\mathrm{HNO}_{3}$. Samples were allowed to digest with the glass vials loosely capped until the characteristic red-orange color had faded, typically $24-48$ hours then diluted to $40 \mathrm{~mL}$ with reagent water. Fine and medium particle size fractions were filtered, while the coarse size fraction was allowed to settle for $24-48$ hours. Preservation with $\mathrm{BrCl}$ was not necessary for aqua regia-digested samples.

\subsection{MERCURY ANALYSIS}

Total $\mathrm{Hg}$ extracted from sediments was quantified using an Ohio Lumex RA-915+ cold vapor atomic absorption spectrometer (CVAAS). $\mathrm{Hg}^{0}$ is generated by addition of a sample aliquot containing fixed $\mathrm{Hg}^{2+}$ to $\mathrm{SnCl}_{2}$ reducing agent. The generated $\mathrm{Hg}^{0}$ is purged from the sample and carried to the detector cell via $\mathrm{Hg}$-free $\mathrm{N}_{2}$ carrier gas. The instrument was calibrated at the beginning of each analytical run with five standards over the range of $20 \mathrm{ng} / \mathrm{L}$ to $500 \mathrm{ng} / \mathrm{L}$. Linear response over this range was verified before proceeding with sample analysis. All samples were diluted to be within the calibration range.

\subsubsection{Total Mercury Determination and Investigation of Sample Variability}

Total mercury concentration for fine sediments was determined by microwave direct mercury analysis (Milestone DMA 80) and compared to total $\mathrm{Hg}$ as determined from aqua regia digestion and analysis using the Lumex CVAAS. Good agreement was achieved between the two methods with a linear correlation coefficient of 0.961 . An investigation of the subsample homogeneity was made in conjunction with total mercury analyses by acid digestion: systematic triplicate analyses of size fractions at sediment sites $06,11,17,21$ and 26 were used to assess variability of THg in sediments. From these analyses, it was determined that greater sediment masses should be used for these specimens. Sample masses of 500 $\mathrm{mg}$ for fines, $1 \mathrm{~g}$ for medium sediments and $1.5 \mathrm{~g}$ for the coarse size fraction were used for sequential extractions beyond the scoping part of the experiment. Solid-to-solution ratios increased over the original method to 1:80, 1:40 and 1:27, respectively. The Bloom et al. method called for $400 \mathrm{mg}$ wet sediments (solid:solution $<1: 100$ ). The current sample set was freeze dried prior to extraction. 


\subsection{METHYLMERCURY EXTRACTION AND ANALYSIS}

Monomethylmercury was analyzed on the fine particle size fraction samples by CEBAM Analytical, Inc., Portland, OR using KOH-methanol digest, extraction with dichloromethane, and separation and detection by GC-CV-AFS (Liang et al., 1996).

MMHg was analyzed on medium and coarse size fraction samples at ORNL by non-aqueous phase extraction (Bloom et al., 1997), which utilizes a two-phase extraction and detection of $\mathrm{Hg}$ isotopes in methylmercury and is described below. All reagents were ACS grade, except $\mathrm{H}_{2} \mathrm{SO}_{4}$, which was trace metal grade.

One (1.0) g sediment subsample and $0.685 \mathrm{ng}{ }^{202} \mathrm{Hg}$ isotope tracer (as ${ }^{202} \mathrm{MMHg}$ ) was placed in $50 \mathrm{~mL}$ low-Hg polypropylene centrifuge tubes and leached for $1 \mathrm{~h}$ with a solution of $2.0 \mathrm{~mL} 1 \mathrm{M} \mathrm{CuSO}_{4}$ (grade) in $10.0 \mathrm{~mL} 18 \%(\mathrm{w} / \mathrm{v}) \mathrm{KBr}$ and $5 \%(\mathrm{v} / \mathrm{v}) \mathrm{H}_{2} \mathrm{SO}_{4}$. Ten (10.0) $\mathrm{mL}$ dichloromethane was added to each centrifuge tube and the samples were placed on a laboratory shaker at high speed for $1 \mathrm{~h}$.

Samples were centrifuged at $3000 \mathrm{rpm}(174 \times g)$ for 30 minutes, resulting in separation of organic and aqueous phases. A $2.0 \mathrm{~mL}$ subsample of the organic layer was placed into $50 \mathrm{~mL}$ polypropylene purge vessels with the addition of $20 \mathrm{~mL} 18 \mathrm{M} \Omega-\mathrm{cm}$ reagent water. Dichloromethane was removed by sparging with UHP $\mathrm{N}_{2}$ in a hot water bath for 15 minutes. $16 \mathrm{~mL}$ aqueous phase was brought to $40 \mathrm{~mL}$ with reagent water. Samples were heated on a Tekran 2750 distillation apparatus and held at $125^{\circ} \mathrm{C}$ until 30 $\mathrm{mL}$ had distilled from sample to receiver (EPA Method 1630).

Distillates were buffered to $\mathrm{pH} 4.9$ with $1 \mathrm{M}$ citrate buffer. Forty $\mu \mathrm{L} 1 \%$ sodium tetraethylborate $\left(\mathrm{NaBEt}_{4}\right)$ in $\mathrm{KOH}$ was added to $40 \mathrm{~mL}$ buffered distillate and used as an ethylating reagent. Headspace was removed from distillation vials prior to analysis.

SAFETY NOTE: $\mathrm{NaBEt}_{4}$ is pyrophoric and sensitive to impact. Care must be taken when preparing the ethylating reagent, including minimizing exposure of tetraethylborate powder to air.

Ethylated distillates were analyzed via a Brooks Rand MERX Hg speciation GC with pyrolysis, coupled to a Perkin-Elmer Sciex Elan DRC-e inductively-coupled plasma mass spectrometer.

\subsection{CARBON, NITROGEN AND SULFATE ANALYSIS}

Carbon, nitrogen and sulfur analyses were performed by the University of Georgia Laboratory for Environmental Analysis, Athens, GA. Total carbon, organic carbon and nitrogen analyses were attained using an elemental analyzer. This method was attempted for total sulfur measurements, but the limit of detection was not sufficiently low for EFPC sediments. Instead, water-extractable sulfates were measured by extracting soils three times with MilliQ water in an ultrasonic bath followed by quantification of soluble $\mathrm{SO}_{4}{ }^{2-}$ by ion chromatography.

\subsection{X-RAY FLUORESCNCE ANALYSIS}

The abundance of 25 other alkali and alkaline earth elements, transition metals, and metalloids (Tables A11 through A-13) present in sediment samples was quantified by x-ray fluorescence (XRF) using a Niton XRF Analyzer (Model XLp 700 Series) following methods described in Spalding (Spalding et al., 2010). Mercury concentration was also obtained during the XRF analysis. Previous published reports (Hall et al., 2011) have questioned the validity of XRF analyses, using instruments similar to the one used in this study, to accurately quantify $\mathrm{Hg}$. The $\mathrm{Hg}$ results obtained as described earlier to those obtained by XRF are compared in Appendix B. 


\subsection{QUALITY ASSURANCE/ QUALITY CONTROL}

Nine samples from different sites and varying size fractions were used for scoping of the method. Initial quality controls were one blank, two standard reference materials (SRMs) and one extraction duplicate. Measurements were conducted in duplicate until relative percent difference (RPD) was $<5 \%$. Continuing calibration verifications were performed every 8 samples to ensure instrument performance throughout the course of the run.

Standard reference materials ERM-CC 580 and NBS 1646, composed of standardized estuarine sediments, were used to assess initial recoveries of SSE technique. ERM-CC 580 showed a $15.5 \%$ difference from accepted reference value, while NBS 1646 was below the limit of detection. These results were repeated in the second stage of the experiment, and further evaluation was deemed unnecessary.

Beyond the scoping stage, QA/QC included one blank, one extraction duplicate per ten samples, and continuing calibration verifications. Analytical batches numbered $20-30$ samples.

\subsection{IMAGE PROCESSING}

Digital images were processed using the open-source freeware GNU Image Manipulation Program (GIMP, v. 2.8.18, www.gimp.org/) to quantify sediment brightness. Brightness values were determined on equal areas for each sediment sample. The mean brightness value of the selected area was recorded as sample brightness. A purely black sample has a brightness value of 0 and a white sample has a value of 255.

\subsection{STATISTICAL ANALYSES}

Statistical analyses were conducted in $R$ (R Core Team, 2016). For all statistical tests results were considered significant by adopting an a priori Type I error rate of 5\%. Reported correlations are Spearman's Rank Correlation coefficient $\left(\rho_{\mathrm{s}}\right)$, a nonparametric measure of monotonic correlation between two variables. Analysis of variance (ANOVA) tests for unequal sample sizes were conducted using grain size and creek reach segment as factors. Data were $\log _{10}$ transformed prior to ANOVA analyses to meet assumptions of normality and homoscedasticity. When significant effects of creek segment or grain size were found, comparisons among groups were made using Tukey's Honestly Significant Differences (Tukey's HSD) test holding the family-wise confidence level at $95 \%$. 


\section{RESULTS}

All results are reported on a sample dry-weight basis.

\subsection{FIELD AND LAB OBSERVATIONS}

\section{Medium grain sized sediment dominated the collected materials by mass. Sediments were angular to subrounded with intermediate to high sphericity. Sediments became lighter in appearance with decreasing grain size and with increasing distance downstream.}

Throughout EFPC the greatest sediment yield by mass was in the medium grain-size fraction which constituted an average $56 \%$ (standard deviation $\pm 9 \%$ ) of sediment followed by the coarse $(34 \pm 9 \%)$ and fine $(5.7 \pm 3.1 \%)$ sediments. Materials larger than $2 \mathrm{~mm}$ and smaller than $125 \mu \mathrm{m}$ together constituted $\sim 3 \%$ of the bulk material (Table A-3). To collect sufficient material for all grain sizes more than $3 \mathrm{~kg}$ sediment were wet sieved in the field per site and for some sites more than $20 \mathrm{~kg}$ of material were processed. Sediments across each size class were angular to subrounded with generally intermediate to high sphericity.

After returning to the lab the dried sediments were arranged in order by location and grain size for visual comparison (Fig. 3). Sediment color appeared lighter with decreasing sediment grain size and with distance downstream. Sediment brightness values reflected this visual impression (Fig. 4). Brightness increased with decreasing grain size and also increased downstream reaching peak values near the transition between Reaches 2 and 1 then remained relatively constant. ANOVA performed on the untransformed data (values were normally distributed) showed significant effects for grain size $(\mathrm{p}<2.0 \mathrm{e}-$ $16)$, creek reach $(\mathrm{p}=4.42 \mathrm{e}-11)$, and grain size by creek reach interaction effects $(\mathrm{p}=5.56 \mathrm{e}-4)$.

Both manganese(III/IV) and Fe(II/III) oxy-hydroxide minerals can darken soils, sediments, and aquifer solids. Organic carbon (OC) can also give soil and sediment samples a dark color. Sediment brightness is expected to decrease with increasing $\mathrm{Mn}, \mathrm{Fe}$ or OC content. Within each grain size, there was a high degree of multicollinearity among Fe, Mn, and percent $\mathrm{OC}$ although the nature of these relationships varied among the grainsize classes (Fig. A-1). Because of the high degree of collinearity among the variables controlling sediment brightness similar patterns and trends observed for brightness and one of these variables were also seen for the other two variables. The specific discussion that follows pertains to the sediment Mn content.

The Mn content of all the sediment size classes had strong to very strong and significant monotonic decreases downstream (coarse $\rho_{\mathrm{s}}=0.758, \mathrm{p}=6.64 \mathrm{e}-5$; medium $\rho_{\mathrm{s}}=0.865, \mathrm{p}=1.68 \mathrm{e}-6$; fine $\rho_{\mathrm{s}}=0.823, \mathrm{p}$ $=2.27 \mathrm{e}-6$ ). Sediment Mn content decreased with decreasing grain size with significant differences among all pairwise comparisons (highest $\mathrm{p}$-value $=1.0 \mathrm{e}-7$ ). The pattern of decreasing Mn content downstream and with decreasing grainsize is consistent with the opposing trend of increasing brightness downstream and with the expected negative correlation between brightness and Mn content. In fine and medium sediments brightness was strongly and significantly correlated with Mn content whereas in the coarse sediments these two variables were not correlated due to the much smaller range of brightness values in the coarse sediment (Fig. A-2)(coarse $\rho_{\mathrm{s}}=-0.291, \mathrm{p}=0.188$; medium $\rho_{\mathrm{s}}=-0.63, \mathrm{p}=2.13 \mathrm{e}-3$; fine $\rho_{\mathrm{s}}=-0.756, \mathrm{p}=7.22 \mathrm{e}-5$ ) suggesting other factors in addition to Mn content contribute to coarse sediment brightness. 
(a)

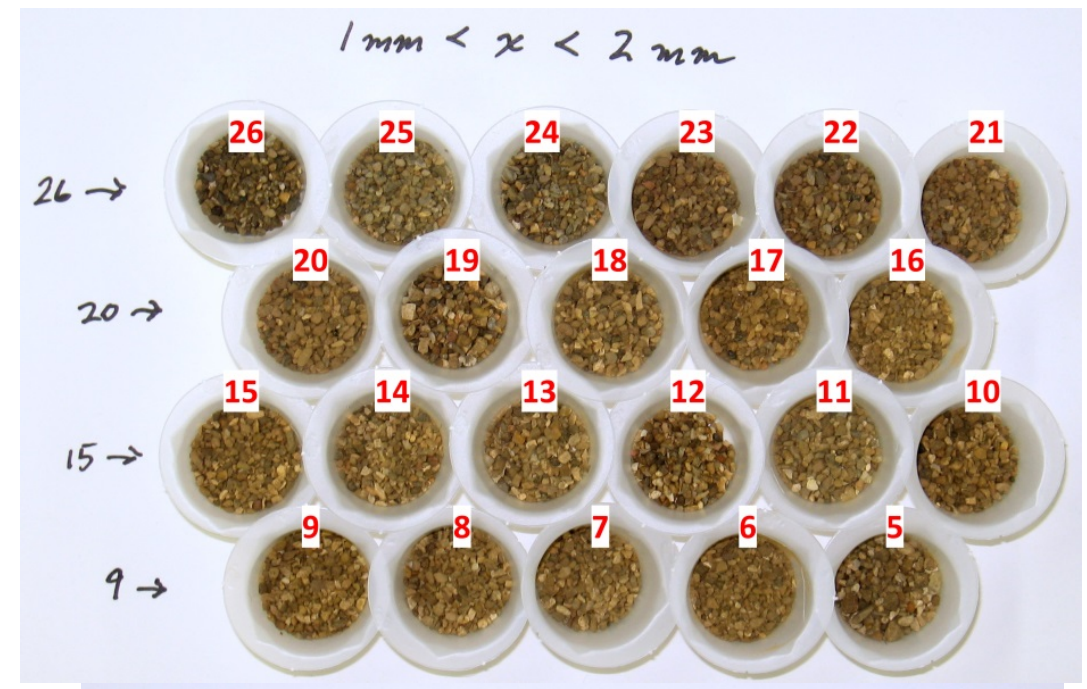

(b)

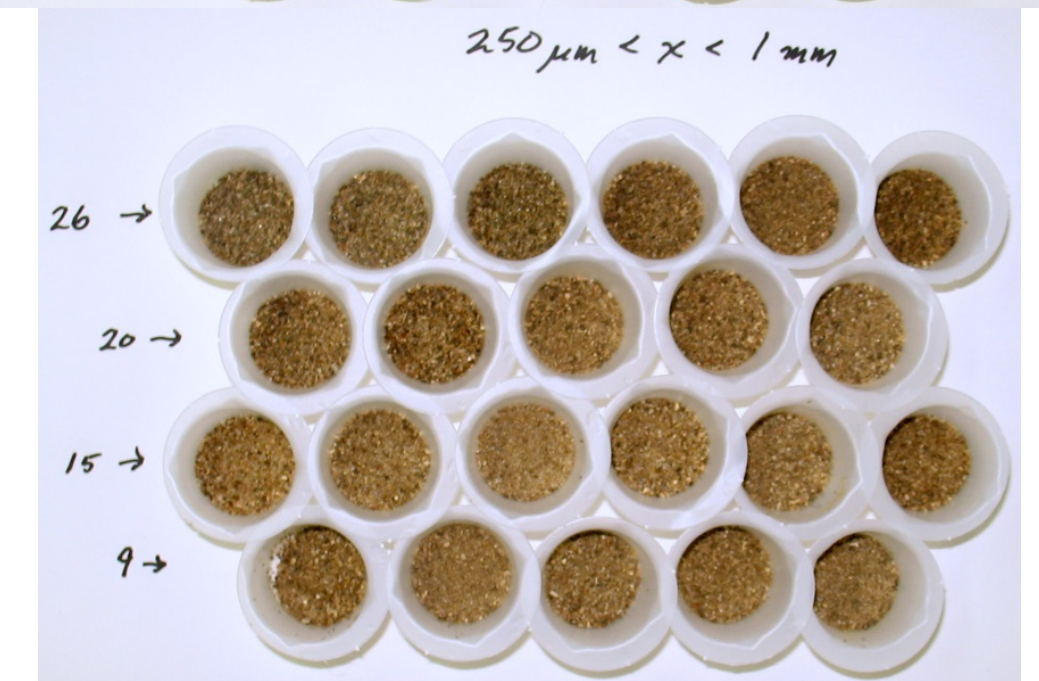

(c)

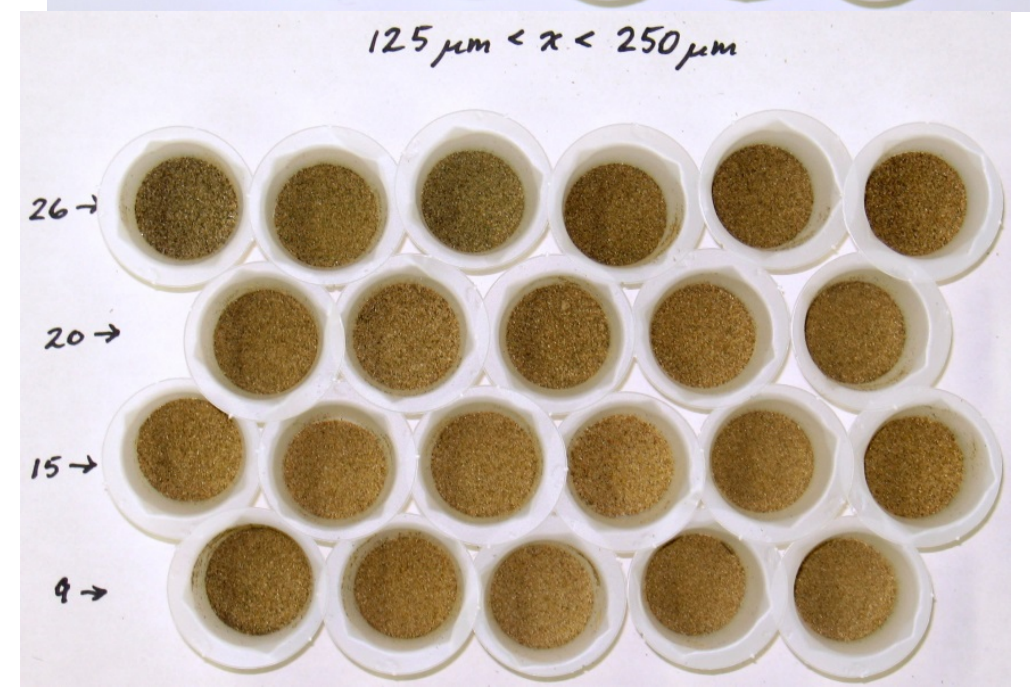

Fig. 3. Photographs of the sediment samples sorted by grain size. (a) coarse-, (b) medium-, and (c) finegrained sediments. Sediment sample numbers shown in panel (a) are in the same order for the other two panels. The HRD layer in bank soils extends from approximately SED-23 to SED-18. 


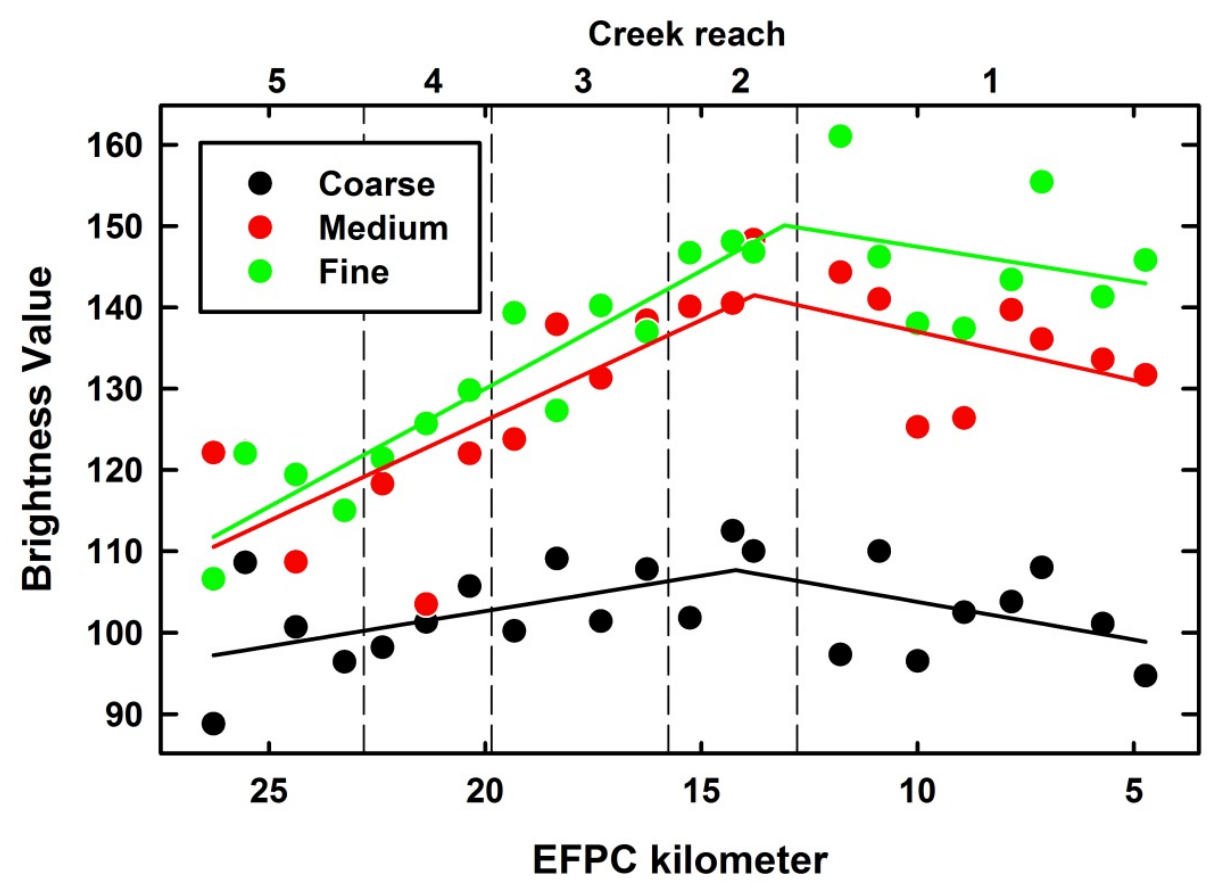

Fig. 4. Sediment brightness value along EFPC as a function of grain size. A value of 0 corresponds to black and a value of 255 corresponds to white. Lines have been added to help visualize patterns in the data. Vertical dashed lines and numbers along the upper $x$-axis indicate creek reach.

\subsection{TOTAL MERCURY IN BULK SEDIMENTS}

Total Hg in bulk sediments is relatively constant downstream of Y-12. A localized reach of higher concentration coincides with one area of the Historical Release Deposit (HRD). A similar but less prominent feature farther downstream is suggestive of another localized area of creek bank or floodplain with elevated $\mathrm{Hg}$ levels. The relative improvement in $\mathrm{Hg}$ sediment concentration is greater upstream which is suggestive of downstream transport of contaminated sediments. Overall, sediment $\mathrm{Hg}$ concentration has decreased substantially over the last 30 years but still remains far above consensus-based sediment quality guidelines.

Total $\mathrm{Hg}\left(\mathrm{Hg}_{\mathrm{T}}\right)$ in bulk sediments ranged from 9.1 to $57.1 \mathrm{mg} / \mathrm{kg}$ (Fig. 5). These concentrations are substantially greater $(23-143 \times)$ than fluvial sediments across the conterminous United States and Europe even after accounting for land use and population (Fig. A-3; (Horowitz and Stephens, 2008; Horowitz et al., 2012; Salminen et al., 2005). Concentrations were highest in Reach 5 which comprised sample locations within the Y-12 NSC and decreased over the upper five to six creek kilometers (through reach 4). A localized area of higher $\mathrm{Hg}$ concentration occurred within Reach 3 (approximate creek kilometers 20 to 16.3$)$. The maximum value in this reach $(27.3 \mathrm{mg} / \mathrm{kg})$ was comparable to two of the sample locations within Y-12. This reach roughly corresponds to the occurrence of the HRD present in creek banks and likely underlying portions of the floodplain (Watson et al., 2016). This localized region of higher sediment $\mathrm{Hg}_{\mathrm{T}}$ may be indicative of inputs from eroding banks containing the HRD. Alternatively, it may indicate a historical "pulse" of contaminated sediment that is slowly migrating downstream or that may be stuck in a local depositional reach of the creek. Nevertheless, for the directly measured samples in lower EFPC (creek kilometer less than 23.4, filled symbols Fig. 5), Hg concentration in sediment was relatively constant (mean $\pm \mathrm{sd}=16.4 \pm 4.9, \mathrm{n}=19$ ) and was not significantly correlated with distance along the creek $\left(\rho_{\mathrm{s}}=-0.154, \mathrm{p}=0.521\right)$. 
Increased $\mathrm{Hg}$ concentration in the upper section of Reach 1 (EFK 11) coincided with a region of the floodplain that had localized higher concentrations during the 1984 site investigation (Tennessee Valley Authority, 1985). One bank soil sample collected in 2014 in close proximity to this sediment sample also had anomalously high $\mathrm{Hg}$ concentration (Dickson et al., in prep). Similar to the higher sediment concentrations in Reach 3, this may indicate local bank erosion inputs of $\mathrm{Hg}$ to stream sediment from legacy $\mathrm{Hg}$ contamination sources.

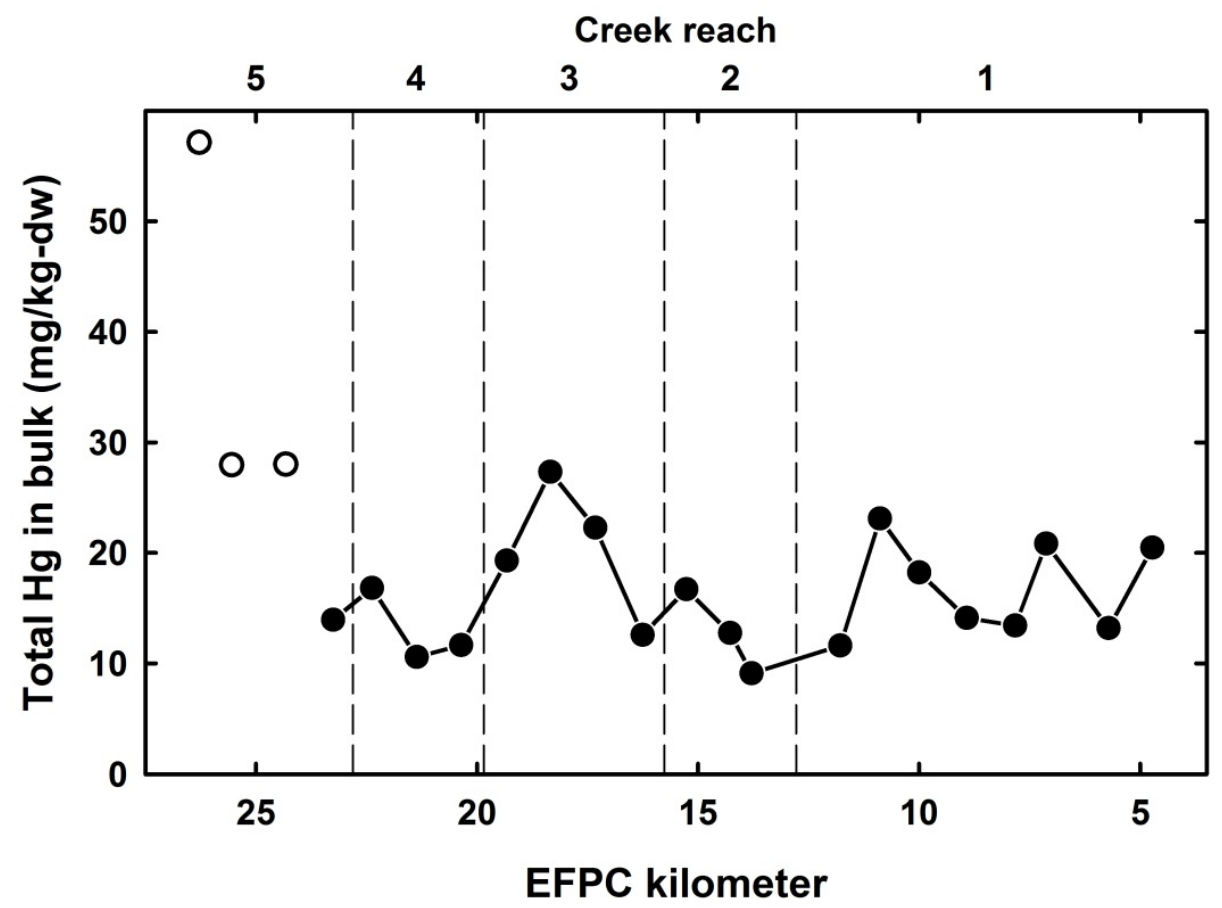

Fig. 5. Total Hg in bulk sediments along East Fork Poplar Creek. Open symbols indicate samples where the bulk sediment reconstruction was estimated using the average grain size mass fraction from the other 19 samples. Vertical dashed lines and numbers along the upper $x$-axis indicate creek reach.

An ANOVA on $\mathrm{Hg}_{\mathrm{T}}$ versus creek reach showed a significant creek reach effect $(\mathrm{p}=0.032)$. Reach 5 was significantly different from Reach $2(p=0.05)$ and nearly different from Reach $4(p=0.052)$. No other reach pairs were significantly different.

Total $\mathrm{Hg}$ in the bulk sediment ranges from between 8 to 53 times greater than the PEC for freshwater sediments (Table 1). The PEC proposed by MacDonald (MacDonald et al., 2000) correctly predicted $100 \%$ of the tested samples to be toxic although the limited number of samples available for evaluation prevented a robust assessment. As with many other CBSQGs, the PEC was derived through a metaanalysis of a large number of studies encompassing many different freshwater bodies. Such a global derivation provides general guidance at the potential expense of accuracy for any specific site. None of the sites included in the MacDonald assessment are from the southeastern US. The applicability of this value to EFPC could be further evaluated with other tests, for example sediment toxicity tests.

Results from previous sediment sampling efforts are compared to the present results in Fig. 6. Overall, there has been a substantial decrease in sediment $\mathrm{Hg}$ concentration along the entire creek relative to the initial site investigation in 1984 (Tennessee Valley Authority, 1985). The broad area of highest Hg concentration (spanning Reaches 2, 3, and 4) show the greatest improvement. The improvement is likely due to three factors (i) downstream sediment transport, (ii) improvements in water quality leaving Y-12, 
and (iii) the removal of more than $34,000 \mathrm{~m}^{3}$ of highly contaminated ( $>400 \mathrm{mg} \mathrm{Hg} / \mathrm{kg}$ ) floodplain soils in the mid-1990s from targeted areas within Reaches 3 and 4. The 1984 data suggest lower creek sediment $\mathrm{Hg}$ concentration in Reach 1 although given the variability in the data there are no significant differences among creek reaches.

More recently, Southworth (Southworth et al., 2013; Southworth et al., 2010) sampled sediments at four locations in lower EFPC. Total $\mathrm{Hg}$ in sediments from Reaches 1, 2, and 5 averaged $10.6 \pm 4.5 \mathrm{mg} / \mathrm{kg}$ and the $\mathrm{Hg}$ concentration in the sample from Reach 3 was $43.5 \mathrm{mg} / \mathrm{kg}$. There is apparent general similarity between the 2008 and 2015 data; however, the higher spatial resolution of the latter data set indicates no significant differences among the creek reaches. Notably, in all three datasets shown in Fig. 6, there is a localized high $\mathrm{Hg}_{\mathrm{T}}$ concentration in the middle of Reach 3 suggesting this feature has persisted for $\sim 30$ years. Additionally, the 1984 data show a high concentration value in Reach 1 (EFK 9.2) in proximity to a localized area of higher floodplain concentration (in the 1984 sampling) and our current sample in that region described earlier.

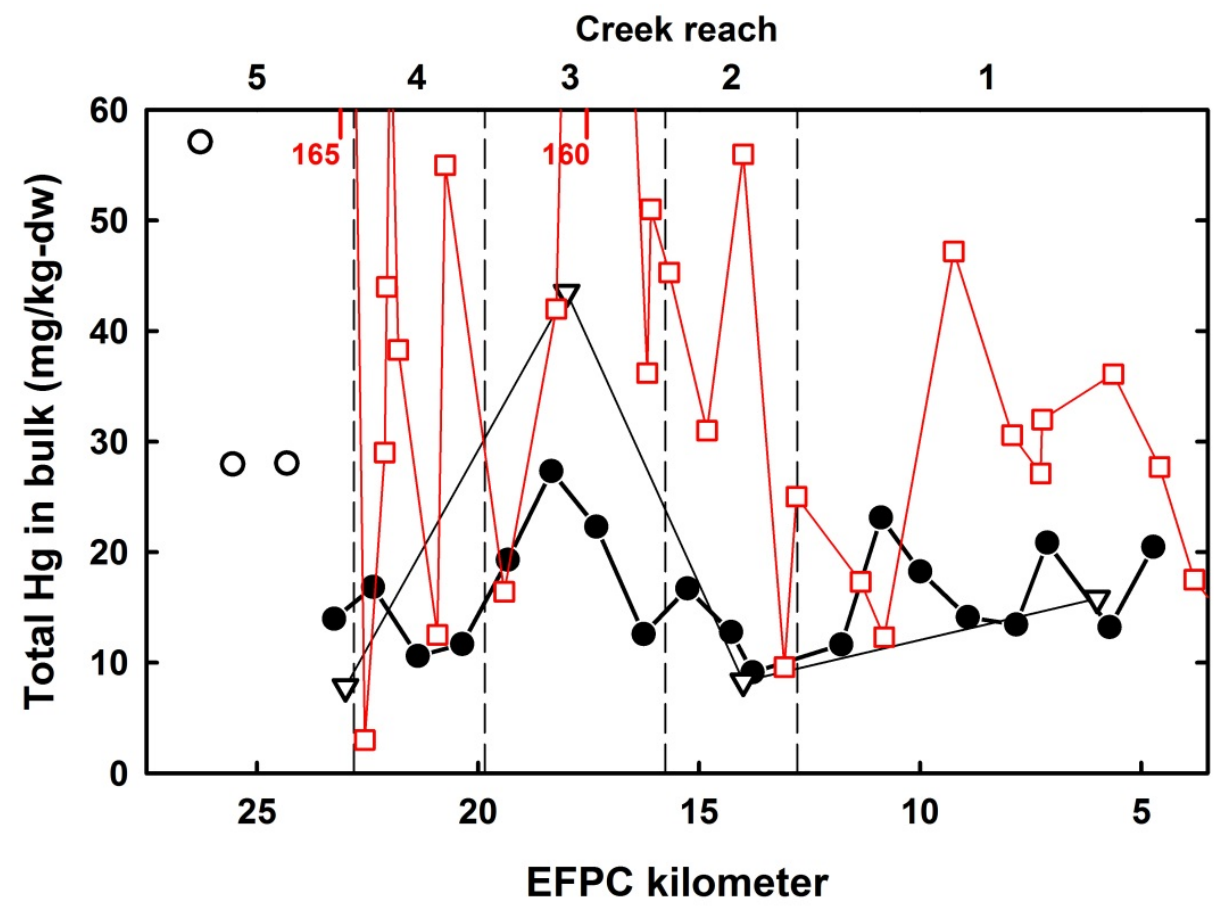

Fig. 6. Total Hg in bulk sediments along East Fork Poplar Creek. Circles (open and filled) represent the same data presented in Fig. 3. Red squares represent the data from the TVA report of 1985 (Tennessee Valley Authority, 1985); the red numbers indicate Hg concentrations for two samples from the TVA report that are offscale. Open inverted triangles represent the data from Southworth (Southworth et al., 2010). Vertical dashed lines and numbers along the upper $x$-axis indicate creek reach.

\subsection{MERCURY CONCENTRATION BY GRAIN SIZE}

Sediment Hg concentration varies with particle size. In the upper reaches of the creek concentration as a function of grain size follows the expected pattern fine $>$ medium $>$ coarse. In the lower reached of the creek this pattern unexpectedly reverses (coarse = medium > fine) due to unknown causes. 
Over the upper six creek kilometers $\mathrm{Hg}_{\mathrm{T}}$ concentration decreased in all three grain size classes (Fig. 7). Mercury concentration decreased most rapidly in the coarse sediments followed by the medium and fine sediments. In the upper two reaches of the creek $\mathrm{Hg}$ concentration in sediment increased with decreasing particle size as expected (Droppo and Jaskot, 1995; Horowitz, 2008; Horowitz et al., 1990; Warren and Zimmermann, 1994). Mercury concentration in all three size classes increased in Reach 3, similar to the bulk sediment values. Sediment $\mathrm{Hg}_{\mathrm{T}}$ in the coarse and medium size fraction remained relatively constant over the lower 20 creek kilometers. Conversely, $\mathrm{Hg}_{\mathrm{T}}$ in the fine sediments continued to decrease over the length of EFPC. Consequently, and contrary to expectation, $\mathrm{Hg}$ concentration decreased with decreasing particle size over the lower 20 creek kilometers. ANOVA results indicated a significant effect of grain size $(\mathrm{p}=1.03 \mathrm{e}-5)$, creek reach $(\mathrm{p}=3.69 \mathrm{e}-8)$, and a significant grain size by creek reach interaction effect $(\mathrm{p}=3.26 \mathrm{e}-7)$. Fine sediments were significantly different from the coarse $(\mathrm{p}=0.0124)$ and medium $(\mathrm{p}=$ $0.0337)$ sediments.

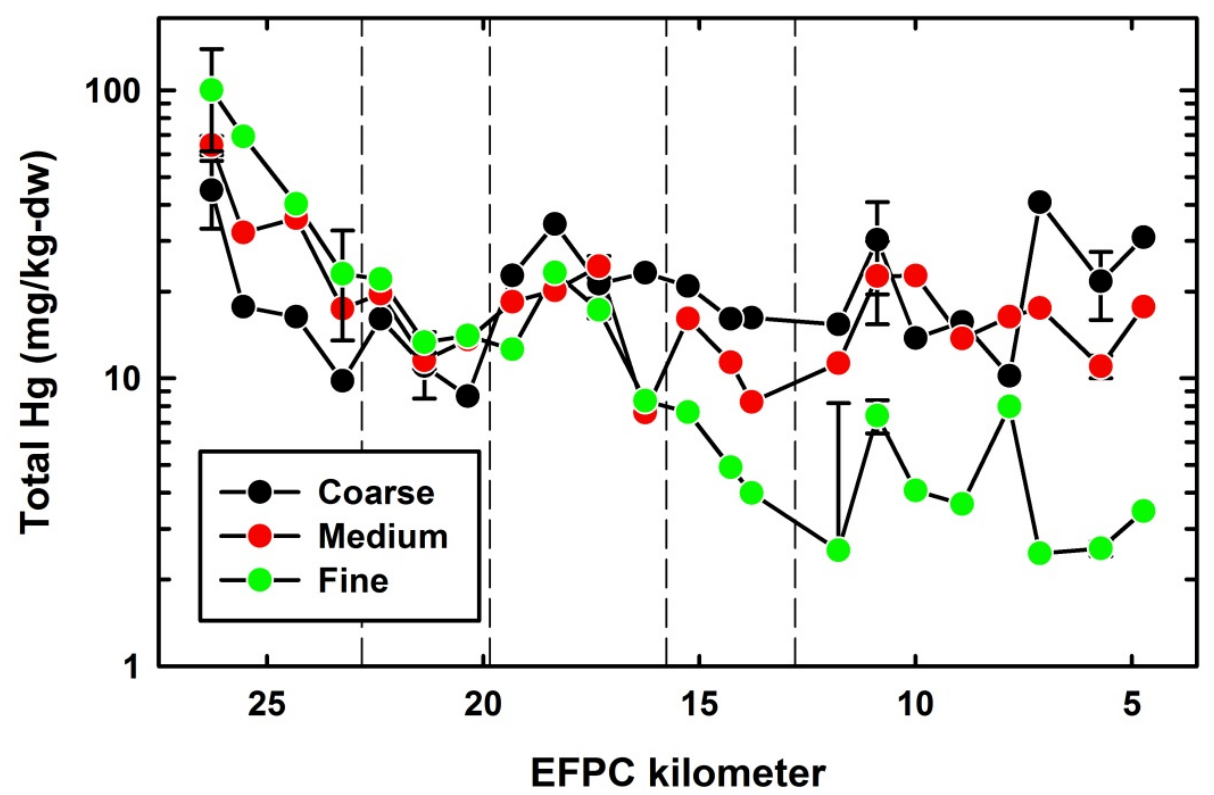

Fig. 7. Total Hg in separate sediment size classes along East Fork Poplar Creek. Error bars represent the standard deviation of triplicate determinations. Vertical dashed lines indicate creek reach.

When expressed on a mass-per-mass basis (e.g., $\mathrm{mg} / \mathrm{kg}$ ) the concentration of trace metals typically increases with decreasing particle size. This pattern is attributed to increasing specific surface area with decreasing particle size and the assumption that surface adsorption is the primary mechanism of the metal-particle association (see Section 6.4). The cause for the unexpected decrease in $\mathrm{Hg}_{\mathrm{T}}$ with decreasing particle size in the lower reaches of the creek is not known but several possible alternative explanations are being considered.

One explanation is that the fine sediments, but not the coarse or medium sediments, are being diluted via mixing with cleaner fine-grained materials of unknown origin that do not accumulate as much $\mathrm{Hg}$ from the constant flow of EFPC over them. Creek bank soil $\mathrm{Hg}_{\mathrm{T}}$ concentration generally decreases over the lower 15 creek kilometers (Dickson et al., in prep) and erosion of these soils into the creek could account for such a dilution effect. Element ratios and trace element abundances also suggest bank soil contributions to creek sediment (Sections 6.8 and 6.9). However, it remains unclear why this would not dilute the medium and coarse sediments also to some extent. Additionally, the mass fraction of fine sediments does not increase downstream (Table A-4). It may be that the coarser particles in the lower 
creek reaches have significant internal porosity or include clusters of smaller particles conveying a higher specific surface area to those grain sizes. Re-expressing the concentrations on a specific surface area basis versus on a sediment mass basis would then reconcile the disparity. Sediment specific surface area measurements are being obtained to test this hypothesis. Finally, $\mathrm{Hg}$ could be preferentially removed from the fine-grained sediments in the lower reaches of the creek via desorption and/or dissolution of $\mathrm{Hg}$ from the solid phase into the aqueous phase. A constituent in the Oak Ridge Waste Water Treatment Plant treated effluent could not be responsible for enhanced desorption/ dissolution. Virtually all of the decrease in $\mathrm{Hg}$ concentration in the fine sediments occurs upstream of the discharge point at EFK 13.5. Presently, it is unclear why desorption/ dissolution processes do not effect similar decreases in $\mathrm{Hg}$ concentration for the medium and coarse sediments.

The high $\mathrm{Hg}$ concentration in bulk sediment in Reach 1 between EFK 11.8 and EFK 7.1 (Fig. 6) is due to localized increased $\mathrm{Hg}$ concentration in all three grain size fractions. In this same length of creek there is a localized area of sediment darkening coupled with increased Fe, Mn, and organic carbon content of the sediment.

\title{
6.4 SEQUENTIAL EXTRACTION RESULTS FOR TOTAL MERCURY
}

\author{
More than $85 \%$ of sediment $\mathrm{Hg}$ is strongly bound regardless of grain size or location \\ along the creek, being removed with concentrated strong acid or a mixture of \\ concentrated strong acids. In the fine sediments, the amount of $\mathrm{Hg}$ held less strongly \\ (removed with $1 \mathrm{M} \mathrm{KOH}$ ) increases steadily downstream. The fraction of $\mathrm{Hg}$ removed \\ with this reagent has been correlated with $\mathrm{Hg}$ methylation potential in aquatic \\ sediments. This may indicate an increasing propensity for sediment-associated $\mathrm{Hg}$ to \\ be methylated with increasing distance downstream from Y-12.
}

The sequential extraction procedure developed by Bloom (Bloom et al., 2003) was applied to the sieved sediments from each sampling site as a means to assess the strength of the $\mathrm{Hg}$-sediment association. The sample is extracted with five different solutions (F1 through F5) designed to extract increasingly recalcitrant $\mathrm{Hg}$ from the sample. These are operationally defined fractions of $\mathrm{Hg}$ and care must be taken not to over-interpret the results in assigning chemical forms of $\mathrm{Hg}$ in the original sample based on which liquid liberated the $\mathrm{Hg}$ (Kim et al., 2003; Kim et al., 2000; LaForce and Fendorf, 2000). Nevertheless, sequential extraction procedures are useful in assessing the strength of the $\mathrm{Hg}$-sediment association.

Across all sampling locations and grain sizes the median amount of total $\mathrm{Hg}$ extracted by both the F1 and F2 reagents was $0.25 \%$ (interquartile range $0.1-0.4 \%$ ) and in only 6 out of 66 samples these two reagents extracted more than $1 \%$ of the total $\mathrm{Hg}$ (Table A-8). Overall these results suggest most of the sediment-associated $\mathrm{Hg}$ is bound relatively strongly as it is not leached with either water or dilute acid. Because the F1 and F2 fractions constitute such a small amount to the overall $\mathrm{Hg}$ budget, the remainder of the discussion will focus on the F3 (1 M KOH), F4 (12 $\left.\mathrm{M} \mathrm{HNO}_{3}\right)$, and F5 (aqua regia) fractions.

In the coarse and medium grain size sediments, $\mathrm{Hg}$ is predominantly removed in the F4 and F5 fractions over the entire length of the creek. Together these two reagents removed more than $95 \%$ of total $\mathrm{Hg}$ in the majority of samples (Fig. 8). This suggests that mechanisms other than simple adsorption govern the $\mathrm{Hg}$-particle association (e.g., precipitation). The fraction of $\mathrm{Hg}$ removed by either F4 or F5 varied within Reach 5 for each size class but then remained relatively constant in downstream reaches 4 through 1. Over a $\sim 3.5$ kilometer reach spanning Reaches 3 and 2 the $\mathrm{F} 3$ reagent removed between $16 \%$ and $32 \%$ of the total $\mathrm{Hg}$ from the medium grain size material. There was a corresponding decrease in the fraction of $\mathrm{Hg}$ extracted by the $\mathrm{F} 5$ reagent over this area. 
The fine-grained sediments behaved differently from the coarse and medium sediments based on the sequential extraction results. In the upper three creek reaches the F4 and F5 fractions removed more than $85 \%$ of total $\mathrm{Hg}$. Through Reaches 3 through 1 the fraction of $\mathrm{Hg}$ extracted by the $\mathrm{F} 3$ reagent increased, accompanied by a small increase in the fraction leached by the F4 reagent. Both of these changes came at the expense of the F5 fraction. Consequently, in the lower 11 creek kilometers the F3 and F4 fraction each constitute $\sim 25 \%$ of the total $\mathrm{Hg}$ and the F5 fraction constitutes $\sim 50 \%$; a decrease from the $70 \%$ total $\mathrm{Hg}$ in $\mathrm{F} 5$ for the upper 15 creek kilometers.

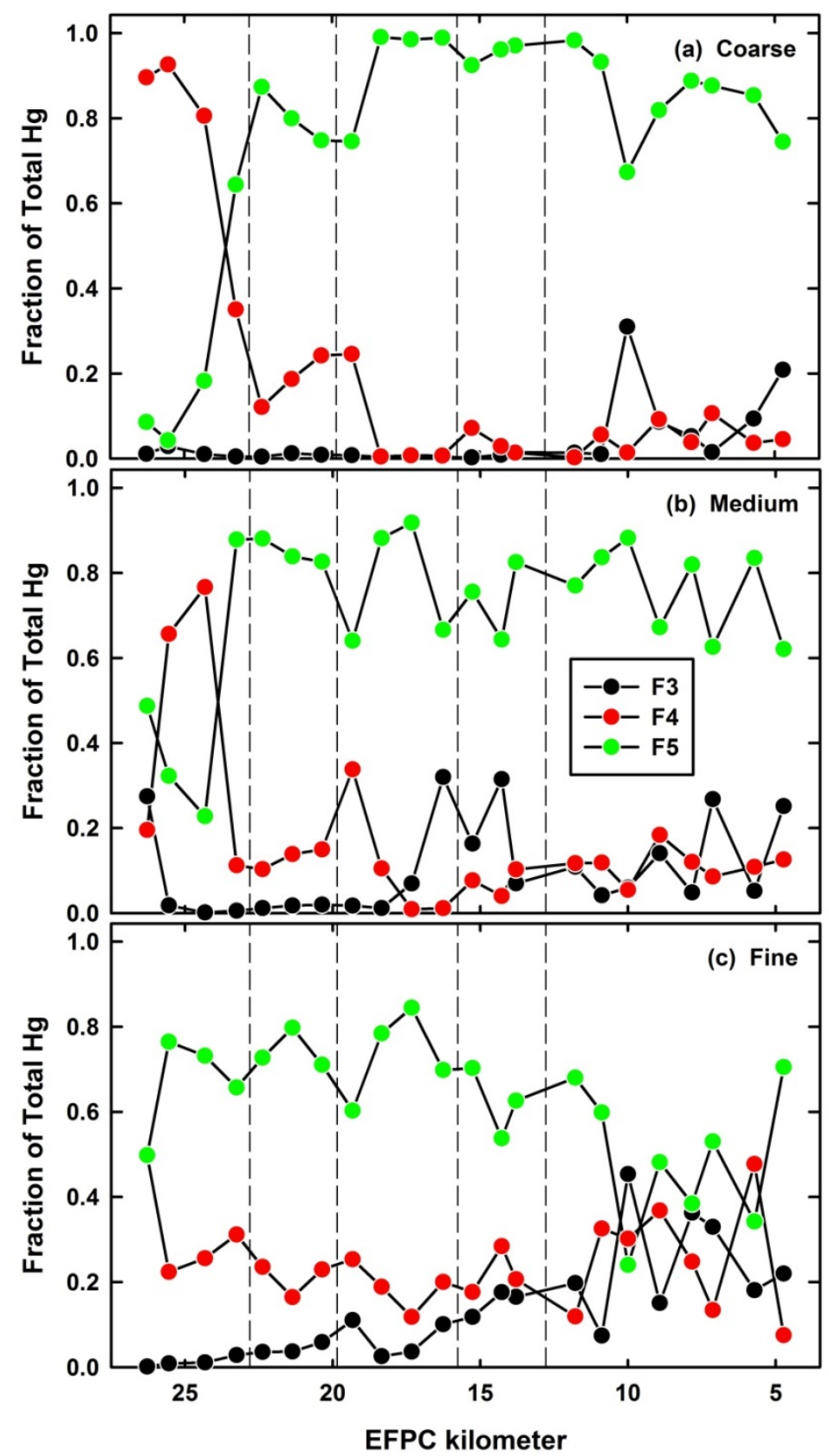

Fig. 8. Fraction of total $\mathrm{Hg}$ leached from sediments in the F3, F4, and $\mathrm{F} 5$ fractions. (a) Coarse-grained sediments, (b) Medium-grained sediments, and (c) Fine-grained sediments. Vertical dashed lines indicate creek reach segments. 
The increased fraction of $\mathrm{Hg}$ leached by F3 in the fine sediments with downstream distance is important for two reasons. First, this represents an increase in the amount of $\mathrm{Hg}$ held less strongly by the sediments and an accompanying decrease in the amount of $\mathrm{Hg}$ held more strongly by the sediments. Mercury in the sediments may be more readily released from the solid phase into the aqueous phase. Second, in the original publication that introduced this sequential extraction method, the amount of $\mathrm{Hg}$ removed in the F3 fraction was most strongly correlated with mercury methylation potential for aquatic sediments. More $\mathrm{Hg}$ in the F3 fraction may indicate a greater propensity for this $\mathrm{Hg}$ to be converted into $\mathrm{MMHg}$.

\title{
6.5 TOTAL MONOMETHYLMERCURY IN BULK SEDIMENT
}

\author{
In general, MMHg in bulk sediment decreased monotonically with distance \\ downstream. A three kilometer reach from EFK 23 to EFK 20 had significantly higher \\ MMHg concentrations reaching $10.4 \mu \mathrm{g} / \mathrm{kg}$. The reasons for this localized enrichment \\ are not understood. The trend of decreasing sediment MMHg concentration with \\ downstream distance opposes the increase in water column MMHg over the same \\ length of creek.
}

Monomethylmercury concentrations in bulk sediment and as a function of grain size are reported. These results inform accumulation by location and grain size and could be used in estimates of sedimentassociated flux or sediment inventory but the concentration values in themselves should not be taken as a measure of site(s) of or rate(s) of MMHg production.

Total MMHg concentration in bulk sediment ranged between 0.55 and $10.4 \mu \mathrm{g}$ per $\mathrm{kg}$ (Fig. 9). Excluding the samples from Reach 4, MMHg in sediments decreased approximately exponentially from Y-12 downstream. Monomethylmercury concentration in sediment is strongly and significantly correlated with creek kilometer either including $\left(\rho_{\mathrm{s}}=0.732, \mathrm{p}=2.15 \mathrm{e}-5\right)$ or excluding $\left(\rho_{\mathrm{s}}=0.654, \mathrm{p}=0.0023\right)$ the values from Reach 4. Similar to the localized enrichment in $\mathrm{Hg}_{\mathrm{T}}, \mathrm{MMHg}$ in creek sediments are substantially and significantly higher in Reach 4 than in Reaches 1-3. However, the high MMHg concentrations in Reach 4 occurred approximately three kilometers upstream of the localized increase in sediment $\mathrm{Hg}_{\mathrm{T}}$. There was no correlation between MMHg and $\mathrm{HgT}$ in the bulk sediments $\left(\rho_{\mathrm{s}}=0.011, \mathrm{p}=0.963\right)$.

Comparison of $\mathrm{MMHg}$ concentrations among different data sets is more challenging than for total $\mathrm{Hg}$. The environmental variables controlling MMHg concentrations are incompletely known but include sample collection decisions including sampling location, time of year, and the time of day of sample collection. There were no measurements of MMHg during the site investigations of the early 1980's but Southworth (Southworth et al., 2010) measured MMHg in EFPC sediments in August 2008 at the same four locations where they measured total $\mathrm{Hg}$ (Fig. 9). The coarser spatial resolution of that dataset was insufficient to assess the persistence of the high concentrations observed in Reach 4. Additionally, in the present sampling effort sediment MMHg concentration was relatively constant in the lower $\sim 15$ creek kilometers whereas the 2008 data suggests a possible increasing concentration over the same length of creek.

A long data record demonstrates that dissolved $\mathrm{MMHg}$ concentration in water increases monotonically with distance downstream regardless of the time of year samples are collected, total MMHg shows less variability with distance. A common feature of both sediment data sets in Fig. 9 is that neither shows a pattern similar to that seen in the surface water. The cause for the disconnect between the sediment and water MMHg concentration is not understood. Nevertheless, this suggests the increase in dissolved $\mathrm{MMHg}$ downstream does not translate into a measureable increase in sediment MMHg. This may simply be a function of the current measurement resolution. Aqueous MMHg concentrations in the surface water 
of EFPC are below $1 \mathrm{ng} / \mathrm{L}$ compared to sediment concentrations expressed in $\mu \mathrm{g} / \mathrm{kg}$ - sediments could be accumulating $\mathrm{MMHg}$ from the water column but the increase in concentration is below measurement precision.

Alternatively, increasing dissolved $\mathrm{MMHg}$ concentration in water coupled with decreasing sediment concentration can be interpreted as decreasing MMHg-solid phase partitioning affinity that could contribute to increasing $\mathrm{MMHg}$ bioaccumulation downstream. In this case, targeted application of sorbents with high MMHg removal efficiency could be a practicable remedial action. Tasks 1 and 2 within the TD project are planning experiments to evaluate sorbents for MMHg removal from water.

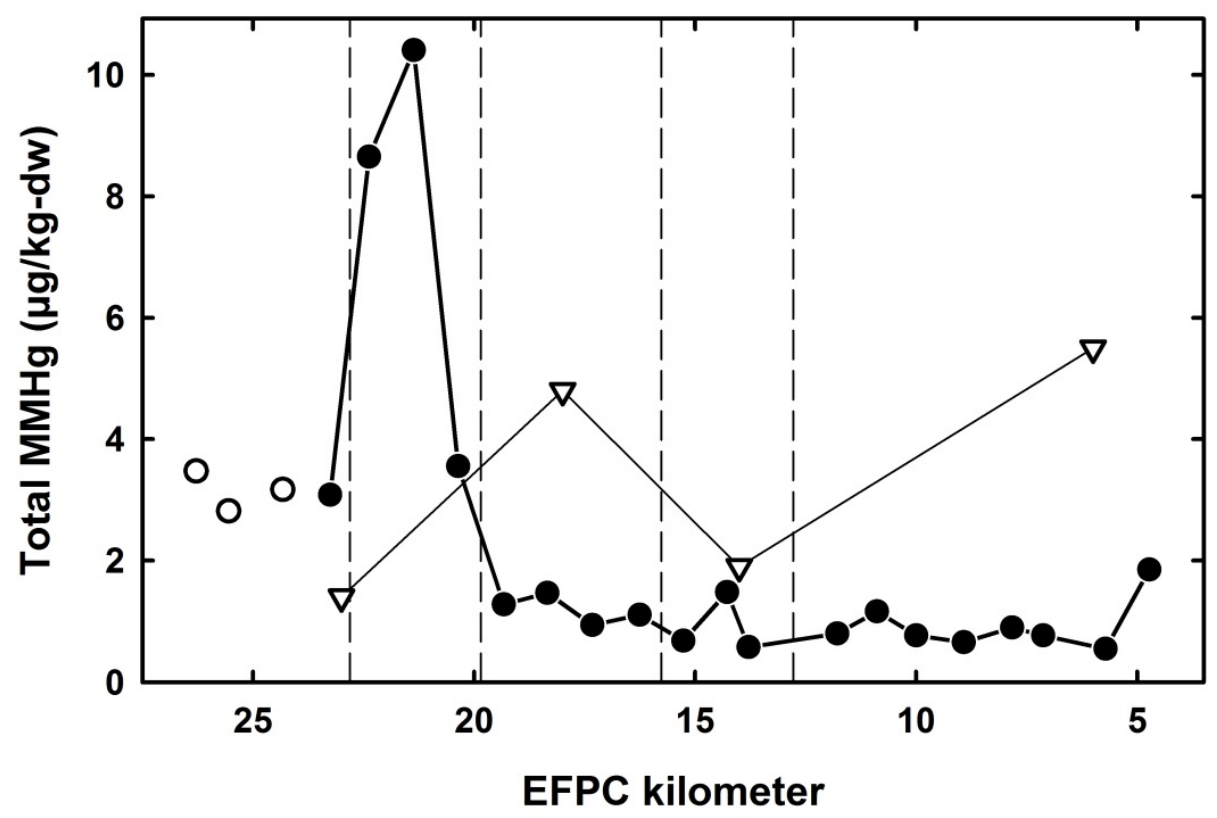

Fig. 9. Total MMHg in bulk sediments along East Fork Poplar Creek. Circles represent data from the present study where filled circles were directly measured and open circles indicate samples where the bulk sediment reconstruction was estimated using the average grain size mass fraction from the other 19 samples.

Open inverted triangles represent data from Southworth (Southworth et al., 2010). Vertical dashed lines indicate creek reach.

\subsection{MONOMETHYLMERCURY CONCENTRATION BY GRAIN SIZE}

In general, MMHg concentration decreased monotonically downstream for all grain sizes similar to the bulk sediment. However, the localized enrichment in MMHg from EFK 23 to EFK 20 was due solely to higher concentration in the coarse-grained sediments in this reach. MMHg concentration in the medium- and fine-grained sediments did not change or decreased over the same reach. MMHg concentration in medium and fine sediments was significantly correlated with $\mathrm{Hg}$. The percent $\mathrm{MMHg}$ with distance varied by grain size: percent MMHg decreased downstream for the coarse sediments, did not change in the medium sediments, and increased in the fine sediments. The percent MMHg in fine sediments was significantly correlated with the fraction of $\mathrm{Hg}$ extracted by the $\mathrm{F} 3$ reagent $(1 \mathrm{M} \mathrm{KOH})$. 
Monomethylmercury concentration in the fine and medium grain sized sediment decreased monotonically downstream (Fig. 10; medium grain size $\rho_{\mathrm{s}}=0.495, \mathrm{p}=0.0192$; fine grain size $\rho_{\mathrm{s}}=0.730, \mathrm{p}=2.95 \mathrm{e}-5$ ). In the coarse-grained sediment MMHg initially decreased then increased in Reach 4 and subsequently decreased with downstream distance with concentrations comparable to those in the medium and fine sediment. These results indicate that the increased MMHg concentration in bulk sediments in Reach 4 is attributed solely to a preferential concentration increase in the coarse size fraction of the sediment. Creek reach segment $(\mathrm{p}=1.81 \mathrm{e}-9)$, sediment grain size $(\mathrm{p}=4.44 \mathrm{e}-7)$, and the reach-by-grain size interaction $(\mathrm{p}$ $=0.00115)$ effects were all significant.

In contrast to the bulk sediment results, $\mathrm{MMHg}$ in the medium and fine grained sediment was moderately to very strongly and significantly correlated with $\operatorname{Hg}_{\mathrm{T}}\left(\rho_{\mathrm{s}}=0.583, \mathrm{p}=4.48 \mathrm{e}-3 ; \rho_{\mathrm{s}}=0.871, \mathrm{p}=2.0 \mathrm{e}-7\right.$, respectively)(Fig. A-4). Monomethylmercury and $\mathrm{Hg}_{\mathrm{T}}$ were not significantly correlated in the coarse sediments even after removing the high MMHg values in Reach 4 as potential high-leverage points.

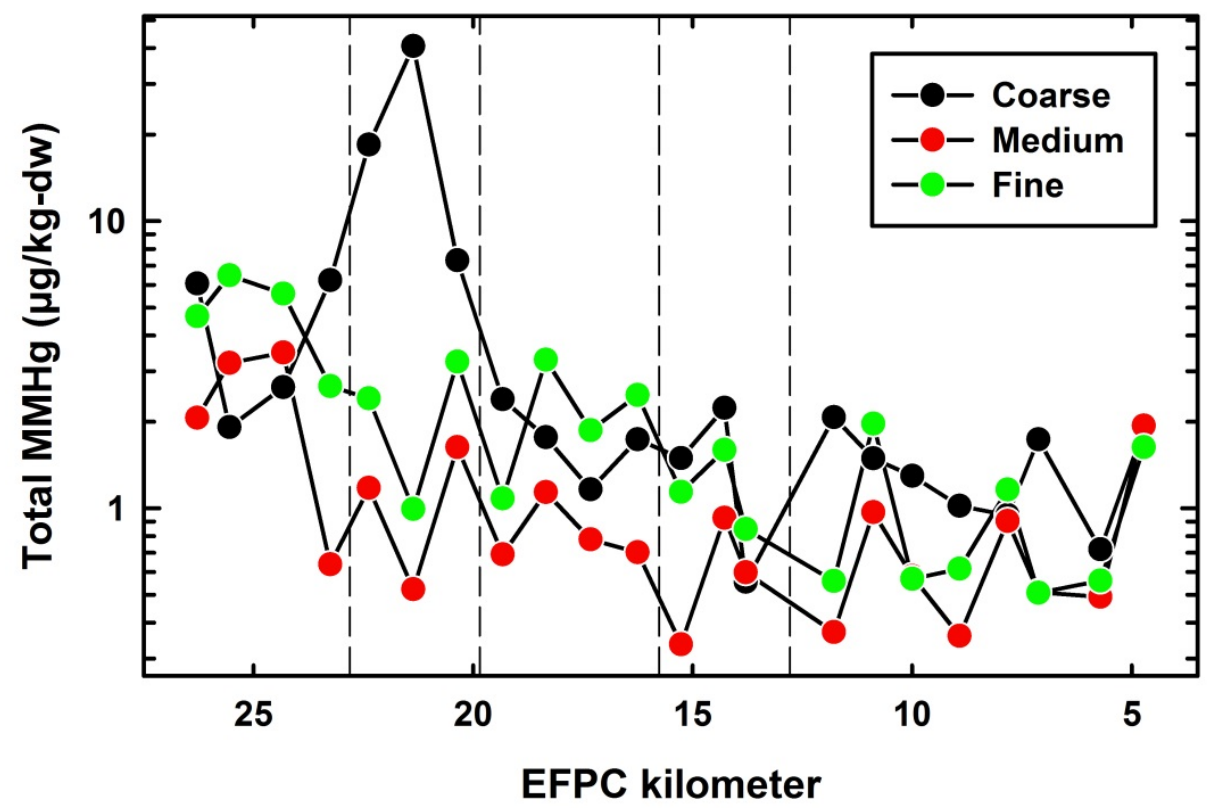

Fig. 10. Total MMHg in separate sediment size classes along East Fork Poplar Creek. Vertical dashed lines indicate creek reach.

\subsubsection{Percent monomethylmercury in sediments as a function of grain size}

The percent of total mercury in sediments present as MMHg is a measure of the amount of MMHg per unit amount of $\mathrm{Hg}$ and indicates potential exposure for sediment-ingesting or sediment-dwelling organisms. The percent MMHg (Pct-MMHg) ranged from a low of $0.0021 \%$ (EFK 15.3, medium grain size) to a maximum of $0.38 \%$ (EFK 21.4, coarse grain size; Fig. 11). Pct-MMHg was strongly and significantly correlated with creek kilometer for both the coarse- and fine-grained sediment $\left(\rho_{\mathrm{s}}=0.664, \mathrm{p}\right.$ $=1.02 \mathrm{e}-3 ; \rho_{\mathrm{s}}=-0.661, \mathrm{p}=1.08 \mathrm{e}-3$, respectively). Note that the negative correlation for the fine-grained sediment indicates that the Pct-MMHg increased downstream (lower EFK values). The Pct-MMHg was not correlated with creek kilometer for the medium sized sediments $\left(\rho_{\mathrm{s}}=0.223, \mathrm{p}=0.317\right)$. Two features of the Pct-MMHg versus creek kilometer figure draw attention. First is the high values measured in Reach 4 for the coarse sediments which mirror the higher absolute MMHg concentrations. The cause for 
this localized enrichment is not understood. The coarse sediments in this reach do not stand out in the other measured parameters (e.g., total $\mathrm{Hg}$, fraction $\mathrm{Hg}$ leached with various extractants, organic $\mathrm{C}$ ). The second feature is the trend of increasing Pct-MMHg in fine sediments with downstream distance. In the original paper describing the sequential extraction procedure, Bloom reported that the percent $\mathrm{MMHg}$ generated by a sediment sample is best correlated with the percent of total $\mathrm{Hg}$ extracted with the $\mathrm{F} 3$ reagent $(1 \mathrm{M} \mathrm{KOH})$. In EFPC fine sediments, the Pct-MMHg was moderately and significantly correlated with the fraction of total $\mathrm{Hg}$ extracted in the F3 phase $\left(\rho_{\mathrm{s}}=0.56, \mathrm{p}=0.0206\right)$. The Pct-MMHg in fine sediment was not correlated with other $\mathrm{Hg}$ sequential extract amounts.

The fine sediments are more prone to resuspension and transport under smaller increases in creek flow and are more likely to be ingested by sediment filter feeders. Therefore, the high Pct-MMHg in fine sediments could be an important first step in bioaccumulation in EFPC. To the extent this is the case, actions to remove these finer particles from bioaccumulative pathways may help decrease fish $\mathrm{MMHg}$ concentration. Novel biomanipulation strategies, such as the reintroduction of native freshwater mussels to the creek for the purpose of suspended sediment control that is being studied under Task 3 of the TD project, would be one way of managing these sediments for the overall benefit of the creek ecosystem.

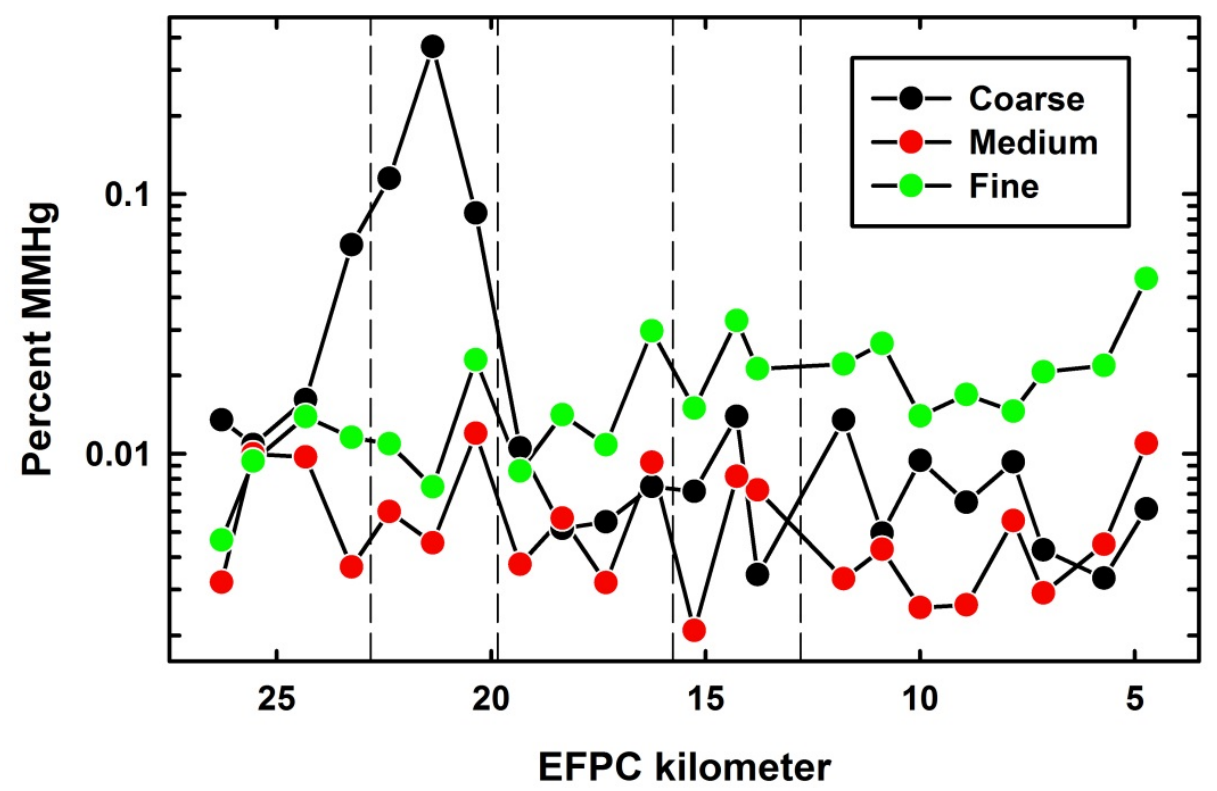

Fig. 11. Percent MMHg in separate sediment size classes along East Fork Poplar Creek. Vertical dashed lines indicate creek reach.

\subsection{STREAM SEDIMENT MERCURY AND MONOMETHYLMERCURY INVENTORY}

The current inventory of $\mathrm{Hg}$ in EFPC bed sediments is estimated to be $334 \mathrm{~kg}$ which represents a $\sim 67 \%$ decrease relative to the initial investigations in 1984. Improved sediment quality likely resulted from improvements in water quality being released from Y-12, transport of contaminated sediment out of EFPC, and inputs of cleaner sediment to the creek. Elevated $\mathrm{Hg}$ flux from $\mathrm{Y}-12$ associated with storm drain cleanout actions in 2011-2012 was too small to detect reliably in EFPC sediments using the current methods. Monomethylmercury sediment inventory was estimated to be $44.1 \mathrm{~g}$, lower but roughly similar to past estimates. Comparing MMHg 


\section{concentrations or inventories among different data sets is more challenging than for total $\mathrm{Hg}$ due to a dependence on sampling date, among other factors.}

Southworth (Southworth et al., 2010) estimated the inventory of $\mathrm{Hg}$ and MMHg in creek sediments $(<1$ $\mathrm{mm}$ grain size) based on four sampling locations approximately equally spaced five kilometers apart; samples were collected in August 2008. Results of the present study, coupled with new information about creek dimensions and creek bed composition from a kayak-based whole creek survey conducted in 2013 (Peterson et al., 2014), were used to update the estimated inventory of these two constituents in EFPC creek sediment. The estimates were computed using reach length between sample points, percent of reach length comprising finer sediments, and mean stream width along each reach. Additional assumptions in the calculation included (i) the bulk density of the sediments $<2 \mathrm{~mm}$ grain size was 340 $\mathrm{kg} / \mathrm{m}^{3}$, and (ii) the mean sediment depth was $30 \mathrm{~cm}$. The first assumption was derived from data provided in the report by Southworth. The latter assumption was based on extensive prior experience coring and vertical profiling along EFPC and is similar to but $\sim 25 \%$ smaller than the average value reported by Southworth. The inventory within each reach was calculated as:

$$
\rho_{b}(\text { width })(\text { length })\left(\text { Pct }_{\text {fines }}\right)(\text { depth })(\text { concentration })
$$

Where $\rho_{b}=$ bulk density $\left(\mathrm{kg} / \mathrm{m}^{3}\right)$, width $=$ mean reach width $(\mathrm{m})$, length $=$ reach length $(\mathrm{m}), P c t_{\text {fines }}=$ percent of the reach length comprising gravelly and finer sediment; depth = mean sediment depth $(\mathrm{m})$, concentration $=$ concentration of either $\mathrm{Hg}$ or $\mathrm{MMHg}$ on the bulk sediment (mass $/ \mathrm{kg}$ ). Total inventory was calculated as the sum of the individual reach inventories.

Using this approach, the estimated sediment $\mathrm{Hg}$ inventory was $334 \mathrm{~kg} \mathrm{Hg}$ (Table 2), nearly $100 \%$ greater than the 2010 estimate $(172 \mathrm{~kg})$ even though the current calculations assumed a shallower sediment depth. The current estimate includes sediment samples in upper EFPC which were not included in the 2010 estimate and these account for $45 \mathrm{~kg}$ of the "extra" $\mathrm{Hg}$. The current estimate also includes sediment in the 1-2 $\mathrm{mm}$ size range which was not included in the 2010 estimate. Because the coarse and medium grain sizes had comparable $\mathrm{Hg}$ concentrations along EFPC, the difference in grain sizes used in the samplings likely is of minor importance in the different inventory estimates. The remaining difference in the two estimates $(117 \mathrm{~kg} \mathrm{Hg})$ can largely be attributed to two factors. First, different stream widths were used in each estimate. In lower EFPC the mean measured stream width $(12.6 \mathrm{~m})$ is $80 \%$ greater than the average of stream widths used in the 2010 estimates. Second, the percent of creek bed comprising smaller grain sizes differed in each estimate. Southworth assumed a value of 50\% throughout EFPC. The kayak-based survey found this varies substantially along the creek ranging from $3 \%$ to $100 \%$ with a median value of $60.2 \%$ (Table 2 ).

To demonstrate the effect of these two factors, the 2010 inventory was re-calculated using the newly measured stream widths and $P c t_{\text {fines }}$ bringing the two inventories into closer agreement. Excluding the inventory in upper EFPC the estimates differ by $\sim 35 \%$ with the 2010 estimate being larger at $451 \mathrm{~kg}$. It is unlikely that there has been a measurable decrease in sediment $\mathrm{Hg}$ inventory over that time. Rather, the 2010 inventory likely represents an overestimate. In the 2010 estimate the high $\mathrm{Hg}$ value measured at EFK 18 (Fig. 4) was applied over a 5-kilometer length of creek. The higher spatial resolution sampling in 2015 indicates a much more localized area for these high concentrations. Additionally, this reach has a high value of $P c t_{\text {fines }}$ (69\%) amplifying the effect of the high $\mathrm{Hg}_{\mathrm{T}}$ in that sample. We suggest that within measurement uncertainty there has been no net change in sediment Hg inventory between 2015 and 2008 (year of sampling).

During the four-year period 2006-2009 the average annual $\mathrm{Hg}$ flux from Y-12 was $3.65 \mathrm{~kg}$. After the 2008 sampling that supported the 2010 inventory estimate, storm drain cleanout actions in Y-12 resulted 
in substantial increases in Hg flux for 2011 and 2012. Mercury flux declined in 2013 but increased to nearly $4 \times$ that previous four-year average to $14.4 \mathrm{~kg}$ in 2014 (UCOR, 2015)(Table A-9). The higher fluxes over the past five years amount to an extra $32 \mathrm{~kg}$ above average pre-cleanout flux, or $10 \%$ of existing inventory. Even if all of the additional $\mathrm{Hg}$ was entrained in EFPC sediments it is unlikely the sampling and analysis methods used are sensitive enough to detect this change.

Using the calculation method outlined previously, the median value for $P_{c t} f_{\text {fines }}$, and the in-stream sediment Hg concentration reported by TVA (Tennessee Valley Authority, 1985), total Hg inventory in stream sediment in 1984 was estimated to be $1004 \mathrm{~kg}$. Thus, our current inventory represents a $67 \%$ decrease in $\mathrm{Hg}$ inventory relative to 1984 . Improved sediment quality likely resulted from improvements in water quality being released from Y-12, transport of contaminated sediment out of EFPC, and inputs of cleaner sediment to the creek.

The updated MMHg inventory (44.1 g) was $\sim 47 \%$ greater than the 2010 estimate ( $30 \mathrm{~g}$ ). Recalculating the 2010 inventory using new measurements of creek dimensions and extent of fine sediments and subtracting out the inventory in upper EFPC from the 2015 estimate, the 2010 inventory is $42 \%$ higher than the 2015 estimate at $67 \mathrm{~g}$. The $2010 \mathrm{MMHg}$ inventory may be an overestimate and for the same reasons outlined previously for total Hg. The two high MMHg values (Fig. 7) were each applied to 5kilometer reaches of the creek when, in all likelihood, these values apply to much shorter creek segments. As described previously, comparing MMHg concentrations or inventories among different data sets is more challenging than for total $\mathrm{Hg}$ due to a dependence on sampling date, among other factors.

Nevertheless, there are reasons to believe the differences in inventory estimates could be real and are related to seasonal changes in MMHg production in EFPC. The present samples were collected in AprilMay and the 2008 samples were collected in August. Monomethylmercury concentration in EFPC water

Table 2. Estimated inventory of mercury (Hg) and methylmercury (MMHg) in streambed sediments

\begin{tabular}{|c|c|c|c|c|c|c|c|}
\hline $\begin{array}{c}\text { Creek } \\
\text { kilometer }\end{array}$ & $\begin{array}{c}\text { Mean } \\
\text { width (m) }\end{array}$ & $\begin{array}{c}\text { Reach } \\
\text { length }(m)\end{array}$ & $\begin{array}{l}\text { Percent } \\
\text { Fines }\end{array}$ & $\begin{array}{c}\text { total Hg } \\
\text { (mg/kg- } \\
\text { dw) }\end{array}$ & $\begin{array}{c}\text { total } \\
\text { MMHg } \\
(\mu \mathrm{g} / \mathrm{kg}- \\
\mathrm{dw}) \\
\end{array}$ & $\begin{array}{c}\mathrm{Hg} \\
\text { inventory } \\
(\mathrm{kg})\end{array}$ & $\begin{array}{c}\text { MMHg } \\
\text { inventory } \\
\text { (g) }\end{array}$ \\
\hline 4.7 & 14.8 & 4724 & $55.2 \%$ & 20.4 & 1.85 & 80.6 & 7.30 \\
\hline 5.7 & 13.9 & 991 & $29.3 \%$ & 13.2 & 0.55 & 5.4 & 0.22 \\
\hline 7.1 & 13.9 & 1410 & $15.4 \%$ & 20.8 & 0.76 & 6.4 & 0.24 \\
\hline 7.8 & 12.4 & 703 & $32.9 \%$ & 13.4 & 0.89 & 3.9 & 0.26 \\
\hline 8.9 & 9.3 & 1095 & $63.8 \%$ & 14.1 & 0.66 & 9.4 & 0.44 \\
\hline 10.0 & 8.9 & 1074 & $69.7 \%$ & 18.1 & 0.76 & 12.3 & 0.52 \\
\hline 10.9 & 8.5 & 889 & $59.3 \%$ & 23.1 & 1.16 & 10.5 & 0.53 \\
\hline 11.8 & 9.8 & 895 & $98.0 \%$ & 11.6 & 0.80 & 10.2 & 0.70 \\
\hline 13.8 & 11.9 & 2006 & $37.7 \%$ & 9.1 & 0.57 & 8.4 & 0.53 \\
\hline 14.3 & 13.3 & 488 & $100.0 \%$ & 12.7 & 1.48 & 8.4 & 0.97 \\
\hline 15.3 & 14.5 & 988 & $75.1 \%$ & 16.7 & 0.68 & 18.3 & 0.74 \\
\hline 16.3 & 14.9 & 992 & $58.0 \%$ & 12.5 & 1.10 & 11.0 & 0.96 \\
\hline 17.3 & 14.1 & 1069 & $58.4 \%$ & 22.3 & 0.94 & 20.0 & 0.84 \\
\hline 18.3 & 12.8 & 1021 & $75.7 \%$ & 27.3 & 1.46 & 27.6 & 1.48 \\
\hline 19.3 & 14.3 & 983 & $71.8 \%$ & 19.2 & 1.28 & 19.8 & 1.31 \\
\hline 20.4 & 14.6 & 1034 & $61.7 \%$ & 11.7 & 3.55 & 11.1 & 3.38 \\
\hline 21.4 & 12.8 & 1000 & $88.2 \%$ & 10.2 & 10.00 & 11.7 & 11.55 \\
\hline 22.4 & 13.0 & 1014 & $61.1 \%$ & 16.5 & 8.46 & 13.5 & 6.94 \\
\hline 23.3 & 12.4 & 878 & $3.1 \%$ & 13.9 & 3.08 & 0.5 & 0.11 \\
\hline 24.3 & 10.7 & 1124 & $50.8 \%$ & 28.0 & 3.17 & 17.4 & 1.97 \\
\hline 25.6 & 8.0 & 1173 & $69.0 \%$ & 27.9 & 2.82 & 18.4 & 1.86 \\
\hline 26.3 & 6.0 & 1051 & $25.3 \%$ & 57.1 & 3.47 & 9.3 & 0.57 \\
\hline Total & & & & & & 334.1 & 44.1 \\
\hline
\end{tabular}


has a strong seasonal signal with higher values in the warmer months of the year but the pattern in sediments is less definitive. As described previously, the current MMHg sediment data set opposes the spatial trends seen in the water column. For these reasons, one cannot make a definitive statement as to whether the sediment MMHg inventory is substantially different from the 2010 estimate.

These estimates are first approximations of $\mathrm{Hg}$ and $\mathrm{MMHg}$ inventory in EFPC sediments and there remains room for improvement. Nevertheless, they are useful for assessing the order-of-magnitude of $\mathrm{Hg}$ inventory and comparing against other compartments in the EFPC system (e.g., stream bank soils). Additionally, they indicate substantial improvements in sediment quality with respect to total $\mathrm{Hg}$ content when compared to older data and provide a baseline against which future assessments can be compared.

\title{
6.8 RELATIONSHIPS AMONG MERCURY, MONOMETHYLMERCURY AND ORGANIC CARBON
}

\begin{abstract}
Mercury and MMHg are correlated with sediment organic carbon $(O C)$ and nitrogen (N). The Hg to OC ratio increased downstream for coarse and medium sediments but decreased for fine sediments. The divergent patterns in $\mathrm{Hg}$ :OC by grain size coupled with similarity of Hg:OC between bank soils and fine sediments suggests contribution of fine particles from creek bank soils to the bed sediments. Organic carbon to nitrogen ratio suggests out-of-stream sources are the dominant source of organic carbon to the creek. The narrow range of sediment $\mathrm{OC}: \mathrm{N}$ values throughout EFPC coupled with their similarity to bank soils suggests bank soil erosion and entrainment into the creek sediments.
\end{abstract}

Hg and MMHg associations with sediment Carbon and Nitrogen Total Hg in fine-grained sediments was strongly to very strongly and significantly correlated with organic $\mathrm{C}(\mathrm{OC})$ and nitrogen $(\mathrm{N})$ content $\left(\rho_{\mathrm{s}}=0.83, \mathrm{p}=1.43 \mathrm{e}-6 ; \rho_{\mathrm{s}}=0.73, \mathrm{p}=1.87 \mathrm{e}-4\right.$, respectively). Total $\mathrm{Hg}$ was moderately correlated with OC in medium grained sediments $\left(\rho_{\mathrm{s}}=0.46, \mathrm{p}=0.0325\right)$ but not correlated with $\mathrm{N}$. Total $\mathrm{Hg}$ showed no significant correlation with $\mathrm{OC}$ or $\mathrm{N}$ in coarse-grained sediments. In contrast $\mathrm{MMHg}$ was significantly correlated with $\mathrm{OC}$ for all sediment size classes and significantly correlated with $\mathrm{N}$ for the fine sediments.

Hg:OC ratio Mercury has a high affinity for associating with organic matter and solid surfaces (Section 2). Consequently, the $\mathrm{Hg}$ to $\mathrm{OC}$ ratio of water, sediment, and soil samples is frequently calculated to assess potential source terms and variables that may control $\mathrm{Hg}$ behavior in the environment. The Hg:OC ratio for coarse and medium sediments is strongly and significantly correlated with downstream distance $\left(\rho_{\mathrm{s}}=-0.762, \mathrm{p}=2.0 \mathrm{e}-7 ; \rho_{\mathrm{s}}=-0.668, \mathrm{p}=6.32 \mathrm{e}-4\right.$, respectively; $\rho_{\mathrm{s}}=-0.688, \mathrm{p}=2.0 \mathrm{e}-7$ for pooled coarse + medium data)(Fig. 12). The trend lines describing this relationship are identical for the two grains sizes. The pattern of increasing $\mathrm{Hg}$ : $\mathrm{OC}$ ratio downstream is driven by declining OC content of sediment (Table A-10) as the $\mathrm{Hg}$ content for these sediments is relatively constant over the same distance (Fig. 7). As described previously, $\mathrm{Hg}$ concentration in EFPC sediment is anomalously high relative to freshwater sediments in the US and Europe (Fig. A-3). Less expected was the finding that EFPC also had lower than expected OC. Consequently, the $\mathrm{Hg}: \mathrm{OC}$ ratio is $\sim 100 \times$ higher than other sediments.

The Hg:OC ratio for fine sediments was lower and showed a different spatial pattern than for the coarseand medium-grained sediments (Fig. 12). $\mathrm{Hg}$ :OC ratio in the fines showed a moderate but significant decrease downstream $\left(\rho_{\mathrm{s}}=0.479, \mathrm{p}=0.024\right)$. The decreasing $\mathrm{Hg}$ : OC ratio was driven by the faster decline in $\mathrm{Hg}_{\mathrm{T}}$ relative to the decline in $\mathrm{OC}$. Interestingly, the $\mathrm{Hg}$ : $\mathrm{OC}$ ratio in creek bank soils along EFPC (Dickson et al., in prep) are similar to fine sediments with respect to magnitude, range, and trend (Fig. 12). Bank soil Hg:OC ratio is weakly but significantly correlated with distance downstream $\left(\rho_{\mathrm{s}}=\right.$ $0.256, \mathrm{p}=2.55 \mathrm{e}-3$ ). Bank soil $\mathrm{Hg}$ : $\mathrm{OC}$ ratio is not similar to either the coarse or medium sediments. Interestingly, the $\mathrm{Hg}$ :OC ratio for suspended solids collected at EFK 5.4 over baseflow and multiple 
storm flow events ranged from a low of 6.2e-6 to a maximum of $2.5 \mathrm{e}-5$ which is comparable to, but lower than, the Hg:OC value of fine sediments and bank soils in that area (Riscassi et al., 2016) and distinctly lower than the $\mathrm{Hg}$ :OC ratio for the coarse and medium sediments.

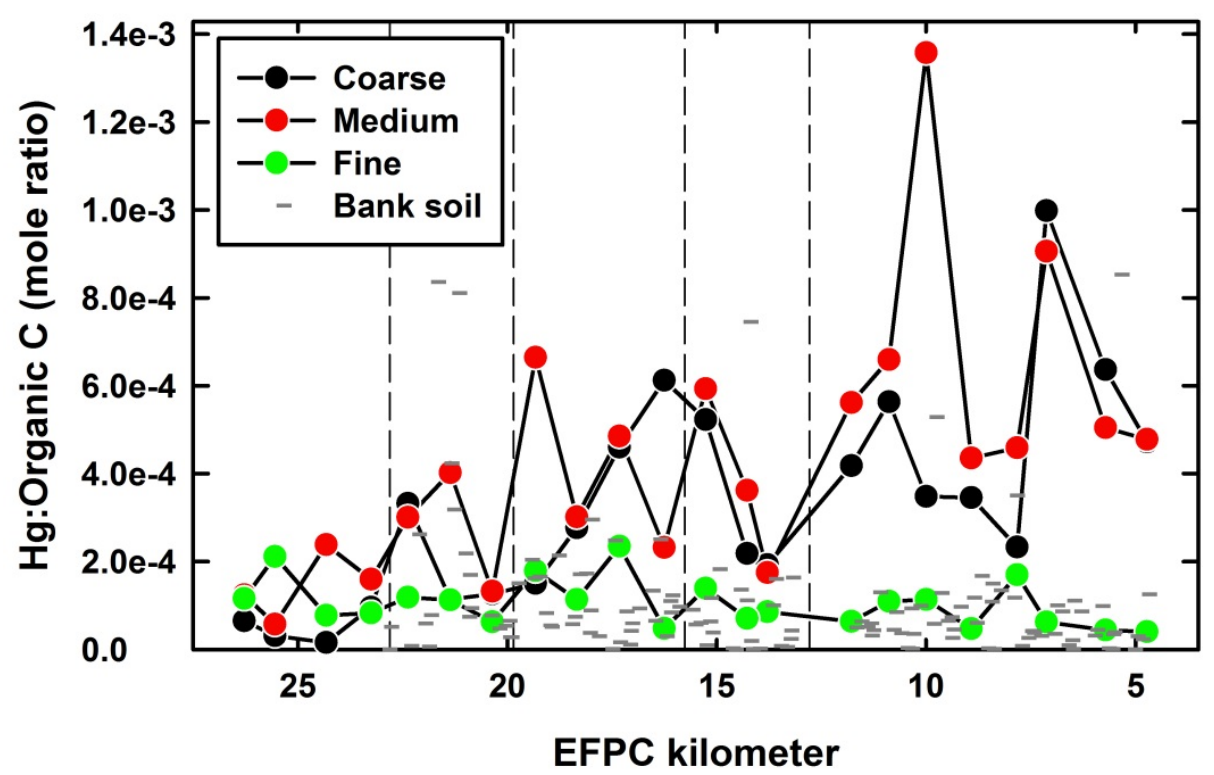

Fig. 12. Hg to organic $\mathrm{C}$ ratio in separate sediment size classes along East Fork Poplar Creek. Vertical dashed lines indicate creek reach.

Sources of organic matter to EFPC The organic carbon to nitrogen mole ratio (OC:N) provides a general indication of organic matter sources to freshwater systems. To explore further the Hg:OC patterns the OC:N was also calculated. During the nonaqueous phase extraction of sediments from within Y-12, it was apparent that these samples contained heavy hydrocarbons (e.g., tar, asphalt) that likely came from construction and paving activity in Y-12. Samples outside Y-12 did not show similar characteristics in the nonaqueous phase extraction. The OC: $\mathrm{N}$ of the samples inside $\mathrm{Y}-12$ were significantly higher than those outside of Y-12 (Fig. 13) but are not characteristic of the natural organic matter that influence $\mathrm{Hg}$ speciation. Therefore, the following analysis and discussion focuses on those samples from outside of Y12.

The OC:N ratio was moderately to strongly and significantly correlated with downstream distance for the coarse and fine sediments $\left(\rho_{\mathrm{s}}=0.564, \mathrm{p}=0.0189 ; \rho_{\mathrm{s}}=0.628, \mathrm{p}=3.96 \mathrm{e}-3\right.$, respectively) but not for the medium sediments $\left(\rho_{\mathrm{s}}=0.0965, \mathrm{p}=0.689\right)$. Additionally, both the fine and medium sediments were significantly different from the coarse sediments $(\mathrm{p}=5.54 \mathrm{e}-4, \mathrm{p}=3.32 \mathrm{e}-3$, respectively), but were similar to each other. The similarity of the fine sediments to the coarse and medium sediments with respect to OC:N magnitude and trend unfortunately does not shed light on the grain size differences in $\mathrm{Hg}$ :OC ratio discussed previously (Fig. 12).

The vast majority of samples had OC:N ratios reflecting terrestrial, or allochthonous/ out-of-stream, sources of organic matter (Fig. 13) and few samples reflected autochthonous/ in-stream organic matter sources. Bank soil OC: $\mathrm{N}$ is very similar to the range observed for soil organic matter ratio, as might be expected, and is weakly and significantly correlated with distance $\left(\rho_{\mathrm{s}}=0.231, \mathrm{p}=6.50 \mathrm{e}-3\right)$. Notably 
bank soil OC:N is very similar to that of the sediments (Fig. 13; (Dickson et al., in prep). Downstream of Y-12 the sediment OC:N ratio has a relatively narrow range (first and third quartiles: $11.3-25.4$ ) suggestive of a common widespread source of organic matter to the creek. These two factors are indicative of a bank soil erosion and deposition into the creek. The connection between bank soils and sediments based on OC: $\mathrm{N}$ ratios would be strengthened with more detailed analyses of stable isotopes of carbon and nitrogen $\left(\delta^{13} \mathrm{C}\right.$ and $\left.\delta^{15} \mathrm{~N}\right)$.

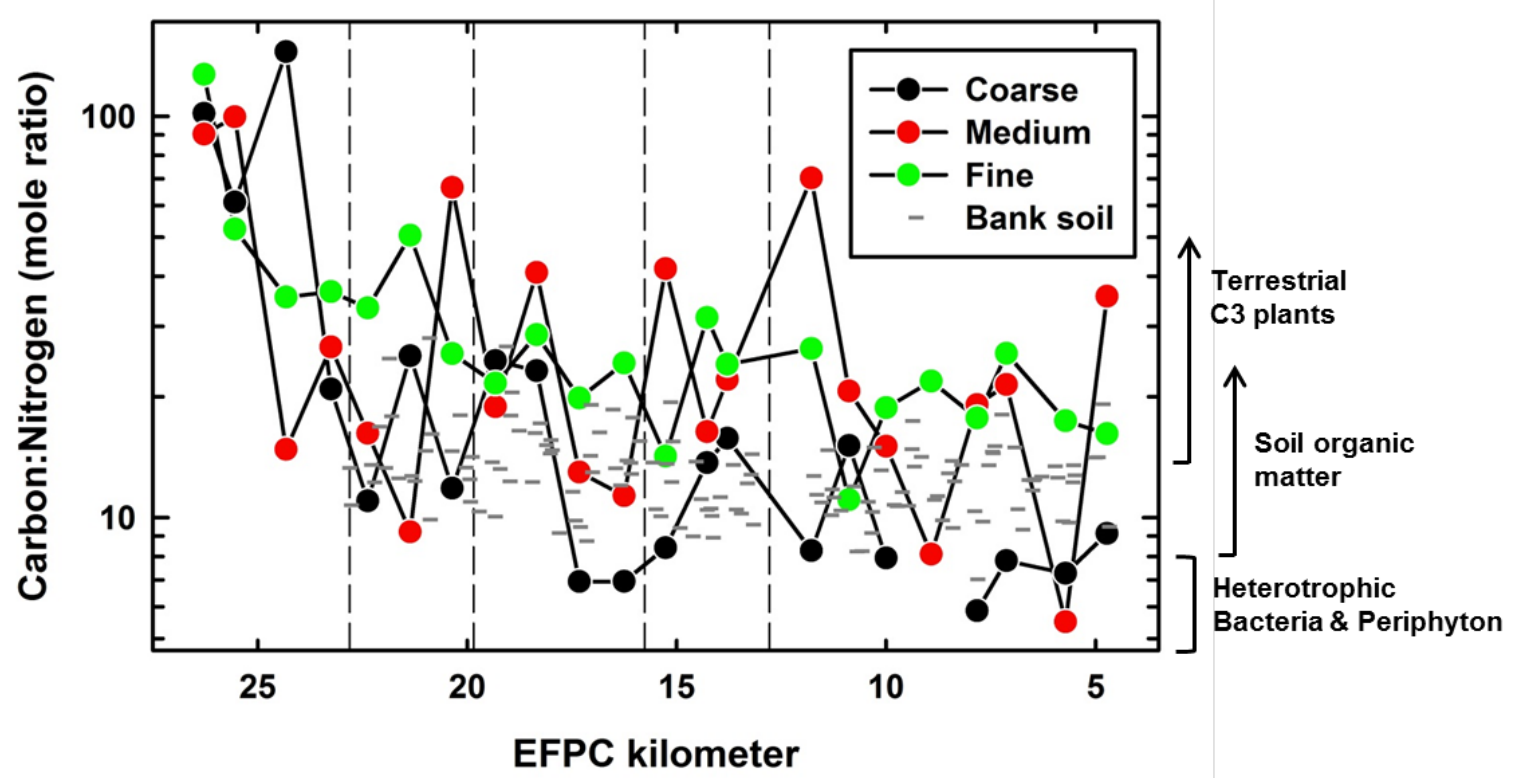

Fig. 13. Carbon to nitrogen ratio in separate sediment size classes along East Fork Poplar Creek. Vertical dashed lines indicate creek reach. The range of $\mathrm{C}: \mathrm{N}$ values for various sources is taken from (Finlay and Kendall, 2007; Kendall et al., 2001)

\subsection{RELATIONSHIPS AMONG MERCURY AND OTHER ELEMENTS PRESENT IN SEDIMENT}

The relationship between $\mathrm{Hg}$ and Fe was strongly dependent on grain size. The two parameters were uncorrelated in coarse sediments, moderately correlated in medium sediments, and very strongly correlated in fine sediments. Similar patterns were seen for the relationship between $\mathrm{Hg}$ and $\mathrm{Mn}$. The underlying cause for this grain size dependence is not known but may be related to increasing surface area to volume ratio with decreasing particle size. Trace element analyses suggest localized areas of stream bank erosion input and derivation of sediments from bedrock underlying the EFPC channel.

The abundance of 26 elements in EFPC sediments was determined by XRF analysis (Tables A-11 through A-13). Nine of those elements (Co, La, Cs, Te, Sb, Sn, Cd, Ag, and Pd) were not present above detection limits (p. A-12) in any sample and are not discussed further. Five elements (Zr, Sr, Rb, Fe, and Mn) were present above their respective detection limits in all samples and are the focus of the following discussion.

Iron(II/III) and Mn(III/IV) oxy-hydroxide minerals and that occur as secondary coatings on surfaces exercise dominant influence on solute sorption behavior (Cerling and Turner, 1982; Dzombak and Morel, 1990; Lee, 1973). To the extent that surface sorption reactions play a prominent role in $\mathrm{Hg}$ retention by 
stream sediments and to the extent the XRF measurement is representative of those sorptive phases, one would expect a positive correlation between the $\mathrm{Fe}$ or $\mathrm{Mn}$ and $\mathrm{Hg}$ sediment concentrations. The formation of solid solutions of $\mathrm{Fe}-\mathrm{Hg}-\mathrm{S}$ is another retention mechanism that could manifest a positive correlation between $\mathrm{Hg}$ and Fe. Previous study of EFPC floodplain and creek bank soils has identified discrete $\beta-\mathrm{HgS}$ (metacinnabar) and Fe-S (ferrous sulfide, pyrite) phases (Barnett et al., 1995; Barnett et al., 1997; Peterson et al., 2014). In addition to sorbing onto its surface, $\mathrm{Hg}$ can replace Fe in the Fe-S structure (sometimes referred to as the pyritization of $\mathrm{Hg}$ ) to form a solid solution of variable $\mathrm{Fe}: \mathrm{Hg}$ ratio that depends on a number of conditions including the availability of "reactive" $\mathrm{Hg}$ and FeS (Huerta-Diaz and Morse, 1992; Morse and Luther, 1999). Scanning electron microscopy (SEM) coupled with energydispersive $\mathrm{x}$-ray spectroscopy (EDX) of EFPC bank soils has shown discrete grains of FeS and $\mathrm{HgS}$ as well as mixed $\mathrm{Fe}-\mathrm{Hg}-\mathrm{S}$ rich precipitates.

As described earlier, there was a high degree of collinearity between Fe and Mn (Fig. A-1).

Consequently, similar trends were seen in the relationship of $\mathrm{Hg}$ with $\mathrm{Fe}$ and $\mathrm{Mn}$. The discussion that follows focuses on the $\mathrm{Hg}-\mathrm{Fe}$ relationship.

For the pooled data, without consideration of grain size, $\mathrm{Hg}$ was moderately and significantly correlated with Fe content $\left(\rho_{\mathrm{s}}=0.542, \mathrm{p}=3.86 \mathrm{e}-6\right)$. However, this analysis masks significant differences in the relationship among the different grain size classes; the direction and strength of the correlation between $\mathrm{Hg}$ and $\mathrm{Fe}$ was highly dependent on grain size (Fig. 14; Fig. A-4). There was a very weak and insignificant negative correlation for these variables in the coarse-grained sediments $\left(\rho_{\mathrm{s}}=-0.193, \mathrm{p}=\right.$ $0.559)$. In medium-grained sediment $\mathrm{Hg}$ was moderately and significantly correlated with Fe content $\left(\rho_{\mathrm{s}}\right.$ $=0.5, \mathrm{p}=0.0292)$. The fine-grained sediments, however, exhibited a very strong and significant positive correlation between $\mathrm{Hg}$ and $\mathrm{Fe}\left(\rho_{\mathrm{s}}=0.951, \mathrm{p}=1.32 \mathrm{e}-10\right)$.

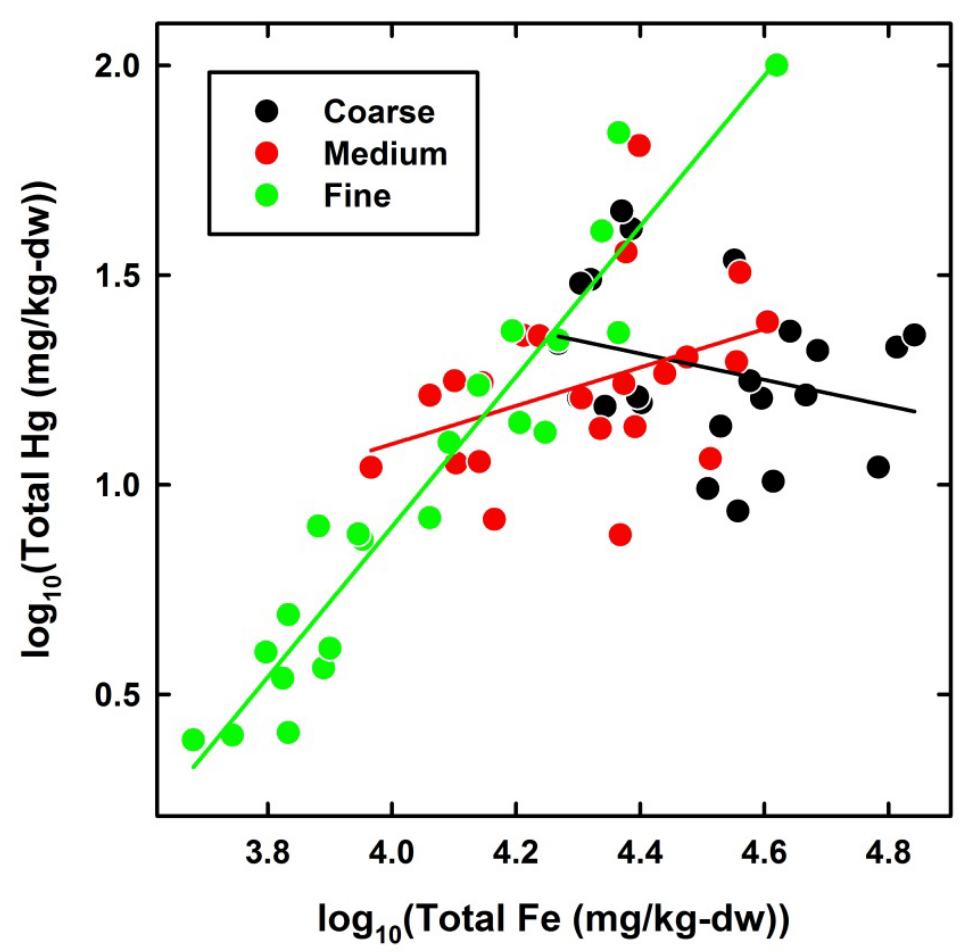

Fig. 14. Relationship between sediment concentrations of $\mathrm{Hg}$ and Iron $(\mathrm{Fe})$ as a function of sediment grain size. 
The underlying cause(s) for the grain size dependence in the Hg-Fe relationship is currently unknown but may reflect changes in the $\mathrm{Hg}$ retention mechanism among grain size classes. For example, if $\mathrm{Hg}$ in the coarse sediments is primarily retained as discrete $\mathrm{Hg}$-sulfide precipitates then its abundance may not be correlated with total $\mathrm{Fe}$ content, as observed here. It is difficult to predict the effect of $\mathrm{Hg}$ substitution for $\mathrm{Fe}$ in $\mathrm{FeS}$ solids on the $\mathrm{Hg}$ : $\mathrm{Fe}$ ratio. Additional studies quantifying the degree of pyritization in the sediments are needed to evaluate this mechanism.

Alternatively, changes in the $\mathrm{Hg}$-Fe relationship with grain size may be due to changes in what the XRF measurement represents in each of those grain size classes. The XRF measurement is a bulk average concentration for the sample and does not distinguish structural $\mathrm{Fe}$ at the interior of particles from that present at surfaces that can actively participate in sorption reactions. Therefore, the changing direction and increasing strength of the $\mathrm{Hg}$-Fe correlation with decreasing particle size may reflect a surface areato-volume ratio effect. As the particle size decreases, a greater fraction of the total Fe present in the sample is at the surface where it can actively participate in sorption reactions.

Elemental abundances as tracers of sediment sources Earlier, observed patterns of elemental molar ratios were presented and discussed as a possible means to identify sources of sediments to EFPC. Here, the abundance of strontium $(\mathrm{Sr})$, zirconium $(\mathrm{Zr})$, and rubidium $(\mathrm{Rb})$ are discussed as possible tracers of sediment sources in EFPC.

Overall, sediment Sr concentration in EFPC is anomalously low relative to sediments in the US and Europe (Fig. A-6). The low Sr values are surprising given that (i) much of the EFPC channel and floodplain is underlain by carbonate rock expected to be a source of Sr-bearing sediment, and (ii) $\mathrm{Sr}$ concentration in EFPC surface water $(\sim 110 \mu \mathrm{g} / \mathrm{L})$ is generally consistent with US river water $(\sim 100 \mu \mathrm{g} / \mathrm{L}$; (Hem, 1989; Livingstone, 1963). However, this low background can make it easier to detect localized enrichments.

Strontium concentration decreased downstream with very strong significant correlations for all grain sizes (coarse $\rho_{\mathrm{s}}=0.877, \mathrm{p}=2.34 \mathrm{e}-6$; medium $\rho_{\mathrm{s}}=0.846, \mathrm{p}=8.96 \mathrm{e}-7$; fine $\rho_{\mathrm{s}}=0.896, \mathrm{p}=3.35 \mathrm{e}-6$ ). The

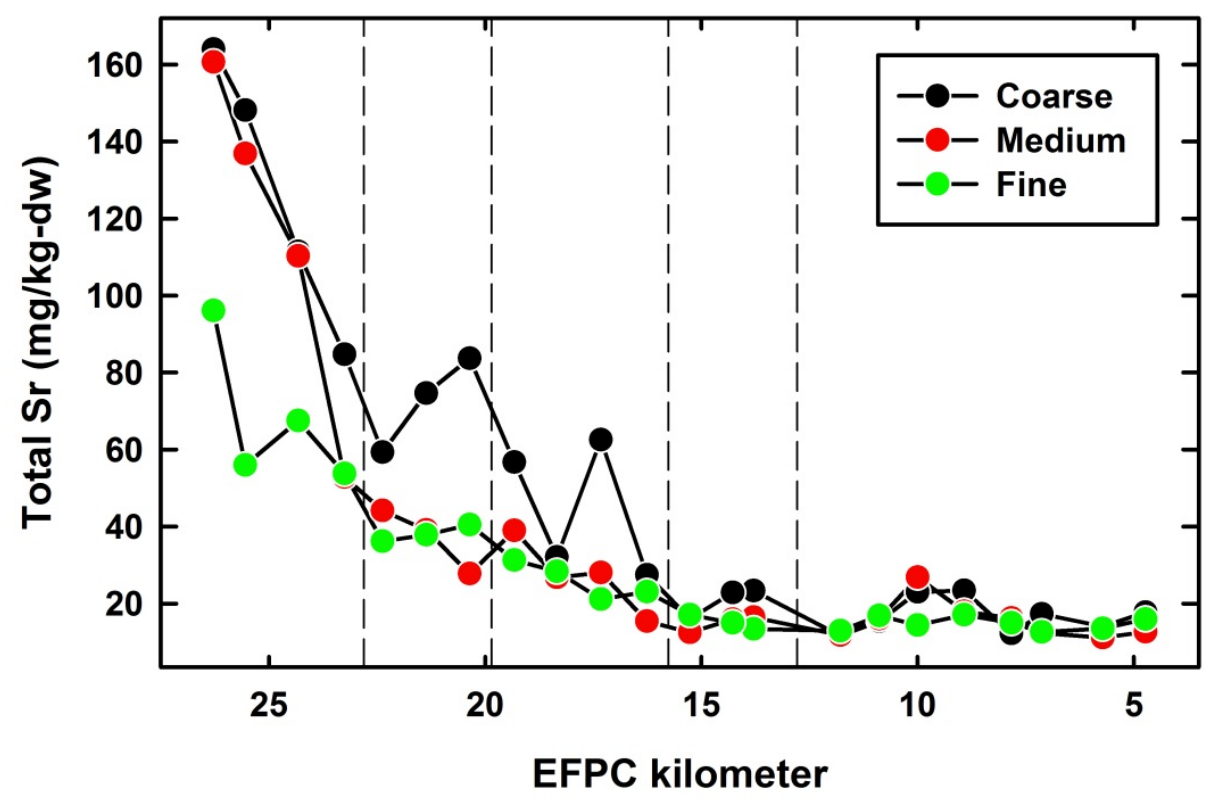

Fig. 15. Total strontium (Sr) concentration in EFPC sediments as a function of grain size. 
coarse sediments were significantly different from the medium and fine sediments due mainly to the localized higher concentrations in Reaches 3 and 4 (Fig. 15). There is an additional localized increase in Sr concentration for the coarse and medium sediments in Reach 1. The areas of higher Sr concentration coincide with similar secondary peaks in sediment $\mathrm{Hg}$ (Fig. 7) which occur in the same general area of known or suspected occurrences of the HRD.

Previous study of the HRD found the layer to contain coal fines and fly ash that may have originated from Y-12 along with the elevated $\mathrm{Hg}$ in these layers (Peterson et al., 2014). Coal contains Sr at levels higher than EFPC sediments. For example, twelve coal samples from Virginia and West Virginia had an average $\mathrm{Sr}$ content of $157 \mathrm{mg} / \mathrm{kg}$ (Trent et al., 1982). Fly ash generally contains higher $\mathrm{Sr}$ concentration than the parent coal from which it is derived (Straughan et al., 1981). The average Sr content of the fly ash released to the Clinch and Emory Rivers following the dike failure at the Kingston fossil fuel plant was $1120 \mathrm{mg} / \mathrm{kg}$ (Rivera et al., 2015).

The historical chemical composition of the coal and fly ash from Y-12 is not known but general properties of these materials suggest the coal fines and fly ash present in the HRD might reasonably be expected to have higher Sr content than average EFPC sediments. Therefore, the co-occurrence of localized increases in $\mathrm{Hg}$ and $\mathrm{Sr}$ concentration suggest localized input of materials derived from the HRD. This possibility could be better evaluated by determining (i) Sr content of EFPC bank soils and the HRD, and (ii) Sr isotope ratio analysis of soils, the HRD, and creek sediments, assuming historical or ongoing operations at Y-12 do not artificially affect these ratios.

Both $\mathrm{Rb}$ and $\mathrm{Zr}$ have low environmental mobility under conditions typical for the EFPC watershed due to their strong association on or in the structure of mineral phases (they are lithophile elements under Goldschmidt's classification). Average concentrations of $\mathrm{Rb}$ and $\mathrm{Zr}$ in shales ( $\sim 160 \mathrm{mg} / \mathrm{kg}$ and $100-300$ $\mathrm{mg} / \mathrm{kg}$, respectively) are higher than in carbonate rocks $(30-60 \mathrm{mg} / \mathrm{kg}$ and $20-130 \mathrm{mg} / \mathrm{kg}$, respectively). Broadly speaking, shales and carbonate rock (dolomite, limestone) are the dominant lithologies underlying the EFPC watershed (Fig. A-7). One would predict that sediments derived from shales would be enriched in these two elements relative to sediments derived from carbonate rocks.

Rubidium has had little use in broad-scale application and geogenic sources are considered more important than anthropogenic sources. Zirconium has broader applications in catalytic converters, furnace bricks, laboratory crucibles, and cladding for nuclear fuel elements (zircalloy). Additionally, during the early- to mid-1950's Y-12 was engaged in large-scale operations to purify zirconium (Ramsey and Whitson, 1951). Although there are no records of zirconium spills or discharges to EFPC, high concentrations of this element were measured in liquids and sludges of the former S-3 ponds that were located on the west end of the Y-12 site (Jeter and Napier, 1978; Union Carbide Corporation, 1983). These unlined infiltration ponds were on a groundwater divide and portions of the resulting groundwater plume emanating from those ponds travels to the northeast in the direction of EFPC. Similar disposal sites located closer to the headwaters of EFPC also created groundwater contamination plumes but information on their chemical constituents were not available. The extent to which these may discharge to EFPC is not known. Nevertheless, given the broader anthropogenic sources of $\mathrm{Zr}$ including some of specific relevance to $\mathrm{Y}-12$ it is possible that $\mathrm{Zr}$ content of bank soils or sediments has been impacted by operations at Y-12. Sediment Zr data are provided in the appendices (Tables A-11 through A-13; Fig. A8 ) but the discussion that follows is focused on $\mathrm{Rb}$ data.

For the first $\sim 2 \mathrm{~km}$ downstream from OF200, EFPC is underlain by carbonate rock. As the creek turns northwest the underlying lithology changes to shales for about $2 \mathrm{~km}$ before changing back to carbonate rock for the remainder of the course of EFPC. 
Through most of EFPC sediment Rb concentration ranged between 6-40 mg/kg, consistent with expected concentration based on the underlying lithology (Fig. 16). Between EFK 24 and EFK 17 there was a noticeable increase in $\mathrm{Rb}$ concentration up to $\sim 80 \mathrm{mg} / \mathrm{kg}$ in coarse sediments at the upstream portion of that reach. Similar trends were seen in all sediment size classes although the increases were greatest for the coarse-grained materials. These results suggest that Rb-rich sediments in Reach 4 derive from underlying shale bedrock and are transported, dispersed, and diluted with other sediments with downstream distance. In general, similar patterns are seen in the $\mathrm{Zr}$ data although the trends are less distinct possibly due to variable anthropogenic inputs along the creek (Fig. A-8).

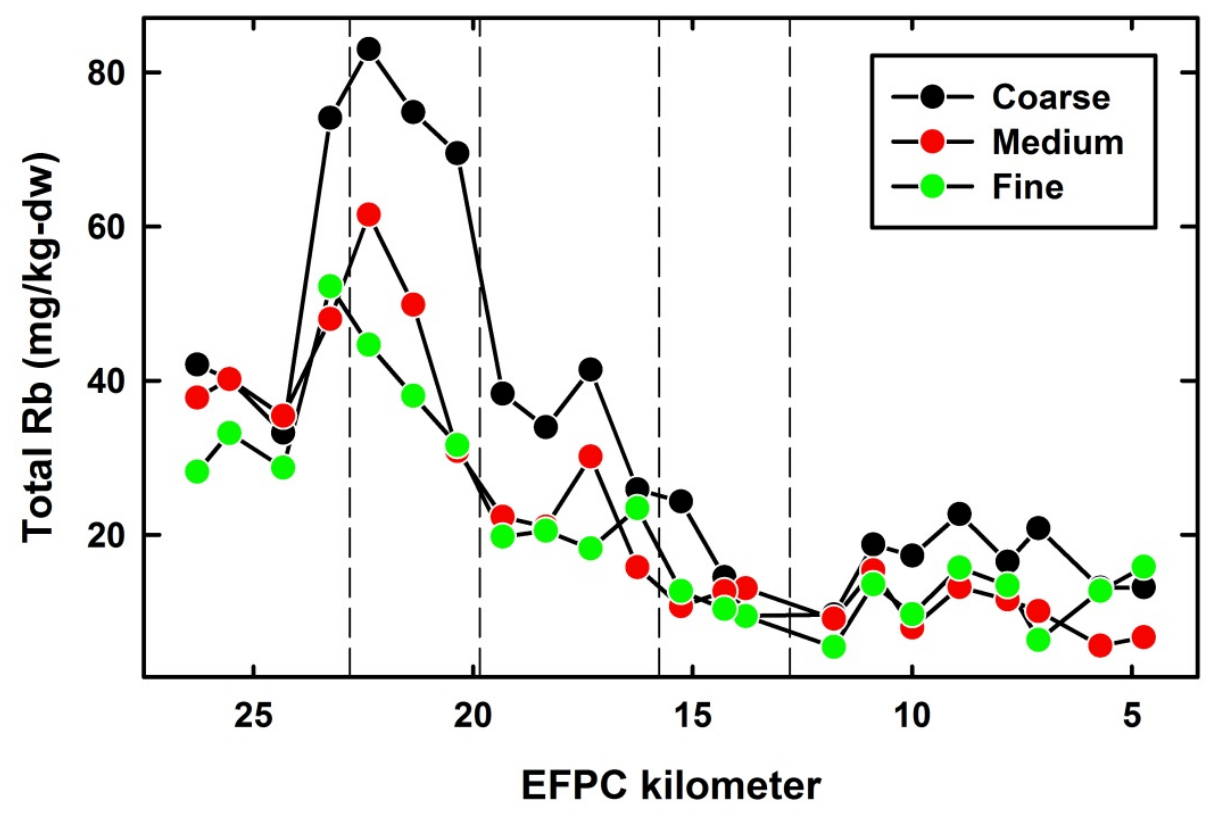

Fig. 16. Sediment rubidium (Rb) concentration as a function of grain size along EFPC. 


\section{CONCLUSIONS}

A broad based assessment of $\mathrm{Hg}$ concentration in EFPC sediments was conducted for the first time since the original site investigations in 1984. Some of the measurements made and/or the resolution at which they were made (e.g., spatial, as function of grain size) are unprecedented. The resulting data set enabled an assessment of changes over the past 30 years and provides a contemporary baseline against which system response to future remedial actions can be compared.

Total Hg in EFPC sediments is substantially lower relative to values measured in 1984. Some features of the $\mathrm{Hg}$ concentration profile along the creek have persisted over that 30 -year period. Specifically, there are two regions of localized higher $\mathrm{Hg}$ concentration, each of which is in proximity to known or suspected areas of higher $\mathrm{Hg}$ concentration in bank or floodplain soils. The downstream feature requires additional investigation but each of these areas may represent high(er) priority locations for targeted remedial actions. The majority of $\mathrm{Hg}$ is strongly bound to sediments regardless of grain size or location along the creek. However, systematic patterns in $\mathrm{Hg}$ extractability from the fine sediments along the creek may contribute to enhanced MMHg production. Leveraged research in other projects at ORNL is addressing this aspect.

The estimated $\mathrm{Hg}$ inventory in sediments has decreased $\sim 67 \%$ over the past 30 years. Barring substantial decreases in $\mathrm{Hg}$ flux exiting Y-12 the pace of $\mathrm{Hg}$ concentration decrease is likely to slow or stagnate and will be dependent on other controlling fluxes such as (i) rate of contaminated sediment flux out of the EFPC stream corridor, (ii) rate of contaminated bank soil flux into the creek, (iii) rate of dilution/ burial with clean(er) sediment input, (iv) rate of $\mathrm{Hg}$ desorption from sediments into the water column and subsequent advective transport out of EFPC as a dissolved solute. Ongoing activities within the TD project are actively addressing (ii), (iii) and (iv) and investigations addressing (i) are under consideration.

Sediment $\mathrm{Hg}$ concentration remains well above consensus-based sediment quality guidelines. However, the extent to which these broad-based guidelines apply to the specific EFPC ecosystem is unknown. Supplemental studies of sediment toxicity using EFPC sediments would help to clarify this or establish site-specific sediment quality guidelines.

Sediment MMHg concentration decreased downstream and for all grain sizes with the exception of a localized region of high $\mathrm{MMHg}$ concentration found only in coarse sediments and located upstream of the localized region of high total $\mathrm{Hg}$. In the medium and fine sediments $\mathrm{MMHg}$ was significantly correlated with total $\mathrm{Hg}$. The percent MMHg in sediments downstream varied by grain size increasing for fine sediments, not changing for medium sediments, and decreasing for coarse sediments. Correlations in the percent MMHg with Hg removed in selective extractions were similar to other aquatic sediments. Actions that target isolating fine sediments from bioaccumulation pathways - such as re-introduction of native clams to EFPC being investigated by Task 3 of this project - could offer long-term benefits.

The along-creek pattern in MMHg content of sediments opposed that seen in surface water suggestive of variable MMHg-particle partitioning. In that case, augmenting sediments with sorbents having high $\mathrm{MMHg}$ removal efficiency may be a practicable remedial action to decrease MMHg concentrations with anticipated consequent decreased $\mathrm{Hg}$ in fish tissue. Investigations to evaluate MMHg-specific sorbents are being planned as part of this project.

Ancillary chemistry data provided circumstantial evidence of bank soil contributions to EFPC sediments, particularly to the fine-grained sediments. To the extent these bank soil inputs deliver $\mathrm{Hg}$ and possibly MMHg loads to the creek, controlling bank erosion should help to decrease $\mathrm{Hg}$ sediment concentration. 
The assessment and control of bank soil inputs are being actively investigated in the TD project, as described previously.

This study provided new information on sediment $\mathrm{Hg}$ and MMHg content and chemistry. The results support the relevance and potential impacts of other active and planned investigations within the TD project (e.g., assessment and control of bank soil inputs, sorbents for MMHg removal, re-introduction of freshwater clams to EFPC) and identify gaps in current understanding that represent opportunities to understand controlling variables that may inform future technology development studies. 


\section{REFERENCES}

Barnett, M.O., Harris, L.A., Turner, R.R., Henson, T.J., Melton, R.E., Stevenson, R.J., 1995.

Characterization of mecury species in contaminated floodplain soils. Water Air Soil Poll. 80, 11051108.

Barnett, M.O., Harris, L.A., Turner, R.R., Stevenson, R.J., Henson, T.J., Melton, R.C., Hoffman, D.P., 1997. Formation of Mercuric Sulfide in Soil. Environ. Sci. Technol. 31, 3037-3043.

Bloom, N.S., Colman, J.A., Barber, L., 1997. Artifact formation of methyl mercury during aqueous distillation and alternative techniques for the extraction of methyl mercury from environmental samples. Fresenius J. Anal. Chem. 358, 371-377.

Bloom, N.S., Preus, E., Katon, J., Hiltner, M., 2003. Selective extractions to assess the biogeochemically relevant fractionation of inorganic mercury in sediments and soils. Analyt. Chim. Acta 479, 233-248.

Brooks, S.C., Southworth, G.R., 2011. History of mercury use and environmental contamination at the Oak Ridge Y-12 Plant. Environ. Poll. 159, 219-228.

Cerling, T.E., Turner, R.R., 1982. Formation of freshwater Fe-Mn coatings on gravel and the behavior of ${ }^{60} \mathrm{Co},{ }^{90} \mathrm{Sr}$, and ${ }^{137} \mathrm{Cs}$ in a small watershed. Geochim. Cosmochim. Acta 46, 1333-1343.

Chapman, P.M., 1989. Current appoaches to developing sediment quality criteria. Environ. Toxicol. Chem. 8, 589-599.

Cornbleet, P.J., Gochman, N., 1979. Incorrect least-squares regression coefficients in method-comparison analysis. Clin. Chem. 25, 432-438.

Dickson, J.O., Brooks, S.C., Watson, D.B., Mehlhorn, T.L., Pierce, E.M., Mayes, M.A., in prep. Diffuse streambank source of mercury loading to a freshwater stream: Implications for targeted remedial actions.

Dong, W.M., Liang, L.Y., Brooks, S., Southworth, G., Gu, B.H., 2009. Roles of dissolved organic matter in the speciation of mercury and methylmercury in a contaminated ecosystem in Oak Ridge, Tennessee. Environ. Chem. 7, 94-102.

Droppo, I.G., Jaskot, C., 1995. Impact of river transport characteristics on contaminant sampling error and design. Environ. Sci. Technol. 29, 161-170.

Dzombak, D.A., Morel, F.M.M., 1990. Surface Complexation Modeling: Hydrous Ferric Oxide. John Wiley \& Sons, New York.

Finlay, J.C., Kendall, C., 2007. Stable isotope tracing of temporal and spatial variability in organic matter sources to freshwater ecosystems, in: Michener, R.H., Lajtha, K. (Eds.), Stable Isotopes in Ecology and Environmental Science, 2nd ed. Wiley-Blackwell, Hoboken, NJ, pp. 283-333.

Hall, G., Buchar, A., Bonham-Carter, G., 2011. Quality Control Assessment of Portable XRF Analysers: Development of Standard Operating Procedures, Performance on Variable Media and Recommended Uses, CAMIRO PROJECT 10E01 Phase I. CANADIAN MINING INDUSTRY RESEARCH ORGANIZATION (CAMIRO) EXPLORATION DIVISION.

Hem, J.D., 1989. Study and Interpretation of the Chemical Characteristics of Natural Water, 3d edition. United States Geological Survey, Washington, DC, p. 264.

Horowitz, A.J., 2008. Determining annual suspended sediment and sediment-associated trace element and nutrient fluxes. Sci. Tot. Environ. 400, 315-343. 
Horowitz, A.J., Rinella, F.A., Lamothe, P., Miller, T.L., Edwards, T.K., Roche, R.L., Rickert, D.A., 1990. Variations in suspended sediment and associated trace element concentrations in selected riverine cross sections. Environ. Sci. Technol. 24, 1313-1320.

Horowitz, A.J., Stephens, V.C., 2008. The effects of land use on fluvial sediment chemistry for the conterminous U.S. - Results from the first cycle of the NAWQA Program: Trace and major elements, phosphorus, carbon, and sulfur. Sci. Tot. Environ. 400, 290-314.

Horowitz, A.J., Stephens, V.C., Elrick, K.A., Smith, J.J., 2012. Concentrations and annual fluxes of sediment-associated chemical constituents from conterminous US coastal rivers using bed sediment data. Hydrological Processes 26, 1090-1114.

Huerta-Diaz, M.A., Morse, J.W., 1992. Pyritization of trace metals in anoxic marine sediments. Geochimica et Cosmochimica Acta 56, 2681-2702.

Jeter, I., Napier, J., 1978. Chemical Analysis of the S-3 Disposal Ponds (April, 1978). Y/DA-7794. Union Carbide Corportation, Nuclear Division, Oak Ridge, TN.

Kendall, C., Silva, S.R., Kelly, V.J., 2001. Carbon and nitrogen isotopic compositions of particulate organic matter in four large river systems across the United States. Hydrol. Proc. 15, 1301-1346.

Kim, C.S., Bloom, N.S., Rytuba, J.J., Brown, G.E., 2003. Mercury speciation by X-ray absorption fine structure spectroscopy and sequential chemical extractions: A comparison of speciation methods. Environ. Sci. Technol. 37, 5102-5108.

Kim, C.S., Brown, G.E., Rytuba, J.J., 2000. Characterization and speciation of mercury-bearing mine wastes using X-ray absorption spectroscopy. Sci. Tot. Environ. 261, 157-168.

Kocman, D., Brooks, S.C., Miller, C.L., Yin, X.P.L., 2013. Evaluation of centrifugal ultrafilters for size fractionation of total mercury and methylmercury in freshwaters. Environ. Chem. 10, 323-332.

LaForce, M.J., Fendorf, S.E., 2000. Solid-phase iron characterization during common selective sequential extractions. Soil Sci. Soc. Am. J. 64, 1608-1615.

Lee, G.F., 1973. Role of hydrous metal oxides in the transport of heavy metals in the environment, in: Krenkel, P.A. (Ed.), Heavy Metals in the Aquatic Environment. Pergamon Press, Nashville, TN, pp. 137-153.

Liang, L., Horvat, M., Cernichiari, E., Gelein, B., Balogh, S., 1996. Simple solvent extraction technique for elimination of matrix interferences in the determination of methylmercury in environmental and biological samples by ethylation gas chromatography cold vapor atomic fluorescence spectrometry. Talanta 43, 1883-1888.

Livingstone, D.A., 1963. Data of Geochemistry, Sixth Edition: Chapter G: Chemical Composition of Rivers and Lakes. USGS Professional Paper 440-G.

Loar, J.M., Stewart, A.J., Smith, J.G., 2011. Twenty-Five Years of Ecological Recovery of East Fork Poplar Creek: Review of Environmental Problems and Remedial Actions. Environ. Manage. 47, 1010-1020.

MacDonald, D.D., Ingersoll, C.G., Berger, T.A., 2000. Development and evaluation of consensus-based sediment quality guidelines for freshwater ecosystems. Arch Environ Contam Toxicol 39, 20-31.

Miller, C.L., Brooks, S.C., Riscassi, A., Kocman, D., Yin, X., 2013. Factors influencing sediment methylmercury concentrations in a mercury contaminated creek, 11th International Conference on Mercury as a Global Pollutant (ICMGP), Edinburgh, Scotland.

Morse, J.W., Luther, G.W., 1999. Chemical influences on trace metal-sulfide interactions in anoxic sediments. Geochimica Et Cosmochimica Acta 63, 3373-3378. 
Peterson, M., Brooks, S., Mathews, T., Bevelhimer, M., Bhaskar, S., Miller, C., Riscassi, A., Southworth, G., 2014. Evaluation of Lower East Fork Poplar Creek Mercury Sources. Oak Ridge National Laboratory, ORNL/TM-2014/474.

R Core Team, 2016. R: A Language and Environment for Statistical Computing. R Foundation for Statistical Computing, Vienna, Austria. URL https://www.R-project.org/.

Ramsey, J.W., Whitson, W.K., 1951. Production of Zirconium at Y-12, Carbide and Carbon Chemicals Company, Oak Ridge, TN, Y-817.

Riscassi, A., Miller, C., Brooks, S., 2016. Seasonal and flow-driven dynamics of particulate and dissolved mercury and methylmercury in a stream impacted by an industrial mercury source. Environ. Toxicol. Chem. 35, 1386-1400.

Rivera, N., Kaur, N., Hesterberg, D., Ward, C.R., Austin, R.E., Duckworth, O.W., 2015. Chemical Composition, Speciation, and Elemental Associations in Coal Fly Ash Samples Related to the Kingston Ash Spill. Energy \& Fuels 29, 954-967.

Salminen, R., Batista, M.J., Bidovec, M., Demetriades, A., De Vivo, B., De Vos, W., Duris, M., Gilucis, A., Gregorauskiene, V., Halamic, J., Heitzmann, P., Lima, A., Jordan, G., Klaver, G., Klein, P., Lis, J., Locutura, J., Marsina, K., Mazreku, A., O'Connor, P.J., Olsson, S.Å., Ottesen, R.-T., Petersell, V., Plant, J.A., Reeder, S., Salpeteur, I., Sandström, H., Siewers, U., Steenfelt, A., Tarvainen, T., 2005. Geochemical Atlas of Europe. Part 1: Background Information, Methodology and Maps. Espoo, Geological Survey of Finland, 526 pages, 36 figures, 362 maps.

Southworth, G., Mathews, T., Greeley, M., Peterson, M., Brooks, S., Ketelle, D., 2013. Sources of mercury in a contaminated stream-implications for the timescale of recovery. Environ. Toxicol. Chem. 32, 764-772.

Southworth, G.R., Greeley, M.S., Peterson, M.J., Lowe, K., Ketelle, R.H., 2010. Sources of Mercury to East Fork Poplar Creek Downstream from the Y-12 National Security Complex: Inventories and Export Rates. ORNL/TM-2009/231. Oak Ridge National Laboratory, Oak Ridge.

Spalding, B.P., Brooks, S.C., Watson, D.B., 2010. Hydrogel-Encapsulated Soil: A Tool to Measure Contaminant Attenuation In Situ. Environmental Science \& Technology 44, 3047-3051.

Stewart, A.J., Smith, J.G., Loar, J.M., 2011. Long-Term Water-Quality Changes in East Fork Poplar Creek, Tennessee: Background, Trends, and Potential Biological Consequences. Environ. Manage. 47, 1021-1032.

Straughan, I.R., Elseewi, A.A., Page, A.L., Kaplan, I.R., Hurst, R.W., Davis, T.E., 1981. Fly ash-derived strontium as an index to monitor deposition from coal-fired power-plants. Science 212, 1267-1269.

Stumm, W., Morgan, J.J., 1981. Aquatic Chemistry: An Introduction Emphasizing Chemical Equilibria in Natural Waters, 2nd ed. ed. Wiley Interscience, New York.

TDEC, 2015. Environmental Monitoring Report 2015, Tennessee Department of Environment and Conservation, Division Of Remediation, Oak Ridge Office. https:/_www.tn.gov/assets/entities/environment/attachments/rem_2015-environmental-monitoringreport.pdf (accessed July 2016).

Tennessee Valley Authority, 1985. Instream Contaminant Study, Task 2: Sediment Characterization. Report to U. S. Department of Energy, Oak Ridge Operations Office. Tennessee Valley Authority, Office of Natural Resources and Economic Development, Knoxville, TN.

Trent, V.A., Medlin, J.H., Coleman, S.L., Stanton, R.W., 1982. Chemical Analyses and Physical Properties of 12 Coal Samples from the Pocahontas Field, Tazewell County, Virginia, and McDowell County, West Virginia. USGS Bulletin 1528. 
UCOR, 2015. 2015 Remediation Effectiveness Report for the U.S. Department of Energy Oak Ridge Reservation, Oak Ridge, Tennessee: Data and Evaluations. Water Resources Restoration Program, URS | CH2M Oak Ridge LLC, DOE/OR/01-2675\&D2.

Union Carbide Corporation, 1983. The Chemical and Radiological Characterization of the S-3 Ponds. Report Y/MA-6400. Oak Ridge, TN.

USEPA, 1997. The Incidence and Severity of Sediment Contamination in the Surface Waters of the United States, Volume 1: National Sediment Quality Survey. US EPA, EPA 823-R-97-006.

USEPA, 2004. The Incidence and Severity of Sediment Contamination in Surface Waters of the United States, National Sediment Quality Survey, Second Edition. US EPA, EPA-823-R-04-004.

Warren, L.A., Zimmermann, A.P., 1994. Suspended particulate grain-size dynamics and their implications for trace-metal sorption in the Don river. Aquat. Sci. 56, 348-362.

Watson, D., Brooks, S., Mathews, T., Bevelhimer, M., DeRolph, C., Brandt, C., Peterson, M., Ketelle, D., 2016. Evaluation of Lower East Fork Poplar Creek Mercury Sources. Oak Ridge National Laboratory, ORNL/TM-2016/134. 
APPENDIX A. DATA TABLES AND SUPPLEMENTARY FIGURES 



\section{APPENDIX A. DATA TABLES AND SUPPLEMENTARY FIGURES}

Table A-1. EFPC creek reach designations

\begin{tabular}{ccc}
\hline Reach & Start (EFPC km) & End (EFPC km) \\
\hline 1 & 0. & 12.78 \\
2 & 12.79 & 15.76 \\
3 & 15.77 & 19.85 \\
4 & 19.86 & 22.81 \\
5 & 22.82 & $26.6^{a}$ \\
\hline
\end{tabular}

${ }^{a}$ This is Outfall 200 - the point at which the creek exits the underground drainage system within Y-12 and represents the farthest upstream point at which samples can be collected without additional requirements. 
Table A-2. Sample site locations

\begin{tabular}{|c|c|c|c|c|}
\hline Site Name & $\begin{array}{c}\text { Latitude } \\
\text { (decimal degrees) }\end{array}$ & $\begin{array}{c}\text { Longitude } \\
\text { (decimal degrees) }\end{array}$ & Creek kilometer $^{a}$ & Notes \\
\hline SED-05 & 35.96228000 & -84.36070000 & 4.7 & \\
\hline SED-06 & 35.96618000 & -84.35625000 & 5.7 & \\
\hline SED-07 & 35.96901000 & -84.35249000 & 7.1 & \\
\hline SED-08 & 35.97065000 & -84.34712000 & 7.8 & $\sim 120$ m downstream Oak Ridge Tnpk overpass \\
\hline SED-09 & 35.97173000 & -84.34086000 & 8.9 & (a) Southwood Ln \\
\hline SED-10 & 35.97583000 & -84.33585000 & 10.0 & $\sim 230 \mathrm{~m}$ upstream of bridge at Sweetgum Ln \\
\hline SED-11 & 35.97897000 & -84.32995000 & 10.9 & \\
\hline SED-12 & 35.98180000 & -84.32520000 & 11.8 & $\sim 220 \mathrm{~m}$ upstream bridge at Gum Hollow Rd \\
\hline SED-13 & 35.98962000 & -84.31979000 & 13.8 & \\
\hline SED-14 & 35.99158000 & -84.31536000 & 14.3 & Big Turtle Park, Monterey Rd overpass of EFPC \\
\hline SED-15 & 35.99200000 & -84.30985000 & 15.3 & \\
\hline SED-16 & 35.99586000 & -84.30384000 & 16.3 & \\
\hline SED-17 & 35.99757000 & -84.29705000 & 17.3 & \\
\hline SED-18 & 36.00228000 & -84.28874000 & 18.3 & \\
\hline SED-19 & 36.00619000 & -84.28097000 & 19.3 & Behind Rocky Top Market at Jefferson Ave. \\
\hline SED-20 & 36.00984000 & -84.27296000 & 20.4 & >85 m downstream Oak Ridge Tnpk overpass of EFPC @ Illinois Ave \\
\hline SED-21 & 36.00712000 & -84.26424000 & 21.4 & Intersection Tulsa Rd \& Illinois Ave. \\
\hline SED-22 & 36.00345697 & -84.25536407 & 22.4 & behind old Kmart \\
\hline SED-23 & 36.00143000 & -84.24709000 & 23.3 & behind self-storage \\
\hline SED-24 & 35.99508300 & -84.23918300 & 24.3 & 50 m downstream of outlet Lake Reality (inside Y-12) \\
\hline SED-25 & 35.98842547 & -84.24517014 & 25.6 & $50 \mathrm{~m}$ upstream truck scale (inside $\mathrm{Y}-12$ ) \\
\hline SED-26 & 35.98568600 & -84.25249500 & 26.3 & Bridge@OF109, downstream side (inside Y-12) \\
\hline
\end{tabular}

Site coordinates indicate the entry point to the creek. Sampling teams may have moved 30 to 50 meters upstream or downstream to collect sufficient material to satisfy analytical needs. ${ }^{a}$ Creek kilometer is measured upstream from the mouth of the creek. Distances were calculated based on the GPS track log collected during a kayak float trip along the entire length of EFPC (Watson et al., 2016). 
Table A-3. Mass fraction of sediment grain sizes constituting bulk samples

\begin{tabular}{|c|c|c|c|}
\hline Sample ID & Coarse $^{a}$ & Medium $^{b}$ & Fine $^{c}$ \\
\hline SED-05 & 0.310 & 0.605 & 0.056 \\
\hline SED-06 & 0.304 & 0.584 & 0.071 \\
\hline SED-07 & 0.231 & 0.640 & 0.074 \\
\hline SED-08 & 0.257 & 0.624 & 0.077 \\
\hline SED-09 & 0.449 & 0.507 & 0.026 \\
\hline SED-10 & 0.288 & 0.618 & 0.060 \\
\hline SED-11 & 0.342 & 0.543 & 0.064 \\
\hline SED-12 & 0.253 & 0.678 & 0.043 \\
\hline SED-13 & 0.225 & 0.614 & 0.097 \\
\hline SED-14 & 0.426 & 0.504 & 0.039 \\
\hline SED-15 & 0.279 & 0.659 & 0.035 \\
\hline SED-16 & 0.340 & 0.565 & 0.049 \\
\hline SED-17 & 0.404 & 0.540 & 0.027 \\
\hline SED-18 & 0.557 & 0.395 & 0.010 \\
\hline SED-19 & 0.349 & 0.595 & 0.031 \\
\hline SED-20 & 0.339 & 0.620 & 0.020 \\
\hline SED-21 & 0.247 & 0.599 & 0.072 \\
\hline SED-22 & 0.433 & 0.411 & 0.081 \\
\hline SED-23 & 0.394 & 0.392 & 0.142 \\
\hline SED-24 & - & - & - \\
\hline SED-25 & - & - & - \\
\hline SED-26 & - & - & - \\
\hline
\end{tabular}


Table A-4. Total Hg and MMHg in reconstructed bulk sediment samples. Values are expressed on a sediment dry weight basis

\begin{tabular}{|c|c|c|c|}
\hline Sample ID & EFPC kilometer & $\begin{array}{l}\text { total Hg } \\
\text { (mg/kg) }\end{array}$ & $\begin{array}{c}\text { total MMHg } \\
(\mu \mathrm{g} / \mathrm{kg})\end{array}$ \\
\hline SED-05 & 4.7 & 20.44 & 1.85 \\
\hline SED-06 & 5.7 & 13.20 & 0.55 \\
\hline SED-07 & 7.1 & 20.79 & 0.76 \\
\hline SED-08 & 7.8 & 13.39 & 0.89 \\
\hline SED-09 & 8.9 & 14.09 & 0.66 \\
\hline SED-10 & 10.0 & 18.12 & 0.76 \\
\hline SED-11 & 10.9 & 23.07 & 1.16 \\
\hline SED-12 & 11.8 & 11.59 & 0.80 \\
\hline SED-13 & 13.8 & 9.09 & 0.57 \\
\hline SED-14 & 14.3 & 12.71 & 1.48 \\
\hline SED-15 & 15.3 & 16.68 & 0.68 \\
\hline SED-16 & 16.3 & 12.55 & 1.10 \\
\hline SED-17 & 17.3 & 22.26 & 0.94 \\
\hline SED-18 & 18.3 & 27.27 & 1.46 \\
\hline SED-19 & 19.3 & 19.25 & 1.28 \\
\hline SED-20 & 20.4 & 11.66 & 3.55 \\
\hline SED-21 & 21.4 & 10.18 & 10.00 \\
\hline SED-22 & 22.4 & 16.46 & 8.46 \\
\hline SED-23 & 23.3 & 13.94 & 3.08 \\
\hline SED-24 $4^{a}$ & 24.3 & 28.01 & 3.17 \\
\hline SED- $25^{a}$ & 25.6 & 27.94 & 2.82 \\
\hline SED-26 ${ }^{a}$ & 26.3 & 57.11 & 3.47 \\
\hline
\end{tabular}

${ }^{a}$ bulk sediment reconstruction was estimated using the average grain size mass fraction from the other 19 samples 
Table A-5. Total Hg (mg/kg-dw) in separate grain-size classes

\begin{tabular}{ccccccc}
\hline Sample ID & Coarse $^{\boldsymbol{a}}$ & s.d. & Medium $^{\boldsymbol{b}}$ & S.d. & Fine $^{\boldsymbol{c}}$ & .d. $^{\boldsymbol{d}^{\mathbf{d}}}$ \\
\hline SED-05 & 30.84 & & 17.70 & & 3.45 & \\
SED-06 & 21.71 & 5.75 & 10.98 & 0.98 & 2.56 & 0.15 \\
SED-07 & 40.79 & & 17.53 & & 2.46 & \\
SED-08 & 10.18 & & 16.34 & & 7.96 & \\
SED-09 & 15.69 & & 13.74 & & 3.65 & \\
SED-10 & 13.79 & & 22.69 & & 4.07 & \\
SED-11 & 30.22 & 10.66 & 22.64 & 7.25 & 7.40 & 0.98 \\
SED-12 & 15.37 & & 11.25 & & 2.53 & 5.67 \\
SED-13 & 16.20 & & 8.26 & & 3.99 & \\
SED-14 & 16.07 & & 11.33 & & 4.90 & \\
SED-15 & 20.89 & & 16.10 & & 7.62 & \\
SED-16 & 23.22 & & 7.59 & & 8.33 & \\
SED-17 & 21.30 & 2.39 & 24.45 & 2.12 & 17.26 & \\
SED-18 & 34.32 & & 20.17 & & 23.29 & \\
SED-19 & 22.75 & & 18.42 & & 12.60 & \\
SED-20 & 8.64 & & 13.61 & & 14.06 & \\
SED-21 & 11.00 & 2.51 & 11.52 & 0.75 & 13.33 & \\
SED-22 & 16.07 & & 19.65 & & 22.12 & \\
SED-23 & 9.78 & & 17.43 & & 23.04 & \\
SED-24 & 16.36 & & 35.91 & & 40.26 & \\
SED-25 & 17.70 & & 32.07 & & 69.08 & \\
SED-26 & 44.96 & 11.91 & 64.40 & 4.86 & 100.14 & 38.77 \\
\hline
\end{tabular}

${ }^{a} 1 \mathrm{~mm}<x<2 \mathrm{~mm}$

${ }^{b} 250 \mu \mathrm{m}<x<1 \mathrm{~mm}$

${ }^{c} 125 \mu \mathrm{m}<x<250 \mu \mathrm{m}$

${ }^{d}$ standard deviation of triplicate determinations 
Table A-6. Total MMHg ( $\mu \mathrm{g} / \mathrm{kg}-\mathrm{dw})$ in separate grain-size classes

\begin{tabular}{cccc}
\hline Sample ID & Coarse $^{\boldsymbol{a}}$ & Medium $^{\boldsymbol{b}}$ & Fine $^{\boldsymbol{c}}$ \\
\hline SED-05 & 1.89 & 1.94 & 1.63 \\
SED-06 & 0.72 & 0.49 & 0.56 \\
SED-07 & 1.74 & 0.51 & 0.51 \\
SED-08 & 0.95 & 0.90 & 1.16 \\
SED-09 & 1.02 & 0.36 & 0.62 \\
SED-10 & 1.30 & 0.58 & 0.57 \\
SED-11 & 1.49 & 0.97 & 1.97 \\
SED-12 & 2.08 & 0.37 & 0.56 \\
SED-13 & 0.55 & 0.60 & 0.85 \\
SED-14 & 2.23 & 0.93 & 1.60 \\
SED-15 & 1.49 & 0.34 & 1.14 \\
SED-16 & 1.74 & 0.70 & 2.48 \\
SED-17 & 1.16 & 0.78 & 1.87 \\
SED-18 & 1.77 & 1.14 & 3.29 \\
SED-19 & 2.39 & 0.69 & 1.08 \\
SED-20 & 7.30 & 1.63 & 3.23 \\
SED-21 & 40.59 & 0.52 & 0.99 \\
SED-22 & 18.43 & 1.18 & 2.41 \\
SED-23 & 6.23 & 0.64 & 2.66 \\
SED-24 & 2.64 & 3.48 & 5.58 \\
SED-25 & 1.92 & 3.20 & 6.47 \\
SED-26 & 6.06 & 2.06 & 4.66 \\
\hline${ }^{a} 1 \mathrm{~mm}<x<2 \mathrm{~mm}$ & & & \\
${ }^{b} 250 \mu \mathrm{m}<x<1 \mathrm{~mm}$ & & & \\
${ }^{c} 125 \mu \mathrm{m}<x<250 \mu \mathrm{m}$ & & &
\end{tabular}


Table A-7. Total Hg in sequential extraction reagents (mg $\mathrm{Hg} / \mathrm{kg}-\mathrm{dw})$

\begin{tabular}{|c|c|c|c|c|c|c|c|c|c|c|c|c|c|c|c|}
\hline \multirow[b]{2}{*}{ Sample ID } & \multicolumn{5}{|c|}{ Coarse grain-size } & \multicolumn{5}{|c|}{ Medium grain-size } & \multicolumn{5}{|c|}{ Fine grain-size } \\
\hline & F1 & F2 & F3 & F4 & F5 & F1 & F2 & F3 & F4 & F5 & F1 & F2 & F3 & F4 & F5 \\
\hline SED-05 & 0.03 & 0.00 & 5.91 & 1.29 & 21.07 & 0.02 & 0.00 & 3.04 & 1.52 & 7.49 & 0.00 & 0.00 & 0.83 & 0.28 & 2.66 \\
\hline SED-06 & 0.02 & 0.30 & 1.97 & 0.78 & 17.93 & 0.02 & 0.03 & 0.71 & 1.48 & 11.39 & 0.00 & 0.00 & 0.40 & 1.05 & 0.75 \\
\hline SED-07 & 0.06 & 0.00 & 0.58 & 4.02 & 33.03 & 0.02 & 0.11 & 1.71 & 0.55 & 3.99 & 0.01 & 0.00 & 0.66 & 0.27 & 1.05 \\
\hline SED-08 & 0.07 & 0.35 & 1.06 & 0.78 & 17.93 & 0.18 & 0.00 & 0.77 & 1.91 & 12.99 & 0.02 & 0.00 & 1.44 & 0.99 & 1.53 \\
\hline SED-09 & 0.10 & 0.00 & 3.08 & 3.28 & 29.19 & 0.04 & 0.00 & 1.69 & 2.20 & 8.06 & 0.00 & 0.00 & 0.51 & 1.25 & 1.64 \\
\hline SED-10 & 0.04 & 0.00 & 4.90 & 0.23 & 10.64 & 0.04 & 0.00 & 0.78 & 0.71 & 11.46 & 0.02 & 0.00 & 1.40 & 0.93 & 0.74 \\
\hline SED-11 & 0.03 & 0.00 & 0.39 & 2.09 & 34.58 & 0.04 & 0.00 & 0.56 & 1.57 & 11.07 & 0.02 & 0.00 & 0.59 & 2.61 & 4.80 \\
\hline SED-12 & 0.01 & 0.00 & 0.36 & 0.07 & 26.08 & 0.03 & 0.00 & 0.82 & 0.89 & 5.81 & 0.01 & 0.00 & 0.56 & 0.34 & 1.94 \\
\hline SED-13 & 0.01 & 0.00 & 0.43 & 0.40 & 27.81 & 0.02 & 0.00 & 0.69 & 1.01 & 8.16 & 0.01 & 0.00 & 0.71 & 0.89 & 2.71 \\
\hline SED-14 & 0.02 & 0.00 & 0.20 & 0.67 & 22.14 & 0.03 & 0.00 & 5.42 & 0.69 & 11.07 & 0.01 & 0.00 & 0.83 & 1.34 & 2.54 \\
\hline SED-15 & 0.02 & 0.00 & 0.14 & 3.51 & 45.06 & 0.04 & 0.03 & 2.42 & 1.14 & 11.22 & 0.02 & 0.00 & 0.89 & 1.32 & 5.28 \\
\hline SED-16 & 0.03 & 0.00 & 0.15 & 0.29 & 41.95 & 0.03 & 0.00 & 4.49 & 0.16 & 9.36 & 0.01 & 0.00 & 0.94 & 1.87 & 6.53 \\
\hline SED-17 & 0.02 & 0.02 & 0.28 & 0.33 & 43.15 & 0.09 & 0.00 & 1.93 & 0.26 & 25.54 & 0.02 & 0.00 & 0.61 & 1.99 & 14.21 \\
\hline SED-18 & 0.02 & 0.00 & 0.12 & 0.15 & 31.02 & 0.04 & 0.00 & 0.25 & 2.18 & 18.36 & 0.03 & 0.00 & 0.46 & 3.37 & 14.00 \\
\hline SED-19 & 0.02 & 0.00 & 0.17 & 5.50 & 16.68 & 0.03 & 0.00 & 0.12 & 2.36 & 4.48 & 0.31 & 0.16 & 1.53 & 3.52 & 8.38 \\
\hline SED-20 & 0.01 & 0.00 & 0.10 & 2.73 & 8.42 & 0.04 & 0.00 & 0.17 & 1.30 & 7.18 & 0.02 & 0.00 & 0.64 & 2.53 & 7.83 \\
\hline SED-21 & 0.01 & 0.00 & 0.19 & 2.87 & 12.28 & 0.03 & 0.00 & 0.12 & 0.93 & 5.65 & 0.02 & 0.00 & 0.41 & 1.86 & 9.06 \\
\hline SED-22 & 0.02 & 0.00 & 0.11 & 2.91 & 20.92 & 0.06 & 0.00 & 0.18 & 1.54 & 13.11 & 0.04 & 0.00 & 0.58 & 3.84 & 11.86 \\
\hline SED-23 & 0.02 & 0.00 & 0.08 & 5.72 & 10.51 & 0.07 & 0.00 & 0.09 & 1.90 & 14.89 & 0.09 & 0.00 & 0.71 & 7.88 & 16.62 \\
\hline SED-24 & 0.01 & 0.00 & 0.08 & 5.87 & 1.33 & 0.16 & 0.00 & 0.06 & 29.06 & 8.64 & 0.08 & 0.00 & 0.45 & 10.65 & 30.44 \\
\hline SED-25 & 0.01 & 0.01 & 0.53 & 16.89 & 0.78 & 0.11 & 0.00 & 0.66 & 23.77 & 11.67 & 0.19 & 0.00 & 0.45 & 12.02 & 41.11 \\
\hline SED-26 & 0.13 & 0.01 & 0.23 & 18.69 & 1.79 & 0.53 & 0.00 & 3.35 & 2.38 & 5.94 & 0.37 & 0.00 & 0.13 & 52.89 & 52.94 \\
\hline
\end{tabular}


Table A-8. Percent of total $\mathrm{Hg}$ in sequential extraction reagents

\begin{tabular}{|c|c|c|c|c|c|c|c|c|c|c|c|c|c|c|c|}
\hline \multirow[b]{2}{*}{ Sample ID } & \multicolumn{5}{|c|}{ Coarse grain-size } & \multicolumn{5}{|c|}{ Medium grain-size } & \multicolumn{5}{|c|}{ Fine grain-size } \\
\hline & F1 & F2 & F3 & F4 & F5 & F1 & F2 & F3 & F4 & F5 & F1 & F2 & F3 & F4 & F5 \\
\hline SED-05 & 0.09 & 0.01 & 20.88 & 4.56 & 74.46 & 0.18 & 0.00 & 25.15 & 12.60 & 62.07 & 0.00 & 0.02 & 21.98 & 7.49 & 70.51 \\
\hline SED-06 & 0.08 & 1.44 & 9.39 & 3.70 & 85.38 & 0.16 & 0.23 & 5.24 & 10.87 & 83.50 & 0.00 & 0.00 & 18.06 & 47.71 & 34.23 \\
\hline SED-07 & 0.16 & 0.00 & 1.53 & 10.66 & 87.65 & 0.35 & 1.68 & 26.79 & 8.60 & 62.59 & 0.52 & 0.12 & 32.94 & 13.41 & 53.02 \\
\hline SED-08 & 0.37 & 1.73 & 5.26 & 3.85 & 88.79 & 1.15 & 0.02 & 4.84 & 12.03 & 81.96 & 0.52 & 0.00 & 36.30 & 24.77 & 38.42 \\
\hline SED-09 & 0.28 & 0.01 & 8.63 & 9.21 & 81.88 & 0.34 & 0.00 & 14.07 & 18.37 & 67.21 & 0.00 & 0.00 & 15.07 & 36.78 & 48.15 \\
\hline SED-10 & 0.22 & 0.03 & 31.00 & 1.43 & 67.32 & 0.33 & 0.00 & 5.99 & 5.46 & 88.23 & 0.49 & 0.00 & 45.34 & 30.16 & 24.00 \\
\hline SED-11 & 0.08 & 0.00 & 1.05 & 5.63 & 93.25 & 0.29 & 0.00 & 4.20 & 11.85 & 83.66 & 0.22 & 0.00 & 7.39 & 32.55 & 59.84 \\
\hline SED-12 & 0.05 & 0.00 & 1.37 & 0.27 & 98.31 & 0.38 & 0.00 & 10.88 & 11.73 & 77.01 & 0.36 & 0.02 & 19.72 & 11.91 & 67.99 \\
\hline SED-13 & 0.05 & 0.00 & 1.50 & 1.39 & 97.06 & 0.25 & 0.00 & 6.98 & 10.24 & 82.52 & 0.25 & 0.00 & 16.51 & 20.64 & 62.59 \\
\hline SED-14 & 0.08 & 0.00 & 0.88 & 2.91 & 96.14 & 0.15 & 0.01 & 31.49 & 4.01 & 64.34 & 0.22 & 0.00 & 17.58 & 28.42 & 53.78 \\
\hline SED-15 & 0.04 & 0.01 & 0.28 & 7.20 & 92.47 & 0.24 & 0.19 & 16.33 & 7.69 & 75.56 & 0.28 & 0.00 & 11.81 & 17.62 & 70.29 \\
\hline SED-16 & 0.07 & 0.00 & 0.35 & 0.67 & 98.92 & 0.23 & 0.02 & 31.96 & 1.16 & 66.62 & 0.13 & 0.00 & 10.04 & 20.01 & 69.82 \\
\hline SED-17 & 0.05 & 0.05 & 0.63 & 0.76 & 98.50 & 0.33 & 0.00 & 6.94 & 0.93 & 91.80 & 0.13 & 0.00 & 3.62 & 11.80 & 84.45 \\
\hline SED-18 & 0.07 & 0.00 & 0.39 & 0.47 & 99.07 & 0.18 & 0.00 & 1.18 & 10.49 & 88.15 & 0.15 & 0.00 & 2.56 & 18.86 & 78.43 \\
\hline SED-19 & 0.09 & 0.00 & 0.78 & 24.59 & 74.55 & 0.43 & 0.00 & 1.75 & 33.79 & 64.03 & 2.22 & 1.16 & 11.03 & 25.33 & 60.26 \\
\hline SED-20 & 0.09 & 0.00 & 0.89 & 24.23 & 74.78 & 0.45 & 0.00 & 1.99 & 14.95 & 82.61 & 0.15 & 0.00 & 5.85 & 22.94 & 71.05 \\
\hline SED-21 & 0.07 & 0.02 & 1.25 & 18.70 & 79.96 & 0.48 & 0.00 & 1.79 & 13.87 & 83.86 & 0.21 & 0.00 & 3.64 & 16.42 & 79.74 \\
\hline SED-22 & 0.08 & 0.00 & 0.45 & 12.13 & 87.34 & 0.41 & 0.00 & 1.19 & 10.34 & 88.06 & 0.23 & 0.00 & 3.55 & 23.53 & 72.70 \\
\hline SED-23 & 0.11 & 0.00 & 0.48 & 35.04 & 64.37 & 0.39 & 0.00 & 0.55 & 11.22 & 87.83 & 0.34 & 0.00 & 2.81 & 31.16 & 65.70 \\
\hline SED-24 & 0.16 & 0.00 & 1.04 & 80.55 & 18.25 & 0.42 & 0.00 & 0.15 & 76.65 & 22.78 & 0.20 & 0.00 & 1.07 & 25.59 & 73.14 \\
\hline SED-25 & 0.08 & 0.06 & 2.92 & 92.64 & 4.29 & 0.30 & 0.00 & 1.82 & 65.63 & 32.24 & 0.36 & 0.00 & 0.83 & 22.36 & 76.44 \\
\hline SED-26 & 0.64 & 0.04 & 1.13 & 89.59 & 8.60 & 4.32 & 0.00 & 27.44 & 19.55 & 48.70 & 0.35 & 0.00 & 0.12 & 49.74 & 49.78 \\
\hline
\end{tabular}


Table A-9. Annual Hg flux from Y12 measured at Station 17, adapted from (UCOR, 2015)

\begin{tabular}{lc}
\hline Year & Hg Flux (kg) \\
\hline 2000 & 12.0 \\
2001 & 9.4 \\
2002 & 7.3 \\
2003 & 8.8 \\
2004 & 8.2 \\
2005 & 14.6 \\
$2006^{a}$ & 4.0 \\
2007 & 4.0 \\
2008 & 2.7 \\
2009 & 3.9 \\
2010 & 7.0 \\
2011 & 12.2 \\
2012 & 11.1 \\
2013 & 5.2 \\
2014 & 14.4 \\
\hline
\end{tabular}

${ }^{a}$ the Big Springs Water Treatment System came online in 2006 
Table A-10. Other chemical composition data for sediment samples. All values are expressed on a sediment dry weight basis

\begin{tabular}{|c|c|c|c|c|c|c|c|c|c|c|c|c|}
\hline \multirow[b]{2}{*}{ Sample ID } & \multicolumn{4}{|c|}{ Coarse grain-size } & \multicolumn{4}{|c|}{ Medium grain-size } & \multicolumn{4}{|c|}{ Fine grain-size } \\
\hline & $\begin{array}{c}\text { Total C } \\
(\%)\end{array}$ & $\begin{array}{c}\text { Organic } \\
\text { C (\%) }\end{array}$ & $\begin{array}{c}\text { Nitrogen } \\
(\%)\end{array}$ & $\begin{array}{c}\text { Sulfate } \\
(\mathrm{mg} / \mathrm{kg})^{a}\end{array}$ & $\begin{array}{c}\text { Total C } \\
(\%)\end{array}$ & $\begin{array}{c}\text { Organic } \\
\text { C }(\%)\end{array}$ & $\begin{array}{c}\text { Nitrogen } \\
(\%)\end{array}$ & $\begin{array}{c}\text { Sulfate } \\
(\mathrm{mg} / \mathrm{kg})^{a}\end{array}$ & $\begin{array}{c}\text { Total C } \\
(\%)\end{array}$ & $\begin{array}{c}\text { Organic } \\
\text { C (\%) }\end{array}$ & $\begin{array}{c}\text { Nitrogen } \\
(\%)\end{array}$ & $\begin{array}{c}\text { Sulfate } \\
(\mathrm{mg} / \mathrm{kg})^{a}\end{array}$ \\
\hline SED-05 & 0.524 & 0.391 & 0.050 & 0.320 & 0.378 & 0.222 & 0.007 & 1.327 & 0.646 & 0.510 & 0.037 & 1.015 \\
\hline SED-06 & 0.234 & 0.204 & 0.033 & 0.277 & 0.203 & 0.130 & 0.028 & 0.314 & 0.484 & 0.348 & 0.023 & 0.249 \\
\hline SED-07 & 0.282 & 0.245 & 0.037 & 0.348 & 0.169 & 0.116 & 0.006 & 1.530 & 0.256 & 0.236 & 0.011 & 0.057 \\
\hline SED-08 & 0.296 & 0.262 & 0.052 & 0.233 & 0.259 & 0.213 & 0.013 & 1.194 & 0.338 & 0.281 & 0.019 & 0.828 \\
\hline SED-09 & 0.306 & 0.272 & 0.000 & 1.007 & 0.297 & 0.189 & 0.027 & 0.790 & 0.617 & 0.464 & 0.025 & 0.067 \\
\hline SED-10 & 0.282 & 0.237 & 0.035 & 0.238 & 0.119 & 0.100 & 0.008 & 0.436 & 0.306 & 0.214 & 0.013 & 0.064 \\
\hline SED-11 & 0.488 & 0.321 & 0.025 & 0.161 & 0.214 & 0.206 & 0.012 & 0.025 & 0.819 & 0.405 & 0.043 & 0.042 \\
\hline SED-12 & 0.224 & 0.220 & 0.031 & 1.396 & 0.169 & 0.120 & 0.002 & 0.043 & 0.258 & 0.237 & 0.010 & 0.070 \\
\hline SED-13 & 0.737 & 0.504 & 0.037 & 1.325 & 0.288 & 0.283 & 0.015 & 1.201 & 0.417 & 0.279 & 0.014 & 0.049 \\
\hline SED-14 & 1.008 & 0.441 & 0.038 & 0.465 & 0.195 & 0.188 & 0.013 & 0.142 & 0.475 & 0.415 & 0.015 & 0.117 \\
\hline SED-15 & 0.400 & 0.240 & 0.033 & 0.962 & 0.224 & 0.163 & 0.005 & 0.016 & 0.422 & 0.328 & 0.027 & 0.035 \\
\hline SED-16 & 0.509 & 0.227 & 0.038 & 0.029 & 0.205 & 0.196 & 0.020 & 0.039 & 1.116 & 1.042 & 0.050 & 0.096 \\
\hline SED-17 & 0.954 & 0.277 & 0.047 & 0.031 & 0.819 & 0.302 & 0.027 & 0.226 & 0.611 & 0.441 & 0.026 & 0.010 \\
\hline SED-18 & 1.253 & 0.743 & 0.037 & 0.364 & 0.503 & 0.400 & 0.011 & 3.641 & 1.494 & 1.227 & 0.050 & 0.071 \\
\hline SED-19 & 2.834 & 0.906 & 0.043 & 0.048 & 0.830 & 0.166 & 0.010 & 0.262 & 1.176 & 0.422 & 0.023 & 0.076 \\
\hline SED-20 & 1.426 & 0.410 & 0.040 & 0.029 & 0.973 & 0.616 & 0.011 & 0.230 & 1.854 & 1.337 & 0.061 & 0.065 \\
\hline SED-21 & 1.365 & 0.578 & 0.027 & 0.394 & 0.375 & 0.172 & 0.022 & 0.239 & 0.903 & 0.709 & 0.016 & 0.000 \\
\hline SED-22 & 1.218 & 0.290 & 0.031 & 0.130 & 0.912 & 0.392 & 0.028 & 0.333 & 1.307 & 1.117 & 0.039 & 0.030 \\
\hline SED-23 & 2.852 & 0.611 & 0.034 & 0.539 & 2.055 & 0.653 & 0.029 & 0.083 & 2.215 & 1.667 & 0.053 & 0.023 \\
\hline SED-24 & 7.457 & 6.300 & 0.051 & 0.058 & 4.114 & 0.903 & 0.071 & 0.109 & 4.449 & 3.112 & 0.102 & 0.029 \\
\hline SED-25 & 5.621 & 3.397 & 0.065 & 0.620 & 6.402 & 3.354 & 0.039 & 0.230 & 4.057 & 1.955 & 0.044 & 0.042 \\
\hline SED-26 & 5.521 & 4.145 & 0.048 & 0.100 & 5.926 & 3.106 & 0.040 & 0.074 & 6.050 & 5.176 & 0.047 & 0.102 \\
\hline
\end{tabular}

${ }^{a}$ water-extractable sulfate (see section 5.6) 
Tables A-11 through A-13presented on the following pages report the XRF analytical results for sediment samples as a function of grain size. Twenty six elements were quantified by this method: $\mathrm{Mo}, \mathrm{Zr}, \mathrm{Sr}, \mathrm{U}$, $\mathrm{Rb}, \mathrm{Th}, \mathrm{Pb}, \mathrm{Se}, \mathrm{As}, \mathrm{Hg}, \mathrm{Zn}, \mathrm{Cu}, \mathrm{Ni}, \mathrm{Co}, \mathrm{Fe}, \mathrm{Mn}, \mathrm{Cr}, \mathrm{La}, \mathrm{Ba}, \mathrm{Cs}, \mathrm{Te}, \mathrm{Sb}, \mathrm{Sn}, \mathrm{Cd}, \mathrm{Ag}$, and Pd. Results for the nine elements that were below detection in every sample are not included in the tables. The average detection limit $(\mathrm{n}=66)$ for these elements were:

\begin{tabular}{cc} 
Element & Mean Detection Limit ( $\mathbf{m g} / \mathbf{k g})$ \\
\hline $\mathrm{Co}$ & 286 \\
$\mathrm{La}$ & 61 \\
$\mathrm{Cs}$ & 44 \\
$\mathrm{Te}$ & 140 \\
$\mathrm{Sb}$ & 148 \\
$\mathrm{Sn}$ & 281 \\
$\mathrm{Cd}$ & 68 \\
$\mathrm{Ag}$ & 160 \\
$\mathrm{Pd}$ & 138 \\
\hline
\end{tabular}

For the remaining 17 elements the concentration and reported uncertainty are given. All results are in units of mg per kilogram dry weight. 
Table A-11. XRF measurements of total element concentration in coarse sediments (mg/kg-dw)

\begin{tabular}{|c|c|c|c|c|c|c|c|c|c|c|c|c|}
\hline Sample ID & Mo & $\begin{array}{c}\text { Mo } \\
\text { Error }\end{array}$ & $\mathbf{Z r}$ & $\begin{array}{c}\text { Zr } \\
\text { Error }\end{array}$ & $\mathrm{Sr}$ & $\begin{array}{c}\text { Sr } \\
\text { Error }\end{array}$ & $\mathbf{U}$ & $\begin{array}{c}\mathrm{U} \\
\text { Error }\end{array}$ & $\mathbf{R b}$ & $\begin{array}{c}\text { Rb } \\
\text { Error }\end{array}$ & Th & $\begin{array}{c}\text { Th } \\
\text { Error }\end{array}$ \\
\hline SED-05 & $<4.5$ & 3.0 & 54.3 & 5.3 & 17.8 & 2.9 & $<14.6$ & 9.7 & 13.2 & 3.3 & $<12.4$ & 8.3 \\
\hline SED-06 & $<4.5$ & 3.0 & 94.0 & 6.2 & 14.1 & 2.7 & $<15.3$ & 10.2 & 13.1 & 3.3 & $<13.0$ & 8.7 \\
\hline SED-07 & 4.2 & 2.2 & 125.4 & 7.0 & 17.3 & 2.8 & $<15.8$ & 10.6 & 20.8 & 3.8 & 10.0 & 6.1 \\
\hline SED-08 & $<5.1$ & 3.4 & 137.9 & 7.5 & 12.2 & 2.8 & $<15.8$ & 10.6 & 16.5 & 3.6 & 10.8 & 6.4 \\
\hline SED-09 & 4.1 & 2.3 & 142.7 & 7.7 & 23.4 & 3.2 & $<16.2$ & 10.8 & 22.7 & 4.0 & 10.8 & 6.6 \\
\hline SED-10 & $<5.0$ & 3.4 & 114.9 & 7.1 & 23.0 & 3.2 & 17.8 & 8.0 & 17.3 & 3.9 & 13.3 & 6.6 \\
\hline SED-11 & $<5.1$ & 3.4 & 104.9 & 6.9 & 15.4 & 3.0 & $<16.5$ & 11.0 & 18.7 & 3.9 & $<13.9$ & 9.3 \\
\hline SED-12 & $<4.8$ & 3.2 & 100.0 & 6.8 & 11.7 & 2.8 & $<15.7$ & 10.5 & 9.7 & 3.3 & $<13.5$ & 9.0 \\
\hline SED-13 & $<4.7$ & 3.1 & 84.0 & 6.2 & 23.4 & 3.1 & $<14.4$ & 9.6 & 9.5 & 3.1 & $<13.3$ & 8.8 \\
\hline SED-14 & $<4.4$ & 3.0 & 89.4 & 6.2 & 22.9 & 3.1 & $<14.0$ & 9.4 & 14.5 & 3.3 & $<13.3$ & 8.9 \\
\hline SED-15 & $<5.1$ & 3.4 & 104.4 & 7.0 & 16.0 & 3.1 & $<18.4$ & 12.3 & 24.3 & 4.3 & $<14.8$ & 9.8 \\
\hline SED-16 & $<5.4$ & 3.6 & 128.1 & 7.7 & 27.5 & 3.6 & $<17.4$ & 11.6 & 25.9 & 4.3 & $<15.5$ & 10.4 \\
\hline SED-17 & $<6.0$ & 4.0 & 169.1 & 9.4 & 62.6 & 5.1 & 16.9 & 10.1 & 41.4 & 5.6 & $<18.3$ & 12.2 \\
\hline SED-18 & $<5.4$ & 3.6 & 158.6 & 8.4 & 32.1 & 3.8 & $<18.0$ & 12.0 & 33.9 & 4.7 & 15.8 & 7.5 \\
\hline SED-19 & $<6.1$ & 4.1 & 139.8 & 8.9 & 56.7 & 5.0 & $<21.3$ & 14.2 & 38.3 & 5.4 & 14.1 & 8.3 \\
\hline SED-20 & $<6.1$ & 4.1 & 274.3 & 11.0 & 83.7 & 5.5 & $<22.3$ & 14.9 & 69.5 & 6.4 & $<18.4$ & 12.3 \\
\hline SED-21 & $<6.6$ & 4.4 & 296.2 & 11.7 & 74.6 & 5.5 & 20.1 & 11.4 & 74.8 & 7.0 & 14.4 & 9.0 \\
\hline SED-22 & $<6.3$ & 4.2 & 267.4 & 11.1 & 59.3 & 4.9 & $<25.2$ & 16.8 & 83.0 & 7.1 & $<19.6$ & 13.1 \\
\hline SED-23 & $<6.1$ & 4.0 & 254.2 & 10.7 & 84.8 & 5.5 & $<24.0$ & 16.0 & 74.1 & 6.7 & 18.7 & 8.7 \\
\hline SED-24 & $<5.8$ & 3.9 & 119.9 & 8.7 & 111.5 & 6.5 & 20.3 & 10.3 & 33.2 & 5.3 & $<18.0$ & 12.0 \\
\hline SED-25 & $<5.9$ & 3.9 & 129.8 & 9.2 & 148.2 & 7.4 & $<22.7$ & 15.1 & 40.1 & 5.6 & 15.0 & 8.5 \\
\hline SED-26 & $<6.0$ & 4.0 & 98.7 & 8.6 & 164.0 & 7.8 & 20.4 & 11.1 & 42.1 & 5.9 & $<18.1$ & 12.1 \\
\hline
\end{tabular}


Table A-11. (continued)

\begin{tabular}{|c|c|c|c|c|c|c|c|c|c|c|c|c|}
\hline Sample ID & $\mathbf{P b}$ & $\begin{array}{c}\text { Pb } \\
\text { Error }\end{array}$ & $\mathbf{S e}$ & $\begin{array}{c}\text { Se } \\
\text { Error }\end{array}$ & As & $\begin{array}{c}\text { As } \\
\text { Error }\end{array}$ & $\mathbf{H g}$ & $\begin{array}{c}\mathrm{Hg} \\
\text { Error }\end{array}$ & $\mathbf{Z n}$ & $\begin{array}{c}\text { Zn } \\
\text { Error }\end{array}$ & $\mathbf{C u}$ & $\begin{array}{c}\mathrm{Cu} \\
\text { Error }\end{array}$ \\
\hline SED-05 & $<19.2$ & 12.8 & $<13.4$ & 8.9 & $<14.4$ & 9.6 & 35.1 & 8.6 & 96 & 30 & 58 & 36 \\
\hline SED-06 & $<19.8$ & 13.2 & $<12.7$ & 8.5 & $<14.9$ & 9.9 & 32.3 & 8.4 & 69 & 29 & 83 & 36 \\
\hline SED-07 & $<18.6$ & 12.4 & $<13.3$ & 8.9 & 14.7 & 6.6 & 22.9 & 8.3 & 104 & 30 & 88 & 37 \\
\hline SED-08 & $<19.9$ & 13.2 & $<14.0$ & 9.3 & 15.4 & 7.1 & 35.6 & 9.1 & 126 & 33 & $<86$ & 57 \\
\hline SED-09 & $<20.9$ & 14.0 & $<13.7$ & 9.1 & $<15.9$ & 10.6 & 26.2 & 8.8 & 78 & 31 & 67 & 39 \\
\hline SED-10 & $<21.4$ & 14.3 & $<14.4$ & 9.6 & 16.2 & 7.5 & 30.3 & 9.0 & 95 & 32 & $<86$ & 57 \\
\hline SED-11 & 17.0 & 10.0 & $<14.4$ & 9.6 & $<16.9$ & 11.3 & 24.5 & 9.0 & 115 & 33 & 64 & 40 \\
\hline SED-12 & $<20.8$ & 13.9 & $<14.6$ & 9.7 & 11.7 & 7.2 & 39.0 & 9.5 & 126 & 34 & 67 & 40 \\
\hline SED-13 & $<21.0$ & 14.0 & $<13.5$ & 9.0 & $<15.3$ & 10.2 & 18.1 & 8.4 & 147 & 32 & $<83$ & 55 \\
\hline SED-14 & 20.4 & 9.5 & $<13.4$ & 8.9 & $<15.2$ & 10.1 & 27.7 & 8.3 & 91 & 29 & 57 & 36 \\
\hline SED-15 & 27.7 & 10.7 & $<14.6$ & 9.7 & $<18.3$ & 12.2 & 40.9 & 9.7 & 176 & 36 & 66 & 41 \\
\hline SED-16 & 25.4 & 10.8 & $<15.0$ & 10.0 & $<18.1$ & 12.1 & 33.3 & 9.6 & 142 & 35 & 104 & 43 \\
\hline SED-17 & 45.9 & 13.0 & 11.9 & 7.7 & $<21.8$ & 14.5 & 39.5 & 10.8 & 285 & 43 & 164 & 49 \\
\hline SED-18 & 17.2 & 10.3 & $<14.3$ & 9.6 & 14.8 & 8.0 & 41.8 & 9.8 & 173 & 36 & 73 & 42 \\
\hline SED-19 & 35.2 & 12.4 & $<16.2$ & 10.8 & 17.6 & 9.6 & 34.3 & 10.9 & 279 & 44 & 126 & 50 \\
\hline SED-20 & 21.1 & 11.0 & $<15.3$ & 10.2 & $<18.5$ & 12.4 & 36.5 & 10.1 & 344 & 41 & 118 & 45 \\
\hline SED-21 & 28.5 & 11.9 & $<15.9$ & 10.6 & $<19.8$ & 13.2 & 39.9 & 10.8 & 363 & 44 & 130 & 48 \\
\hline SED-22 & $<25.0$ & 16.7 & $<16.7$ & 11.1 & 14.5 & 8.5 & 32.1 & 10.4 & 353 & 43 & 135 & 48 \\
\hline SED-23 & $<23.7$ & 15.8 & 12.6 & 7.3 & $<17.7$ & 11.8 & 29.7 & 9.9 & 373 & 42 & 92 & 45 \\
\hline SED-24 & 25.2 & 12.0 & $<17.0$ & 11.3 & $<20.0$ & 13.4 & 34.7 & 10.8 & 613 & 50 & 80 & 48 \\
\hline SED-25 & 21.2 & 12.1 & 13.6 & 7.9 & $<19.5$ & 13.0 & 35.8 & 10.9 & 475 & 47 & 165 & 51 \\
\hline SED-26 & 28.5 & 12.4 & $<17.2$ & 11.5 & $<19.9$ & 13.3 & 46.4 & 11.2 & 1025 & 58 & 206 & 52 \\
\hline
\end{tabular}


Table A-11 (continued)

\begin{tabular}{|c|c|c|c|c|c|c|c|c|c|c|}
\hline Sample ID & $\mathbf{N i}$ & $\begin{array}{c}\text { Ni } \\
\text { Error }\end{array}$ & $\mathbf{F e}$ & $\begin{array}{c}\text { Fe } \\
\text { Error }\end{array}$ & Mn & $\begin{array}{c}\text { Mn } \\
\text { Error }\end{array}$ & $\mathbf{C r}$ & $\begin{array}{c}\text { Cr } \\
\text { Error }\end{array}$ & $\mathbf{B a}$ & $\begin{array}{c}\text { Ba } \\
\text { Error }\end{array}$ \\
\hline SED-05 & $<118$ & 79 & 20898 & 342 & 1131 & 127 & $<252$ & 168 & 135 & 52 \\
\hline SED-06 & $<115$ & 77 & 18533 & 319 & 916 & 117 & $<259$ & 173 & 94 & 46 \\
\hline SED-07 & $<120$ & 80 & 24308 & 367 & 1439 & 138 & $<263$ & 176 & 146 & 57 \\
\hline SED-08 & $<131$ & 87 & 41138 & 492 & 1781 & 163 & $<288$ & 192 & 144 & 56 \\
\hline SED-09 & $<131$ & 87 & 25222 & 388 & 1466 & 145 & $<278$ & 185 & 149 & 61 \\
\hline SED-10 & $<130$ & 87 & 33861 & 448 & 1918 & 163 & $<297$ & 198 & 143 & 57 \\
\hline SED-11 & $<129$ & 86 & 20137 & 355 & 838 & 123 & $<268$ & 179 & $<107$ & 71 \\
\hline SED-12 & $<130$ & 87 & 22045 & 374 & 2135 & 168 & $<285$ & 190 & 113 & 55 \\
\hline SED-13 & $<124$ & 83 & 24874 & 380 & 1407 & 141 & $<276$ & 184 & 159 & 59 \\
\hline SED-14 & $<117$ & 78 & 19998 & 333 & 1497 & 137 & $<248$ & 165 & 155 & 59 \\
\hline SED-15 & $<141$ & 94 & 48524 & 550 & 2859 & 200 & 266 & 152 & 110 & 50 \\
\hline SED-16 & $<145$ & 97 & 43815 & 531 & 4556 & 239 & $<339$ & 226 & 141 & 58 \\
\hline SED-17 & $<160$ & 107 & 65097 & 686 & 5017 & 273 & $<395$ & 263 & 233 & 70 \\
\hline SED-18 & $<141$ & 94 & 35616 & 476 & 2218 & 179 & $<320$ & 213 & 230 & 72 \\
\hline SED-19 & 128 & 75 & 69522 & 718 & 3295 & 240 & 338 & 183 & 185 & 64 \\
\hline SED-20 & 129 & 67 & 36112 & 495 & 2650 & 197 & $<318$ & 212 & 378 & 85 \\
\hline SED-21 & 123 & 73 & 60777 & 659 & 4075 & 250 & 259 & 172 & 322 & 79 \\
\hline SED-22 & $<153$ & 102 & 39404 & 531 & 3580 & 228 & $<353$ & 235 & 361 & 87 \\
\hline SED-23 & 119 & 67 & 32293 & 470 & 2950 & 204 & $<334$ & 223 & 399 & 83 \\
\hline SED-24 & $<164$ & 109 & 46455 & 586 & 2619 & 211 & $<365$ & 243 & 322 & 78 \\
\hline SED-25 & 187 & 75 & 37732 & 532 & 2872 & 215 & $<355$ & 237 & 192 & 61 \\
\hline SED-26 & $<159$ & 106 & 23462 & 428 & 3962 & 238 & $<343$ & 229 & 219 & 66 \\
\hline
\end{tabular}


Table A-12. XRF measurements of total element concentration in medium sediments (mg/kg-dw)

\begin{tabular}{|c|c|c|c|c|c|c|c|c|c|c|c|c|}
\hline Sample ID & Mo & $\begin{array}{c}\text { Mo } \\
\text { Error }\end{array}$ & $\mathbf{Z r}$ & $\begin{array}{c}\mathrm{Zr} \\
\text { Error }\end{array}$ & $\mathrm{Sr}$ & $\begin{array}{c}\text { Sr } \\
\text { Error }\end{array}$ & $\mathbf{U}$ & $\begin{array}{c}\mathrm{U} \\
\text { Error }\end{array}$ & $\mathbf{R b}$ & $\begin{array}{c}\text { Rb } \\
\text { Error }\end{array}$ & Th & $\begin{array}{c}\text { Th } \\
\text { Error }\end{array}$ \\
\hline SED-05 & 3.3 & 1.9 & 64.5 & 5.0 & 12.7 & 2.4 & $<12.8$ & 8.5 & 6.7 & 2.7 & $<10.8$ & 7.2 \\
\hline SED-06 & $<3.8$ & 2.6 & 62.1 & 4.8 & 11.2 & 2.2 & $<11.7$ & 7.8 & 5.6 & 2.5 & $<10.3$ & 6.9 \\
\hline SED-07 & 3.5 & 1.9 & 83.9 & 5.7 & 12.4 & 2.4 & $<11.8$ & 7.9 & 10.1 & 2.8 & $<11.5$ & 7.7 \\
\hline SED-08 & $<4.2$ & 2.8 & 104.8 & 6.0 & 16.2 & 2.5 & $<13.5$ & 9.0 & 11.6 & 3.0 & $<12$ & 8.0 \\
\hline SED-09 & $<4.6$ & 3.1 & 101 & 6.3 & 18 & 2.8 & $<14.5$ & 9.7 & 13.2 & 3.2 & 9.4 & 5.8 \\
\hline SED-10 & $<4.2$ & 2.8 & 88.9 & 5.8 & 26.9 & 3.0 & 10.2 & 6.1 & 8 & 2.8 & $<11.8$ & 7.9 \\
\hline SED-11 & $<4.4$ & 2.9 & 97.6 & 6.0 & 16.1 & 2.6 & $<14.3$ & 9.5 & 15.4 & 3.3 & $<11.9$ & 7.9 \\
\hline SED-12 & $<4.1$ & 2.7 & 78 & 5.4 & 11.8 & 2.3 & $<12.2$ & 8.1 & 9.1 & 2.8 & $<11.2$ & 7.5 \\
\hline SED-13 & $<4.7$ & 3.2 & 88.9 & 6.4 & 16.4 & 2.9 & $<13.9$ & 9.3 & 13 & 3.3 & $<12.8$ & 8.6 \\
\hline SED-14 & $<4.4$ & 3.0 & 95.5 & 6.3 & 15.9 & 2.8 & $<13.6$ & 9.0 & 12.7 & 3.2 & 10 & 6.0 \\
\hline SED-15 & $<4.5$ & 3.0 & 81.8 & 5.8 & 12.5 & 2.6 & $<13.4$ & 8.9 & 10.7 & 3.1 & $<12.2$ & 8.1 \\
\hline SED-16 & $<4.5$ & 3.0 & 108 & 6.5 & 15.4 & 2.7 & $<14.9$ & 9.9 & 15.8 & 3.4 & 9.3 & 5.9 \\
\hline SED-17 & $<5.3$ & 3.5 & 156.4 & 8.3 & 28 & 3.6 & $<17.9$ & 12.0 & 30.2 & 4.5 & 11 & 7.2 \\
\hline SED-18 & $<4.7$ & 3.2 & 119.3 & 7.0 & 26.8 & 3.3 & $<15.6$ & 10.4 & 21 & 3.8 & $<13.9$ & 9.3 \\
\hline SED-19 & $<4.9$ & 3.3 & 126.3 & 7.5 & 39 & 3.8 & $<16.8$ & 11.2 & 22.3 & 4.0 & $<14.9$ & 9.9 \\
\hline SED-20 & $<4.6$ & 3.1 & 137.4 & 7.2 & 27.8 & 3.2 & $<15.1$ & 10.1 & 30.8 & 4.1 & $<13$ & 8.7 \\
\hline SED-21 & $<5.3$ & 3.5 & 179.7 & 8.4 & 39.1 & 3.8 & $<17.3$ & 11.6 & 49.8 & 5.1 & $<15.1$ & 10.1 \\
\hline SED-22 & $<5.6$ & 3.8 & 218.5 & 9.3 & 44.2 & 4.1 & $<20.2$ & 13.5 & 61.5 & 5.8 & $<17$ & 11.3 \\
\hline SED-23 & $<5.1$ & 3.4 & 172.9 & 8.3 & 52.8 & 4.2 & $<18$ & 12.0 & 48 & 5.1 & $<15.4$ & 10.3 \\
\hline SED-24 & $<5.9$ & 3.9 & 103 & 8.4 & 110.3 & 6.5 & $<22.3$ & 14.9 & 35.4 & 5.4 & 15.1 & 8.3 \\
\hline SED-25 & $<5.7$ & 3.8 & 106 & 8.4 & 136.9 & 6.9 & $<21.9$ & 14.6 & 40.2 & 5.4 & $<17.5$ & 11.7 \\
\hline SED-26 & $<5.5$ & 3.7 & 108.2 & 8.6 & 160.7 & 7.5 & $<22.8$ & 15.2 & 37.8 & 5.4 & $<17.7$ & 11.8 \\
\hline
\end{tabular}


Table A-12 (continued)

\begin{tabular}{|c|c|c|c|c|c|c|c|c|c|c|c|c|}
\hline Sample ID & $\mathbf{P b}$ & $\begin{array}{c}\mathbf{P b} \\
\text { Error }\end{array}$ & Se & $\begin{array}{c}\text { Se } \\
\text { Error }\end{array}$ & As & $\begin{array}{c}\text { As } \\
\text { Error }\end{array}$ & Hg & $\begin{array}{c}\text { Hg } \\
\text { Error }\end{array}$ & $\mathbf{Z n}$ & $\begin{array}{c}\text { Zn } \\
\text { Error }\end{array}$ & $\mathbf{C u}$ & $\begin{array}{c}\mathrm{Cu} \\
\text { Error }\end{array}$ \\
\hline SED-05 & $<16.1$ & 10.8 & $<11.8$ & 7.8 & $<11.9$ & 8.0 & 20 & 7.3 & 45 & 25 & $<70$ & 47 \\
\hline SED-06 & $<16.0$ & 10.7 & $<10.6$ & 7.1 & $<11.7$ & 7.8 & 12 & 6.9 & 46 & 24 & $<68$ & 45 \\
\hline SED-07 & $<17.0$ & 11.4 & $<12$ & 8.0 & $<12.8$ & 8.5 & $<16.6$ & 11.1 & 64 & 27 & $<73$ & 49 \\
\hline SED-08 & $<18.2$ & 12.1 & $<11.7$ & 7.8 & $<12.7$ & 8.5 & 21.5 & 7.4 & 58 & 25 & $<71$ & 47 \\
\hline SED-09 & $<18.0$ & 12.0 & $<12.3$ & 8.2 & $<13.7$ & 9.1 & 19.9 & 7.9 & 82 & 28 & $<77$ & 51 \\
\hline SED-10 & $<17.6$ & 11.8 & $<11.6$ & 7.8 & $<13.1$ & 8.8 & 18.4 & 7.4 & 70 & 26 & 57 & 32 \\
\hline SED-11 & 13.1 & 8.5 & $<12.5$ & 8.3 & $<14$ & 9.3 & 18.2 & 7.6 & 77 & 27 & 60 & 34 \\
\hline SED-12 & $<17.5$ & 11.6 & $<11.5$ & 7.6 & $<12.9$ & 8.6 & 11.8 & 7.2 & 59 & 26 & $<71$ & 48 \\
\hline SED-13 & 23.7 & 10.0 & $<13.7$ & 9.2 & $<16.2$ & 10.8 & 18.8 & 8.5 & 89 & 31 & $<85$ & 57 \\
\hline SED-14 & $<19.1$ & 12.7 & $<12.9$ & 8.6 & $<14.4$ & 9.6 & 25.3 & 8.3 & 100 & 30 & $<79$ & 53 \\
\hline SED-15 & 15.0 & 9.0 & $<13$ & 8.6 & $<14.5$ & 9.7 & 18.0 & 8.0 & 112 & 29 & $<77$ & 51 \\
\hline SED-16 & $<19.7$ & 13.1 & $<13$ & 8.7 & $<14.8$ & 9.9 & 18.4 & 7.9 & 128 & 30 & $<78$ & 52 \\
\hline SED-17 & 29.5 & 10.9 & $<14.8$ & 9.9 & $<18.4$ & 12.3 & 30.8 & 9.4 & 165 & 35 & 71 & 41 \\
\hline SED-18 & 24.4 & 9.8 & $<13.4$ & 8.9 & $<16.1$ & 10.7 & 25.9 & 8.5 & 103 & 31 & $<83$ & 55 \\
\hline SED-19 & 29.0 & 10.6 & $<14.1$ & 9.4 & $<16.8$ & 11.2 & 21.9 & 8.9 & 162 & 34 & 93 & 40 \\
\hline SED-20 & $<18.9$ & 12.6 & $<12.8$ & 8.5 & $<14$ & 9.3 & 16.9 & 8.0 & 145 & 30 & 69 & 36 \\
\hline SED-21 & 16.1 & 9.7 & $<14.4$ & 9.6 & $<15.8$ & 10.5 & 20.6 & 8.7 & 204 & 34 & 89 & 40 \\
\hline SED-22 & 17.0 & 10.0 & $<14$ & 9.4 & $<16.7$ & 11.1 & 26.7 & 9.1 & 291 & 37 & 120 & 42 \\
\hline SED-23 & $<21.0$ & 14.0 & $<13.5$ & 9.0 & $<15.4$ & 10.3 & 19.0 & 8.5 & 281 & 35 & 86 & 39 \\
\hline SED-24 & $<25.4$ & 16.9 & 15.4 & 7.9 & $<19$ & 12.6 & 38.8 & 10.9 & 459 & 47 & 105 & 49 \\
\hline SED-25 & 33.5 & 12.2 & $<16.5$ & 11.0 & $<19.5$ & 13.0 & 39.1 & 10.6 & 415 & 45 & 185 & 49 \\
\hline SED-26 & 56.1 & 13.6 & 12.8 & 7.7 & $<22.4$ & 14.9 & 50.8 & 11.0 & 669 & 50 & 119 & 48 \\
\hline
\end{tabular}


Table A-12 (continued)

\begin{tabular}{|c|c|c|c|c|c|c|c|c|c|c|}
\hline Sample ID & $\mathbf{N i}$ & $\begin{array}{c}\text { Ni } \\
\text { Error }\end{array}$ & $\mathbf{F e}$ & $\begin{array}{c}\text { Fe } \\
\text { Error }\end{array}$ & Mn & $\begin{array}{c}\text { Mn } \\
\text { Error }\end{array}$ & $\mathbf{C r}$ & $\begin{array}{c}\text { Cr } \\
\text { Error }\end{array}$ & $\mathbf{B a}$ & $\begin{array}{c}\text { Ba } \\
\text { Error }\end{array}$ \\
\hline SED-05 & $<102$ & 68 & 12614 & 249 & 593 & 93 & $<213$ & 142 & $<89$ & 59 \\
\hline SED-06 & $<99$ & 66 & 9256 & 211 & 557 & 87 & $<197$ & 131 & $<105$ & 70 \\
\hline SED-07 & $<109$ & 73 & 13971 & 268 & 710 & 101 & $<218$ & 145 & $<94$ & 63 \\
\hline SED-08 & $<101$ & 67 & 11518 & 237 & 708 & 97 & $<228$ & 152 & 121 & 50 \\
\hline SED-09 & $<116$ & 77 & 24639 & 360 & 979 & 120 & $<252$ & 168 & 63 & 41 \\
\hline SED-10 & $<102$ & 68 & 16293 & 283 & 706 & 101 & $<236$ & 157 & $<85$ & 56 \\
\hline SED-11 & $<108$ & 72 & 17284 & 296 & 760 & 105 & $<247$ & 165 & 168 & 58 \\
\hline SED-12 & $<102$ & 68 & 12692 & 250 & 681 & 96 & $<214$ & 143 & 57 & 37 \\
\hline SED-13 & $<124$ & 83 & 14624 & 299 & 637 & 108 & $<249$ & 166 & 82 & 48 \\
\hline SED-14 & $<116$ & 77 & 13834 & 280 & 973 & 116 & $<244$ & 162 & 76 & 46 \\
\hline SED-15 & $<116$ & 78 & 20208 & 330 & 757 & 111 & $<251$ & 167 & $<79$ & 53 \\
\hline SED-16 & $<115$ & 77 & 23334 & 352 & 967 & 120 & $<256$ & 170 & 73 & 43 \\
\hline SED-17 & $<141$ & 94 & 40278 & 502 & 2061 & 176 & $<320$ & 213 & 169 & 63 \\
\hline SED-18 & $<125$ & 84 & 29888 & 411 & 1793 & 153 & $<274$ & 183 & 102 & 48 \\
\hline SED-19 & $<127$ & 84 & 27525 & 409 & 1450 & 148 & $<299$ & 199 & 144 & 56 \\
\hline SED-20 & $<119$ & 79 & 21667 & 343 & 1158 & 127 & $<261$ & 174 & 127 & 55 \\
\hline SED-21 & $<132$ & 88 & 32581 & 438 & 1612 & 153 & $<294$ & 196 & 226 & 68 \\
\hline SED-22 & $<136$ & 91 & 35917 & 467 & 2037 & 171 & 321 & 147 & 244 & 72 \\
\hline SED-23 & $<125$ & 84 & 23655 & 373 & 2007 & 160 & 249 & 133 & 222 & 67 \\
\hline SED-24 & $<157$ & 105 & 23845 & 428 & 1520 & 167 & $<333$ & 222 & 259 & 77 \\
\hline SED-25 & $<155$ & 103 & 36358 & 509 & 2090 & 189 & 655 & 181 & 205 & 62 \\
\hline SED-26 & $<154$ & 103 & 25023 & 430 & 2952 & 208 & $<342$ & 228 & 213 & 64 \\
\hline
\end{tabular}


Table A-13. XRF measurements of total element concentration in fine sediments (mg/kg-dw)

\begin{tabular}{|c|c|c|c|c|c|c|c|c|c|c|c|c|}
\hline Sample ID & Mo & $\begin{array}{c}\text { Mo } \\
\text { Error }\end{array}$ & $\mathbf{Z r}$ & $\begin{array}{c}\mathrm{Zr} \\
\text { Error }\end{array}$ & $\mathrm{Sr}$ & $\begin{array}{c}\mathrm{Sr} \\
\text { Error }\end{array}$ & $\overline{\mathbf{U}}$ & $\begin{array}{c}\mathbf{U} \\
\text { Error }\end{array}$ & $\mathbf{R b}$ & $\begin{array}{c}\mathbf{R b} \\
\text { Error }\end{array}$ & Th & $\begin{array}{c}\text { Th } \\
\text { Error }\end{array}$ \\
\hline SED-05 & $<4.4$ & 2.9 & 160.4 & 7.1 & 15.9 & 2.5 & $<12.1$ & 8.1 & 15.8 & 3.1 & $<11.4$ & 7.6 \\
\hline SED-06 & $<4.1$ & 2.7 & 129.2 & 6.4 & 13.5 & 2.4 & $<11.6$ & 7.7 & 12.7 & 2.9 & $<11$ & 7.3 \\
\hline SED-07 & $<4$ & 2.6 & 113.1 & 5.8 & 12.6 & 2.2 & $<11$ & 7.3 & 6.4 & 2.4 & $<10.1$ & 6.7 \\
\hline SED-08 & $<4.1$ & 2.8 & 123.7 & 6.4 & 15 & 2.5 & $<12.2$ & 8.1 & 13.4 & 3.0 & $<11.2$ & 7.5 \\
\hline SED-09 & $<4.4$ & 3.0 & 183.4 & 7.3 & 17.1 & 2.5 & $<12.3$ & 8.2 & 15.7 & 3.1 & $<11$ & 7.4 \\
\hline SED-10 & $<4.1$ & 2.8 & 121.2 & 6.2 & 14.4 & 2.4 & $<12.5$ & 8.4 & 9.7 & 2.8 & $<11.1$ & 7.4 \\
\hline SED-11 & $<4.2$ & 2.8 & 168.1 & 7.0 & 16.9 & 2.5 & 11.6 & 6.0 & 13.6 & 3.0 & $<11.1$ & 7.4 \\
\hline SED-12 & $<4$ & 2.7 & 103.3 & 5.8 & 12.9 & 2.3 & $<11.2$ & 7.5 & 5.4 & 2.4 & $<10.6$ & 7.1 \\
\hline SED-13 & $<4.3$ & 2.9 & 137.5 & 6.7 & 13.4 & 2.4 & $<11.7$ & 7.8 & 9.4 & 2.8 & $<11.5$ & 7.7 \\
\hline SED-14 & $<4.4$ & 2.9 & 180.4 & 7.2 & 15 & 2.4 & $<12.1$ & 8.1 & 10.4 & 2.8 & $<10.9$ & 7.3 \\
\hline SED-15 & $<4.8$ & 3.2 & 186.2 & 7.8 & 17.1 & 2.7 & $<13.6$ & 9.1 & 12.7 & 3.1 & $<11.2$ & 7.5 \\
\hline SED-16 & $<4.6$ & 3.1 & 234.2 & 8.3 & 23.1 & 2.8 & $<13.8$ & 9.2 & 23.4 & 3.5 & $<12.2$ & 8.1 \\
\hline SED-17 & $<4.3$ & 2.9 & 158.8 & 7.1 & 21.2 & 2.7 & $<14$ & 9.3 & 18.2 & 3.3 & $<11.9$ & 7.9 \\
\hline SED-18 & $<4.8$ & 3.2 & 202.5 & 8.1 & 28.4 & 3.1 & $<14.3$ & 9.5 & 20.5 & 3.5 & $<12.4$ & 8.3 \\
\hline SED-19 & $<4.6$ & 3.1 & 147 & 7.1 & 31.3 & 3.2 & $<14.4$ & 9.6 & 19.7 & 3.5 & $<11.7$ & 7.8 \\
\hline SED-20 & $<5$ & 3.3 & 199.9 & 8.4 & 40.5 & 3.6 & $<15.2$ & 10.2 & 31.6 & 4.2 & $<13.5$ & 9.0 \\
\hline SED-21 & $<5.1$ & 3.4 & 204.1 & 8.6 & 37.8 & 3.6 & $<16.4$ & 10.9 & 38 & 4.5 & $<14$ & 9.4 \\
\hline SED-22 & $<5.3$ & 3.5 & 217.8 & 9.0 & 36.2 & 3.6 & $<17.3$ & 11.6 & 44.6 & 4.9 & $<15$ & 10.0 \\
\hline SED-23 & $<5.5$ & 3.7 & 249.2 & 9.6 & 53.8 & 4.2 & 13.5 & 8.8 & 52.2 & 5.3 & $<15.7$ & 10.5 \\
\hline SED-24 & $<5.4$ & 3.6 & 131.6 & 8.2 & 67.5 & 5.0 & 14.2 & 8.9 & 28.7 & 4.7 & $<16.5$ & 11.0 \\
\hline SED-25 & $<5.6$ & 3.7 & 160.7 & 8.7 & 56 & 4.6 & $<19.6$ & 13.0 & 33.2 & 4.8 & $<15.8$ & 10.5 \\
\hline SED-26 & $<7.3$ & 4.9 & 307.4 & 12.8 & 96.1 & 6.4 & 68.3 & 13.5 & 28.2 & 5.9 & 51.3 & 10.7 \\
\hline
\end{tabular}


Table A-13 (continued)

\begin{tabular}{|c|c|c|c|c|c|c|c|c|c|c|c|c|}
\hline Sample ID & $\mathbf{P b}$ & $\begin{array}{c}\text { Pb } \\
\text { Error }\end{array}$ & Se & $\begin{array}{c}\text { Se } \\
\text { Error }\end{array}$ & As & $\begin{array}{c}\text { As } \\
\text { Error }\end{array}$ & $\mathrm{Hg}$ & $\begin{array}{c}\text { Hg } \\
\text { Error }\end{array}$ & $\mathbf{Z n}$ & $\begin{array}{c}\text { Zn } \\
\text { Error }\end{array}$ & $\mathrm{Cu}$ & $\begin{array}{c}\mathrm{Cu} \\
\text { Error }\end{array}$ \\
\hline SED-05 & $<17$ & 11.3 & $<11.5$ & 7.7 & $<12.1$ & 8.1 & 11.9 & 7.2 & $<56$ & 37 & $<70$ & 47 \\
\hline SED-06 & $<16.4$ & 11.0 & $<11.2$ & 7.5 & $<12$ & 8.0 & $<15.5$ & 10.3 & 39 & 25 & $<71$ & 47 \\
\hline SED-07 & $<14.9$ & 9.9 & $<10.3$ & 6.9 & $<10.8$ & 7.2 & $<14.9$ & 9.9 & $<52$ & 34 & $<65$ & 43 \\
\hline SED-08 & $<17.4$ & 11.6 & $<11.0$ & 7.4 & $<12.6$ & 8.4 & $<15.9$ & 10.6 & $<55$ & 37 & $<69$ & 46 \\
\hline SED-09 & $<16.1$ & 10.7 & $<11.1$ & 7.4 & $<11.9$ & 7.9 & $<15.4$ & 10.2 & $<54$ & 36 & $<68$ & 45 \\
\hline SED-10 & $<16.8$ & 11.2 & $<11.5$ & 7.7 & $<12.1$ & 8.1 & $<15.6$ & 10.4 & $<54$ & 36 & $<68$ & 46 \\
\hline SED-11 & $<17.2$ & 11.5 & $<10.7$ & 7.1 & $<12.3$ & 8.2 & $<15.3$ & 10.2 & 53 & 24 & $<66$ & 44 \\
\hline SED-12 & $<15.6$ & 10.4 & $<11.4$ & 7.6 & $<11.2$ & 7.4 & $<15.5$ & 10.3 & $<53$ & 36 & 47 & 31 \\
\hline SED-13 & 19.1 & 8.5 & $<11.5$ & 7.7 & $<13.1$ & 8.7 & $<16.0$ & 10.7 & 57 & 26 & $<70$ & 47 \\
\hline SED-14 & $<16.2$ & 10.8 & $<10.8$ & 7.2 & $<12.2$ & 8.2 & 13.5 & 7.0 & 55 & 25 & $<68$ & 46 \\
\hline SED-15 & $<17.5$ & 11.6 & $<12.2$ & 8.1 & $<13$ & 8.7 & 16.4 & 7.7 & 63 & 27 & $<75$ & 50 \\
\hline SED-16 & $<17.5$ & 11.7 & $<11.8$ & 7.9 & $<12.9$ & 8.6 & 14.4 & 7.2 & 85 & 26 & 50 & 32 \\
\hline SED-17 & 19.1 & 8.6 & $<11.8$ & 7.9 & $<14.1$ & 9.4 & 13.7 & 7.3 & 85 & 27 & $<72$ & 48 \\
\hline SED-18 & 17.9 & 8.8 & $<12.5$ & 8.3 & $<14.2$ & 9.5 & $<16.7$ & 11.1 & 99 & 28 & 66 & 34 \\
\hline SED-19 & $<19.0$ & 12.7 & $<12.4$ & 8.3 & $<13.8$ & 9.2 & 16.5 & 7.6 & 83 & 28 & 55 & 34 \\
\hline SED-20 & 18.9 & 9.2 & $<12.5$ & 8.4 & $<14.8$ & 9.8 & 12.7 & 7.9 & 193 & 32 & 68 & 36 \\
\hline SED-21 & $<17.9$ & 12.0 & $<13.4$ & 8.9 & 10.2 & 6.2 & 14.6 & 8.1 & 170 & 32 & $<81$ & 54 \\
\hline SED-22 & 22.8 & 9.9 & $<13.5$ & 9.0 & $<15.7$ & 10.4 & 19.3 & 8.4 & 137 & 32 & $<84$ & 56 \\
\hline SED-23 & 18.9 & 9.7 & $<12.9$ & 8.6 & $<15.7$ & 10.5 & 22.3 & 8.6 & 224 & 34 & 89 & 39 \\
\hline SED-24 & 43.0 & 12.0 & $<15.0$ & 10.0 & $<19.0$ & 12.7 & 35.2 & 9.9 & 352 & 41 & 83 & 43 \\
\hline SED-25 & 25.4 & 11.0 & $<15.2$ & 10.2 & $<18.3$ & 12.2 & 39.2 & 9.9 & 247 & 38 & $<95$ & 63 \\
\hline SED-26 & 44.1 & 14.2 & $<17.9$ & 11.9 & $<21.7$ & 14.5 & 49.5 & 11.7 & 610 & 52 & 159 & 53 \\
\hline
\end{tabular}


Table A-13 (continued)

\begin{tabular}{|c|c|c|c|c|c|c|c|c|c|c|}
\hline Sample ID & $\mathbf{N i}$ & $\begin{array}{c}\text { Ni } \\
\text { Error }\end{array}$ & $\mathbf{F e}$ & $\begin{array}{c}\text { Fe } \\
\text { Error }\end{array}$ & Mn & $\begin{array}{c}\text { Mn } \\
\text { Error }\end{array}$ & $\mathbf{C r}$ & $\begin{array}{c}\text { Cr } \\
\text { Error }\end{array}$ & $\mathbf{B a}$ & $\begin{array}{c}\text { Ba } \\
\text { Error }\end{array}$ \\
\hline SED-05 & $<102$ & 68 & 6671 & 187 & 318 & 77 & $<210$ & 140 & $<93$ & 62 \\
\hline SED-06 & $<100$ & 67 & 6808 & 187 & 512 & 85 & $<200$ & 133 & 106 & 56 \\
\hline SED-07 & $<93$ & 62 & 4788 & 154 & 224 & 67 & $<184$ & 123 & $<76$ & 51 \\
\hline SED-08 & $<105$ & 70 & 7615 & 198 & 345 & 78 & $<198$ & 132 & $<108$ & 72 \\
\hline SED-09 & $<98$ & 65 & 7764 & 196 & 254 & 73 & $<206$ & 138 & 106 & 52 \\
\hline SED-10 & $<103$ & 68 & 7946 & 198 & 455 & 82 & $<199$ & 132 & 103 & 52 \\
\hline SED-11 & $<98$ & 65 & 8957 & 208 & 749 & 94 & $<200$ & 133 & 82 & 47 \\
\hline SED-12 & $<96$ & 64 & 5532 & 168 & 373 & 77 & $<198$ & 132 & $<91$ & 61 \\
\hline SED-13 & $<103$ & 69 & 6264 & 183 & 300 & 76 & $<201$ & 134 & $<107$ & 71 \\
\hline SED-14 & $<94$ & 63 & 6808 & 184 & 461 & 82 & $<206$ & 137 & 96 & 50 \\
\hline SED-15 & $<108$ & 72 & 8831 & 221 & 553 & 93 & $<214$ & 143 & 70 & 46 \\
\hline SED-16 & $<102$ & 68 & 11508 & 238 & 636 & 93 & $<204$ & 136 & 191 & 69 \\
\hline SED-17 & $<104$ & 70 & 13795 & 262 & 1089 & 112 & $<211$ & 141 & 86 & 51 \\
\hline SED-18 & $<109$ & 73 & 15633 & 286 & 1365 & 126 & $<241$ & 161 & 80 & 49 \\
\hline SED-19 & $<111$ & 74 & 12363 & 256 & 630 & 98 & $<225$ & 150 & 85 & 51 \\
\hline SED-20 & $<112$ & 75 & 16066 & 300 & 876 & 114 & $<251$ & 168 & 167 & 65 \\
\hline SED-21 & $<116$ & 78 & 17656 & 316 & 843 & 115 & $<253$ & 169 & 158 & 63 \\
\hline SED-22 & $<122$ & 81 & 18531 & 331 & 1314 & 134 & $<254$ & 170 & 206 & 79 \\
\hline SED-23 & $<124$ & 83 & 23190 & 368 & 1231 & 135 & $<261$ & 174 & 235 & 73 \\
\hline SED-24 & $<140$ & 93 & 21789 & 385 & 921 & 133 & $<295$ & 197 & 183 & 72 \\
\hline SED-25 & $<141$ & 94 & 23191 & 394 & 936 & 134 & $<283$ & 189 & 81 & 51 \\
\hline SED-26 & $<168$ & 112 & 41707 & 574 & 1291 & 175 & 303 & 173 & 198 & 73 \\
\hline
\end{tabular}




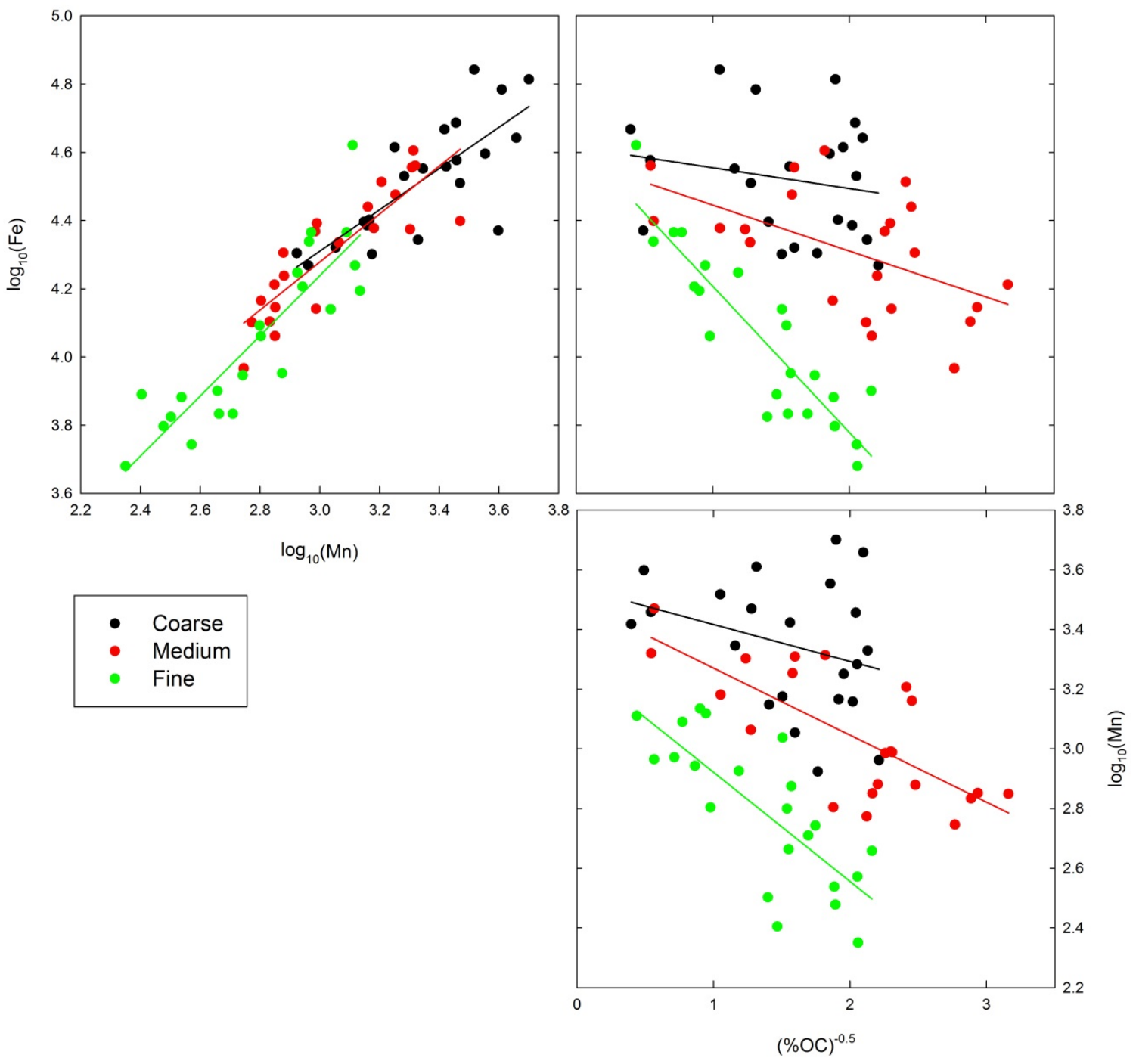

Fig. A-1. Scatterplot matrix of relationships among Fe, Mn and organic $\mathrm{C}(\mathrm{OC})$ as a function of grainsize. Note the plotted variables have been transformed to elucidate the relationships but the transformation does not alter the significance of the Spearman Rank Correlation test. Fe and Mn are strongly correlated for all grainsizes as is expected given the tight geochemical coupling of these two elements. 


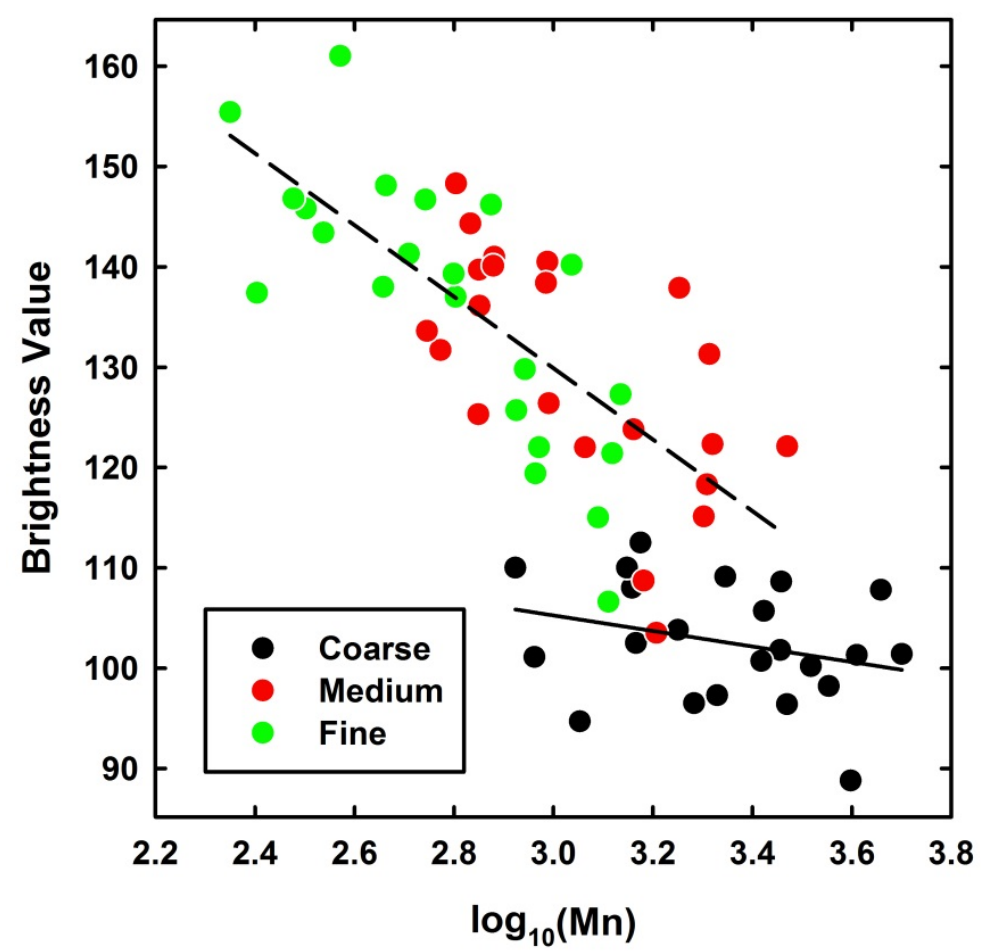

Fig. A-2. Sediment brightness value versus the logarithm of the sediment Mn content as a function of grain size. Solid black line is the linear regression line for coarse sediments. Broken black line is linear regression for pooled medium and fine sediment data as analysis of covariance showed these two groups had a common slope and intercept. 
(a)

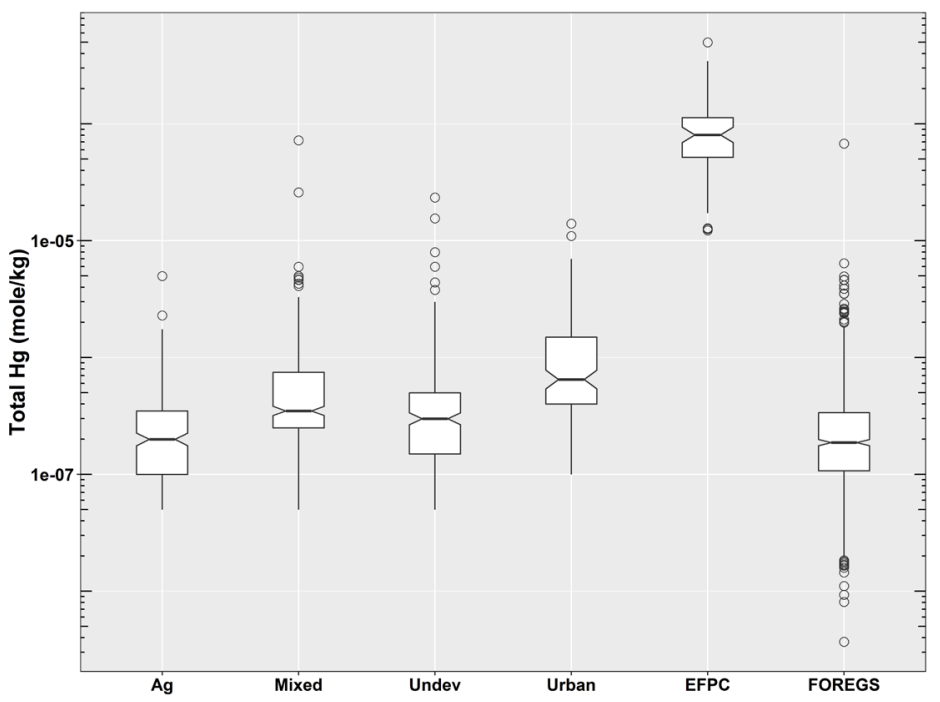

(b)

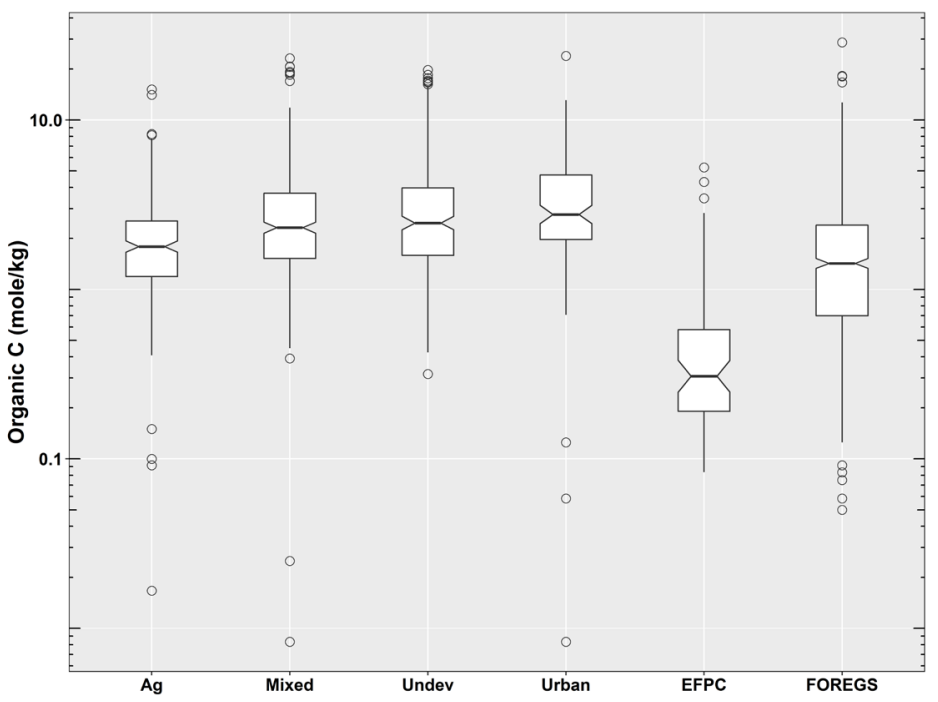

(c)

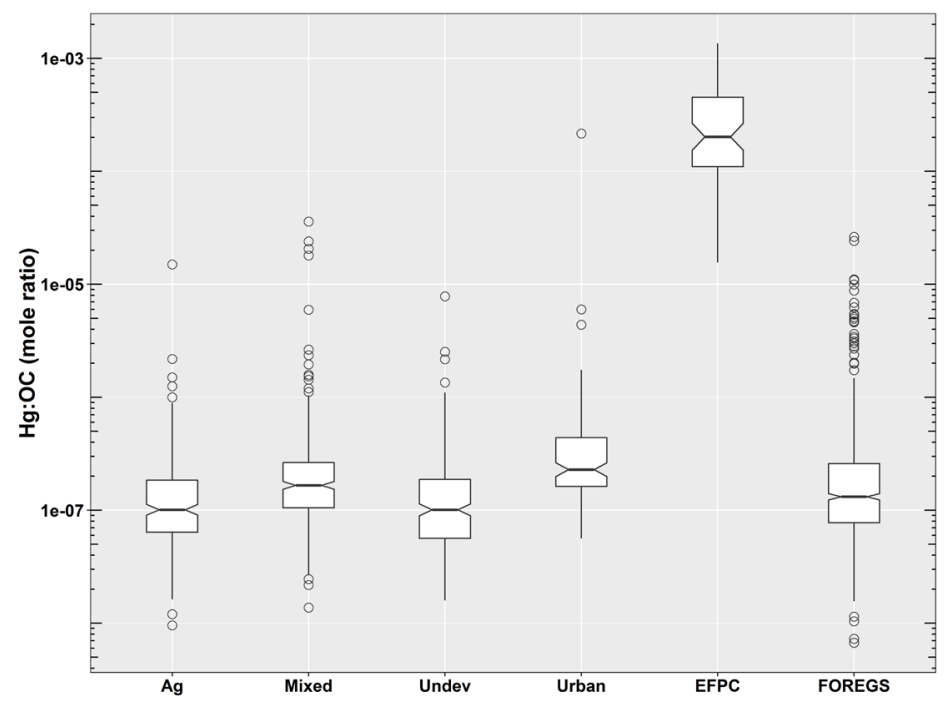

Fig. A-3. Box and whisker plots of (a) $\mathrm{Hg}$, (b) organic carbon, and (c) $\mathrm{Hg}$ : $\mathrm{OC}$ ratio in fluvial sediments for different land use classes across the conterminous United States (Horowitz and Stephens, 2008), EFPC, and Europe. Line in the middle of each box represents the median. The notches in the box indicate the approximate $95 \%$ confidence interval for the median. Box limits indicate the interquartile range (IQR). The whiskers extend to the most extreme data point which is no more than $1.5 \times$ the IQR. $\mathrm{Ag}=$ agricultural; Undev $=$ undeveloped; FOREGS = sediment data from the Geochemical Atlas of Europe (Salminen et al., 2005). 


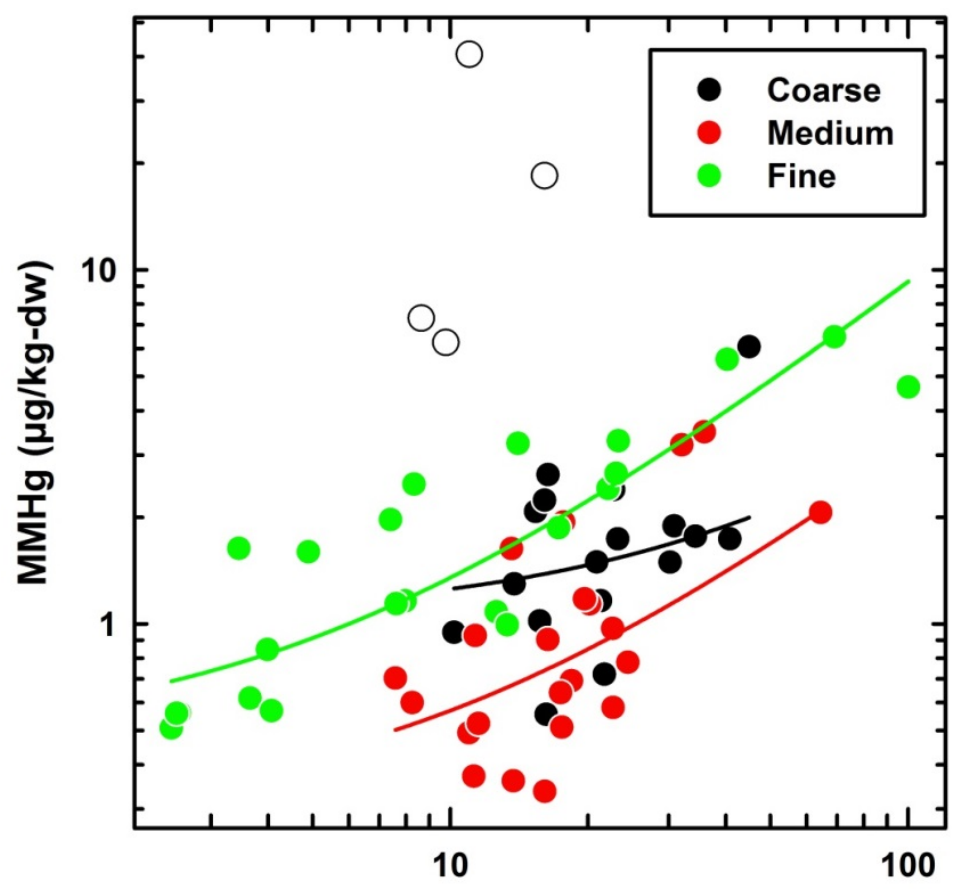

$\mathrm{Hg}(\mathrm{mg} / \mathrm{kg}-\mathrm{dw})$

Fig. A-4. Monomethylmercury versus total $\mathrm{Hg}$ in sediments sorted by grainsize. MMHg in the medium- and fine-grained sediment was moderately to very strongly and significantly correlated with $\operatorname{Hg}_{\mathrm{T}}\left(\rho_{\mathrm{s}}=0.583, \mathrm{p}=\right.$ $4.48 \mathrm{e}-3 ; \rho_{\mathrm{s}}=0.871, \mathrm{p}=2.0 \mathrm{e}-7$, respectively). Monomethylmercury and $\mathrm{Hg}_{\mathrm{T}}$ were not significantly correlated in the coarse sediments even after removing the high MMHg values in Reach 4 as potential high-leverage points (indicated by the open black circles). Lines are added to help visualize the patterns in the data. 


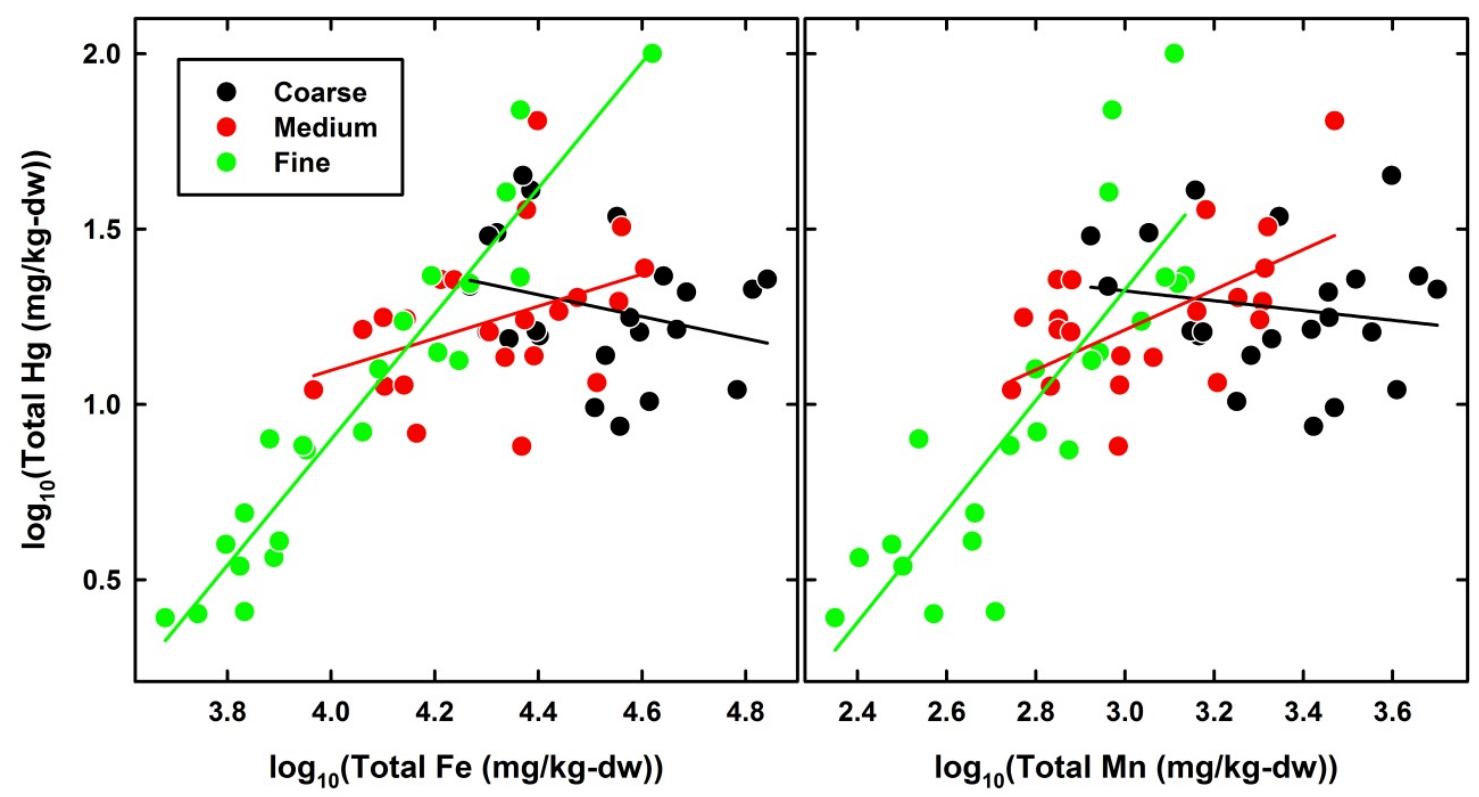

Fig. A-5. Relationship between sediment concentrations of $\mathrm{Hg}$, Iron (Fe), and Manganese (Mn) as a function of sediment grain size. 


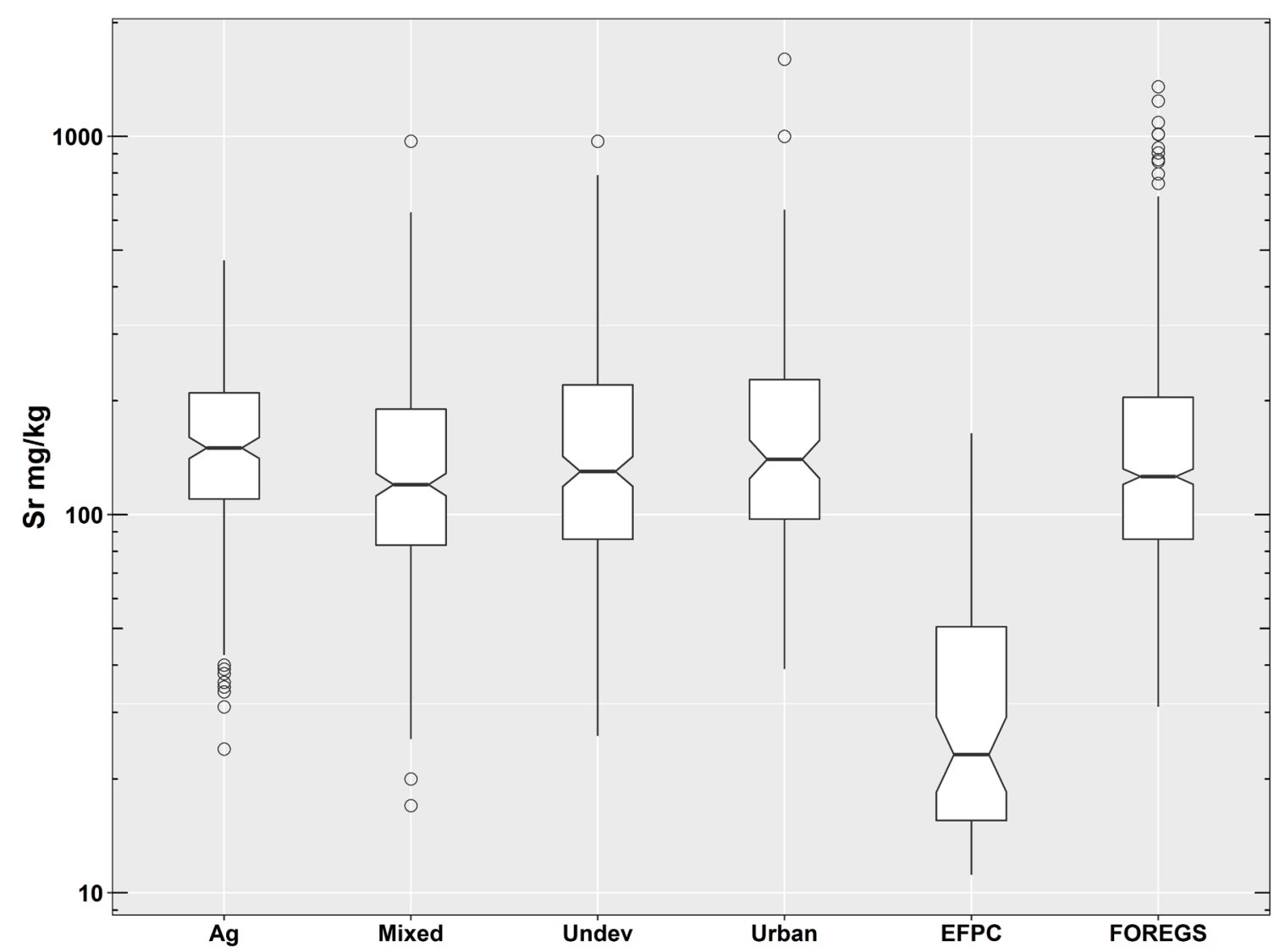

Fig. A-6. Box and whisker plot of $\mathrm{Sr}$ in fluvial sediments for different land use classes across the conterminous United States (Horowitz and Stephens, 2008), EFPC, and Europe. Line in the middle of each box represents the median. The notches in the box indicate the approximate $95 \%$ confidence interval for the median. Box limits indicate the interquartile range (IQR). The whiskers extend to the most extreme data point which is no more than $1.5 \times$ the IQR. Ag = agricultural; Undev = undeveloped; FOREGS = sediment data from the Geochemical Atlas of Europe (Salminen et al., 2005). 


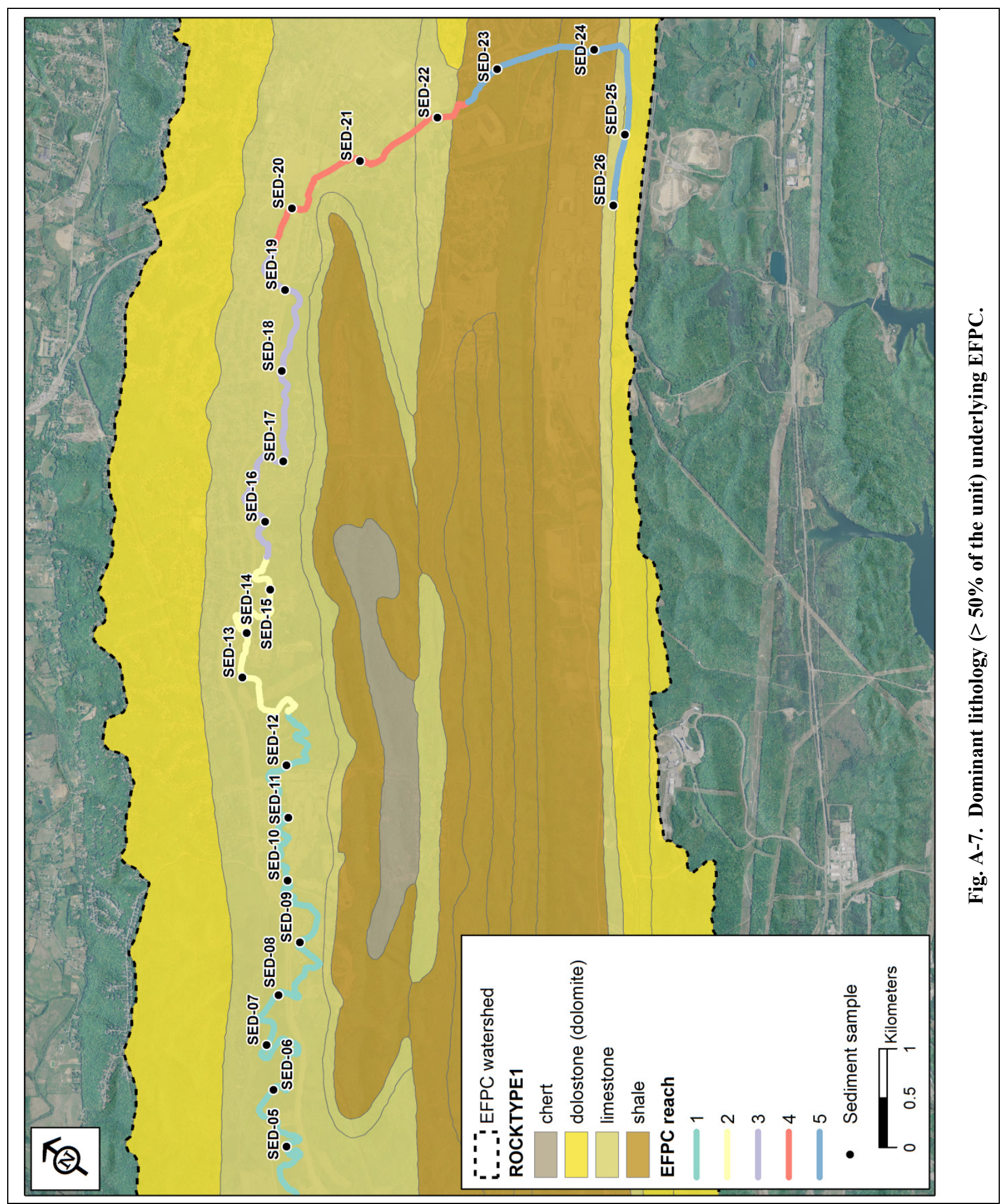




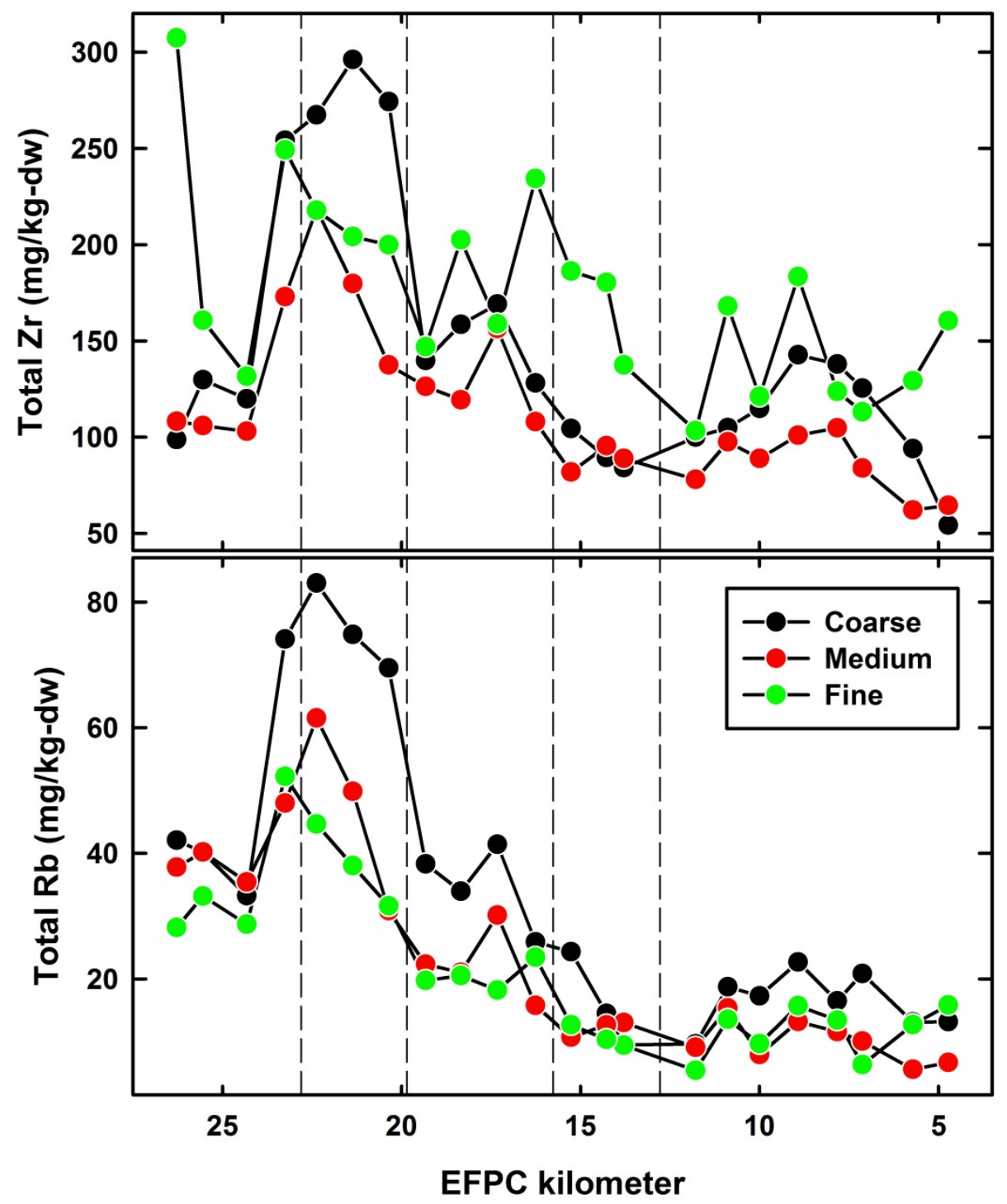

Fig. A-8. Sediment Zirconium ( $\mathrm{Zr}$ ) and Rubidium (Rb) concentration as a function of grain size along EFPC. 


\section{APPENDIX B. MERCURY DETERMINATION BY X-RAY FLUORESCENCE SPECTROSCOPY (XRF)}





\section{APPENDIX B. MERCURY DETERMINATION BY X-RAY FLUORESCENCE SPECTROSCOPY (XRF)}

The total $\mathrm{Hg}$ data presented in the main body of this report was determined using aqua regia digestion and $\mathrm{Hg}$ detection by cold vapor atomic absorption spectroscopy (CVAAS). This method showed good repeatability and acceptable values were obtained using this method for standard reference materials. Analysis of replicate samples by digestion/ CVAAS showed a mean coefficient of variation (standard deviation/ average) of $19 \%( \pm 13 \%)$ with no grain-size effect. This estimate of variability represents a combination of sample and method variability. The method itself is not particularly difficult but does involve some hazards - the use of strong concentrated acids, aqua regia generates noxious nitrosyl chloride gas - and the method effectively destroys the sample for other analyses.

Total Hg concentrations were also obtained as a routine part of the output during XRF analysis of sediments. Sample analysis by handheld XRF holds some potential advantages over the CVAAS method. XRF analysis is non-destructive - the same sample can be used in subsequent tests, XRF requires little sample preparation and does not involve the use of hazardous chemicals although precautions must be taken to prevent exposure to ionizing radiation. Analysis by XRF can be much more rapid than digestion/ CVAAS, and the handheld instruments can be easily taken into the field for onsite analyses.

Previous reports have raised concerns about the validity of XRF analyses to accurately quantify $\mathrm{Hg}$ using instruments and methods similar to those used in this work (Hall et al., 2011). Results obtained by the two techniques on our samples are compared here. The data are reported in Tables A-5, A-11, A-12, and A-13. The digestion/CVAAS analyses were conducted many months before the XRF analysis and because the former method is destructive the measurements reported are not for the same sample but replicate subsamples of the same source material.

Initial inspection of the data included plotting $\mathrm{Hg}$ determined by XRF $\left(\mathrm{Hg}_{\mathrm{XRF}}\right)$ versus $\mathrm{Hg}$ determined by digestion/ CVAAS ( $\left.\mathrm{Hg}_{\mathrm{CVAAS}}\right)$ (Fig. B-1). ANOVA analysis indicated a significant grain size effect and the symbols used in Fig. B-1 are color-coded by grain size to illustrate this effect. One sample of the medium grain sediment and nine samples of the fine grain sediment had $\mathrm{Hg}_{\mathrm{XRF}}$ results that were below detection. These samples are represented in the figures by open symbols using the nominal detection limit for that sample as the $\mathrm{Hg}_{\mathrm{XRF}}$ value. None of the $\mathrm{Hg}_{\mathrm{CVAAS}}$ results were below detection. Linear regression parameters were determined by Type II regression, which allows for error in both the $x$ - and $y$ values, using the method recommended by Deming (Cornbleet and Gochman, 1979). Samples for which $\mathrm{Hg}_{\mathrm{XRF}}$ were below detection were excluded from the regression analysis.

Considering all the data together, $\mathrm{Hg}_{\text {CVAAS }}$ ranged from 2.5 to $100 \mathrm{mg} / \mathrm{kg}$ and $\mathrm{Hg}$ XRF ranged between 12 and $51 \mathrm{mg} / \mathrm{kg}$. The majority of samples have $\mathrm{Hg}_{\text {CVAAS }}$ less than $40 \mathrm{mg} / \mathrm{kg}$, i.e., this data set contains few samples at higher $\mathrm{Hg}$ concentration particularly with respect to the range of $\mathrm{Hg}$ concentrations present in EFPC sediments and bank soils (up to several thousand $\mathrm{mg} / \mathrm{kg}$ ). For the majority of samples $\mathrm{Hg}_{\text {XrF }}$ fell above the 1:1 correspondence line. Deming regression parameters showed evidence of both systematic (non-zero intercept) and proportional (slope not equal to 1) error (Table B-1). Ten samples were below detection by XRF analysis with an average detection limit of $15.8( \pm 0.6) \mathrm{mg} / \mathrm{kg}$. However, eight other samples had $\mathrm{Hg}_{\mathrm{XRF}}$ values below $15.8 \mathrm{mg} / \mathrm{kg}$ and were not identified by the XRF software as below detection. This indicates that in addition to $\mathrm{Hg}$ concentration other currently unknown factors affect the detection limit by this method.

Because ANOVA analysis indicated a grain size effect, results for each grain size are considered. There was no correlation between methods for the coarse sediments (Fig. B-2a). $\mathrm{Hg}_{\text {CVAAS }}$ in the coarse sediments covered a relatively narrow range $(\sim 9-45 \mathrm{mg} / \mathrm{kg})$ and the $\mathrm{Hg}_{\text {XRF }}$ values ranged from $18-46$ 
$\mathrm{mg} / \mathrm{kg}$. Deming regression parameters indicated systematic and proportional differences between the methods (Table B-1). The mean $\mathrm{Hg}_{\mathrm{XRF}}$ response for all coarse sediments was $33.5 \mathrm{mg} / \mathrm{kg}$. Future analyses that include samples covering a broader concentration range may reveal a relationship between the two methods but the present data suggest $\mathrm{Hg}_{\mathrm{XRF}}$ is not useful for these coarse materials when $\mathrm{Hg}_{\mathrm{CVAAS}}$ is up to $45 \mathrm{mg} / \mathrm{kg}$ and possibly higher concentrations.

For the medium sediments $\mathrm{Hg}_{\mathrm{CVAAS}}$ and $\mathrm{Hg}_{\mathrm{XRF}}$ spanned slightly broader ranges ( $\sim 8-64 \mathrm{mg} / \mathrm{kg}$ and $12-51$ $\mathrm{mg} / \mathrm{kg}$, respectively)(Fig. B-2b). Deming regression parameters suggest systematic differences between the methods but proportional differences are less pronounced and the $95 \%$ confidence interval of the slope includes 1 (Table B-1). Additional samples, covering a broader concentration range, are needed to complete a more robust methods comparison including the assessment of any proportional differences and the uncertainty associated with the $\mathrm{Hg}_{\mathrm{XRF}}$ measurement.

$\mathrm{Hg}_{\text {CVAAS }}$ spanned the broadest range for the fine sediments $(2.5-100 \mathrm{mg} / \mathrm{kg})$ but the $\mathrm{Hg}_{\text {XRF }}$ range was similar to the medium sediments $(12-50 \mathrm{mg} / \mathrm{kg})(\mathrm{Fig}$. B-2c). Deming regression parameters indicate significant systematic and proportional differences between the methods (Table B-1). Visual inspection of the plot of $\mathrm{Hg}_{\mathrm{XRF}}$ versus $\mathrm{Hg}_{\text {CVAAS }}$ suggests no relationship between the two methods for $\mathrm{Hg}_{\text {CVAAS }}<20$ $\mathrm{mg} / \mathrm{kg}$ (Fig B-2c); the mean response of $\mathrm{Hg}_{\text {XRF }}$ when $\mathrm{Hg}_{\text {CVAAS }}<20 \mathrm{mg} / \mathrm{kg}=14.2 \mathrm{mg} / \mathrm{kg}$ (excluding $\mathrm{Hg}_{\text {XRF }}$ non-detect values). As a rough first approximation one could use the mean response of $\mathrm{Hg}_{\mathrm{XRF}}$ when $\mathrm{Hg}_{\text {CVAAS }}<20$ as the limit below which $\mathrm{Hg}_{\mathrm{XRF}}$ values are unreliable for the fine sediments. For $\mathrm{Hg}_{\mathrm{CVAAS}}>$ $20 \mathrm{mg} / \mathrm{kg}$, there does appear to be a relationship between $\mathrm{Hg}_{\mathrm{XRF}}$ and $\mathrm{Hg}_{\mathrm{CVAAS}}$ which deviates substantially from a 1:1 relationship and also deviates from the Deming slope estimate for medium sediments.

Systematic and proportional differences were found between $\mathrm{Hg}_{\mathrm{XRF}}$ and $\mathrm{Hg}_{\mathrm{CVAAS}}$ for all data and for individual grain sizes. Nevertheless, it may be possible to develop useful calibration functions whereby $\mathrm{Hg}_{\mathrm{XRF}}$ is related to $\mathrm{Hg}_{\mathrm{CVAAS}}$. The strong grain size dependence for the relationship between $\mathrm{Hg}_{\mathrm{XRF}}$ and $\mathrm{Hg}_{\text {CVAAS }}$ is concerning because there is no clear resolution for analysis of samples with unknown grain size distribution and it is not known if additional discrepancies exist for grain sizes outside the range of those studied here. It may be possible to overcome the grain size dependence by grinding samples to a consistent grain size range. However, this would negate the minimal sample prep advantage of XRF analysis, limit the ability to use handheld XRF analyses in a field setting, and would necessitate careful cleaning of grinding equipment to prevent cross-contamination. Alternatively, the grain size dependence may diminish to acceptable levels with higher total $\mathrm{Hg}$ concentration.

Despite the equivocal results presented here comparing Hg determination by XRF to CVAAS, several avenues for additional investigation remain to evaluate and possibly improve XRF performance including, but not limited to, the following. Working with the instrument manufacturer: When the current XRF was acquired 10+ years ago, scientists in ORNL's Environmental Sciences Division worked closely with the manufacturer to optimize setup and calibration of our instrument for certain elements of specific interest at that time. Mercury was not included in that original specific calibration and it may be possible to improve instrument performance in this way. Additionally, these instruments have continued to improve over the years and newer models, data processing algorithms, and x-ray sources have improved instrument performance. A more rigorous evaluation will be accomplished by collecting more data over a broader range of $\mathrm{Hg}$ concentrations. Only 66 samples were analyzed ( 22 per grain size) and most of those had less than $30 \mathrm{mg} / \mathrm{kg} \mathrm{Hg}$. Improved instrumentation and a more rigorous definition of the relationship between $\mathrm{Hg}_{\mathrm{XRF}}$ and $\mathrm{Hg}_{\mathrm{CVAAS}}$ will help to evaluate better the practical usefulness of the XRF technique. Suffice it to say, considerable work remains to be done before $\mathrm{Hg}_{\mathrm{XRF}}$ is considered to be comparable to $\mathrm{Hg}_{\text {CVAAS }}$ to the extent the former could replace the latter. 
Table B-1. Deming regression parameter estimates ( $\pm 95 \%$ confidence intervals) for HgXrF $_{\text {versus }} \mathrm{Hg}_{\mathrm{CV} A a s}$ values

\begin{tabular}{ccc}
\hline & Intercept & Slope \\
\hline All data & $16.3(5.4-20.0)$ & $0.494(0.358-1.09)$ \\
Coarse & $30(14-45)$ & $0.169(-0.628-0.927)$ \\
Medium & $8.93(0.728-12.2)$ & $0.733(0.61-1.16)$ \\
Fine & $10.8(7.39-12.7)$ & $0.412(0.377-0.646)$ \\
\hline
\end{tabular}

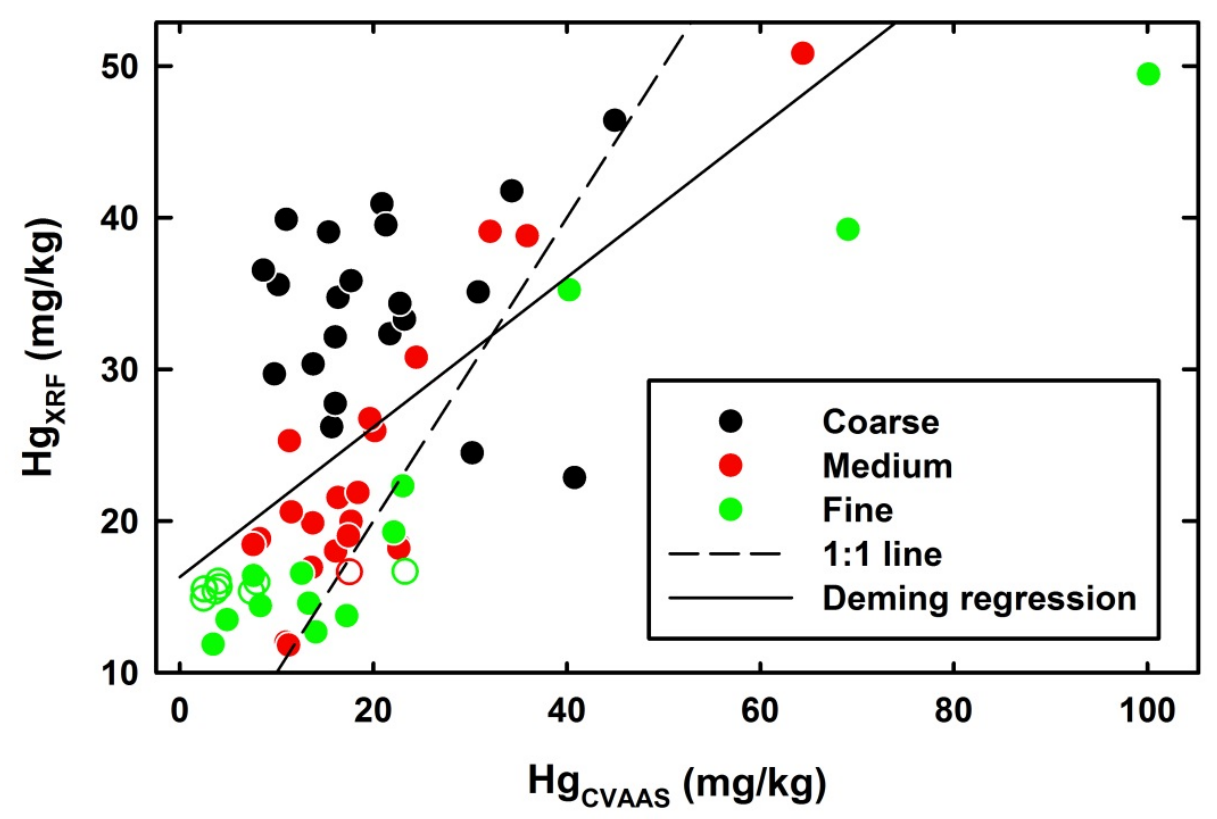

Fig. B-1. Total Hg determined by XRF versus total mercury determined by digestion/ CVAAS. The dashed line represents the 1:1 correspondence for data and the solid line represents the Deming regression line for all the data (see Table B-1). Samples for which $\mathrm{Hg}_{\mathrm{XRF}}$ was below detection are indicated by open symbols and were not included in the regression analysis. 


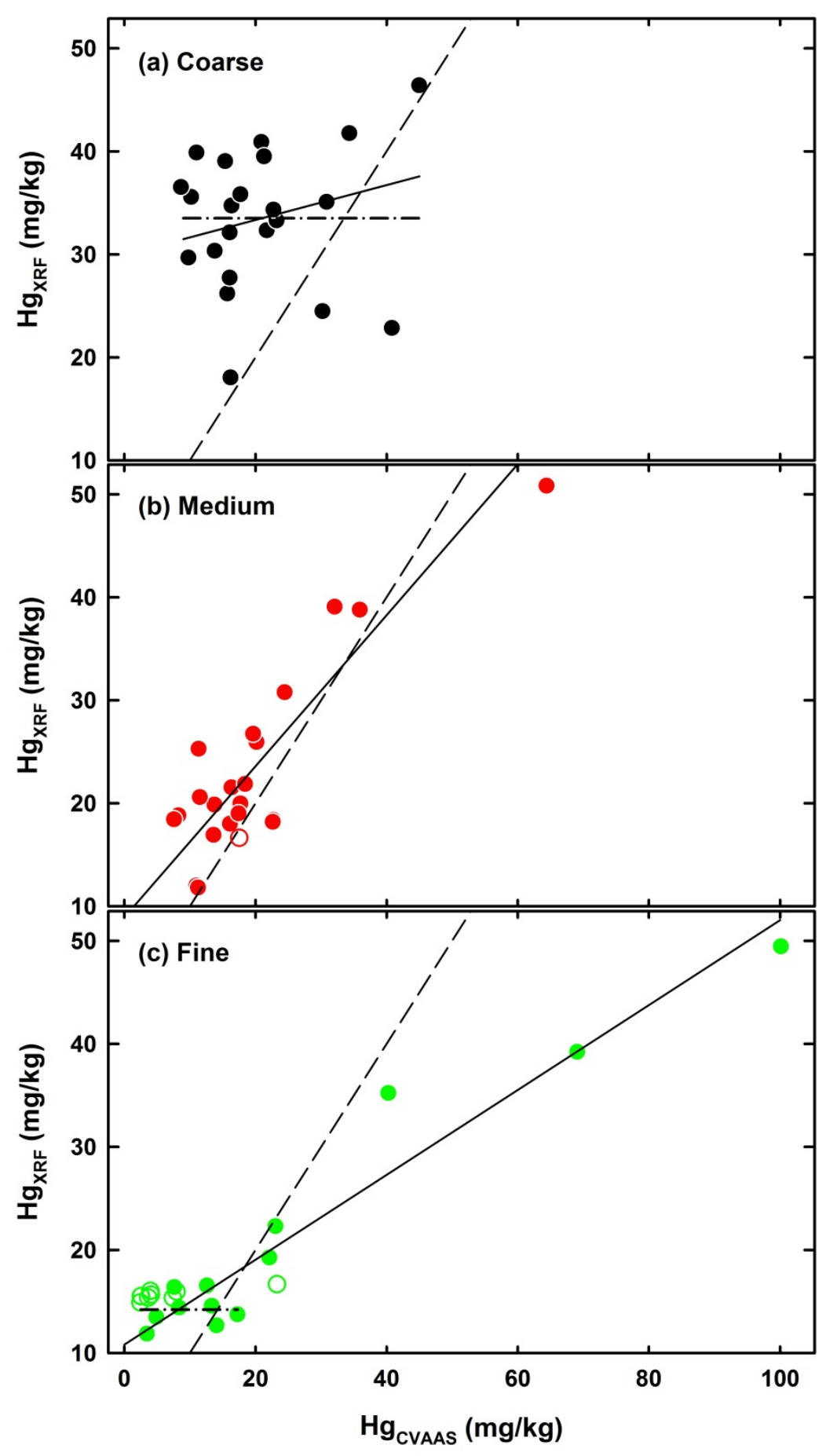

Fig. B-2. Total Hg determined by XRF versus total mercury determined by digestion/ CVAAS as a function of grain size. (a) Coarse sediments, (b) Medium sediments, and (c) Fine sediments. The dashed line in each plot represents the 1:1 correspondence line and the solid line represents the Deming regression line (see Table B-1). Samples for which $\mathrm{Hg}_{\mathrm{XrF}}$ was below detection are indicated by open symbols and were not included in the regression analysis. Horizontal dashed-dot line in (a) and (c) represents mean $\mathrm{Hg}_{\mathrm{XRF}}$ response when $\mathrm{Hg}_{\text {CVAAS }}<45 \mathrm{mg} / \mathrm{kg}$ and $20 \mathrm{mg} / \mathrm{kg}$, respectively 